\title{
Rotator Cuff Tears
}

Short- and long-term aspects on treatment outcome

Mats Ranebo

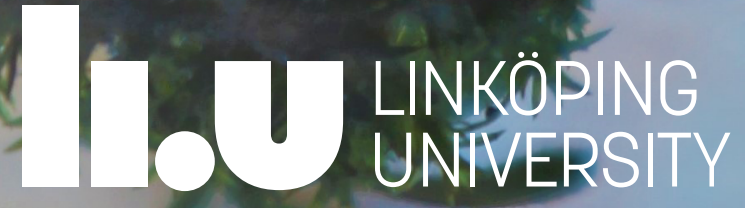




\title{
Rotator Cuff Tears
}

\section{Short- and long-term aspects on treatment outcome}

\author{
Mats Ranebo
}

Department of Clinical and Experimental Medicine

Linköping University, Sweden

Linköping 2020 
(C) Mats Ranebo, 2020

Cover photo: Ida Ranebo

Illustrations in this thesis: Per Ranebo

Published articles have been reprinted with the permission of the copyright holder.

Printed in Sweden by LiU-Tryck, Linköping, Sweden, 2020

ISBN 978-91-7929-924-8

ISSN $0345-0082$ 
To Charlotte, Ida and Oscar!

"Since I have been able clinically to diagnose cases of supraspinatus rupture with only a small percentage of error, and have in more than 40 cases sutured the ruptured tendon, my own conviction is naturally in favor of a traumatic cause. Yet I am by no means convinced that there is not an underlying degenerative process in the tendon which makes it prone to rupture. The frequency of finding that this is a bilateral condition, together with the fact that the lesion seldom occurs in young men, makes it highly probable that there is some general cause, which, with the trauma, produces the condition which we are studying."

- Earnest Codman, 1931 



\section{CONTENTS}

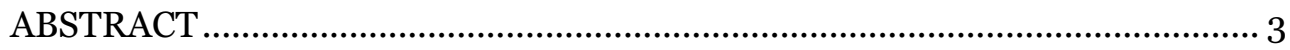

SVENSK SAMMANFATTNING ……………………................................ 7

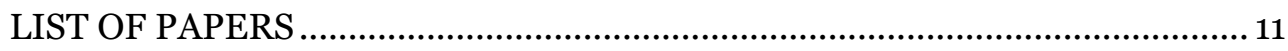

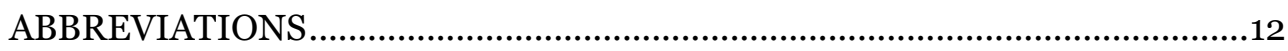

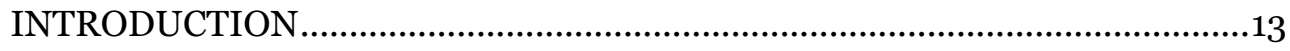

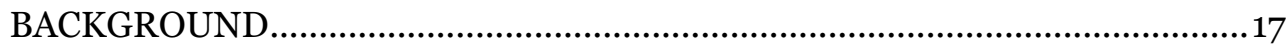

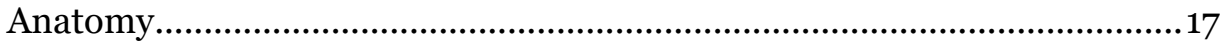

Osseous anatomy of the shoulder................................................................. 17

The ligaments of the shoulder joint ............................................................... 19

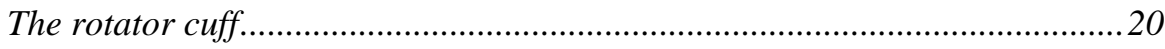

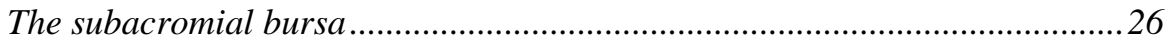

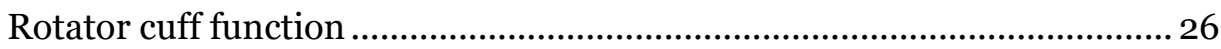

Cuff tear anatomy and classification ......................................................... 27

Prevalence and predisposing factors for rotator cuff tear ............................28

Intrinsic changes in torn rotator cuff tendons .............................................. 30

Treatment of rotator cuff tears .....................................................................31

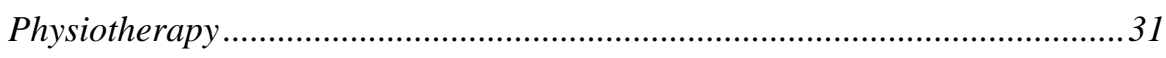

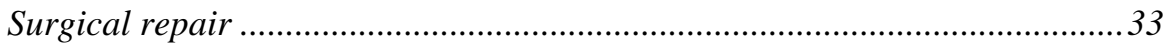

Surgical alternatives other than a complete cuff repair ....................................35

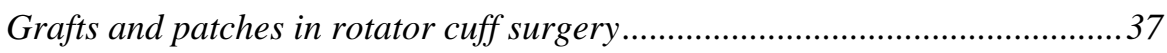

Rationale for this thesis ..........................................................................41

AIMS OF THIS THESIS ............................................................................. 43

MATERIALS \& METHODS ........................................................................... 45

Overview of papers and their design .......................................................... 45

Study participants ................................................................................. 46

Methods ….......................................................................................... 49

Surgical treatments................................................................................... 49

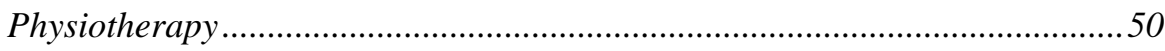




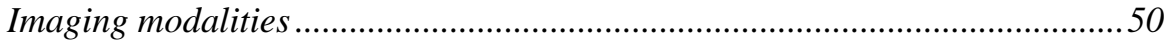

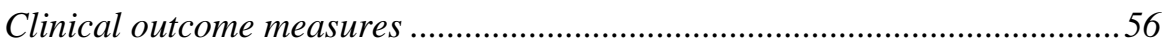

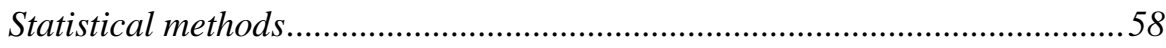

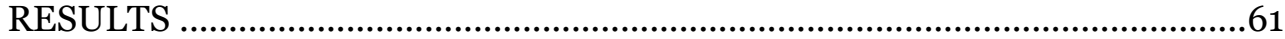

Paper I: Long-term results of unrepaired cuff tears. .................................61

Paper II: The status of the contralateral shoulder in patients with long-standing cuff tears

Paper III: Long-term results of synthetic interposition grafts for rotator cuff tear ............................................................................................. 71

Paper IV: Randomised trial of acute traumatic cuff tears. …….................. 76

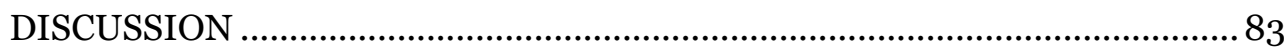

What are the long-term consequences regarding tear size enlargement and symptoms of not repairing a tear in the rotator cuff?........................... 83

Do patients with rotator cuff tears develop arthropathy in the long term and which are the clinical implications?

Assessment and classification of cuff tear arthropathy on radiographs

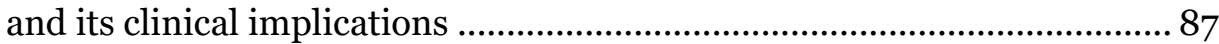

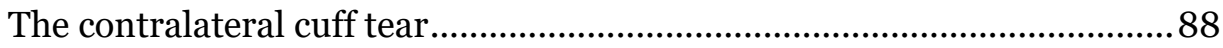

Acromioplasty without cuff repair ................................................................. 89

Can cuff tear arthropathy be prevented with an interposition graft in shoulders with irreparable cuff tears?

Are the results after cuff repair of a full-thickness rotator cuff tear superior to physiotherapy without repair in a short-term perspective? .... 92 What is the natural long-term course of rotator cuff tears, with and without repair?

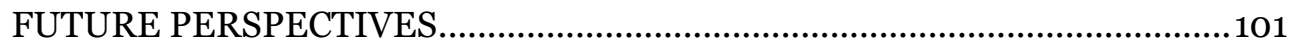

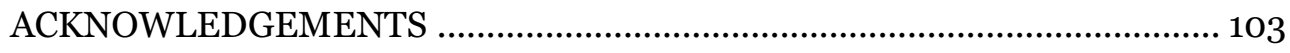

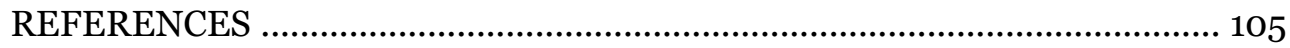

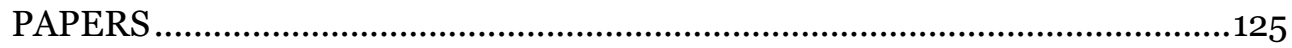




\section{ABSTRACT}

Rotator cuff tear is a common disorder and there is a lack of knowledge of appropriate treatment and consequences of different treatment modalities. The overall aim of this thesis was to examine short- and long-term results of rotator cuff tear treatment.

In Paper I we did a retrospective 21 to 25-year follow-up of a consecutive series of patients with partial and full-thickness rotator cuff tears, treated with acromioplasty without cuff repair. The cuff status had been documented in a specific perioperative protocol in all patients at the index operation. We did x-ray, ultrasonography and clinical scores with Constant score and Western Ontario Rotator Cuff index (WORC) at follow-up. We identified 111 patients with either a partial or a full-thickness tear, but at follow-up 21 were deceased and 11 were too ill from medical conditions unrelated to their shoulder. Out of the remaining 78 eligible patients, 69 were examined (follow-up rate $88 \%$ ) and they had a mean age at the index operation of 49 years (range 19-69 years). Forty-five had a partial tear and 24 a full-thickness tear at the index operation. At follow-up, $74 \%$ of patients with full-thickness tear had cuff tear arthropathy grade 2 or more according to the arthropathy classification of Hamada (grade 1 to 5) and $87 \%$ had developed tear progression (i.e. a larger tear). Corresponding numbers in those with a partial tear was $7 \%$ arthropathy and $42 \%$ tear progression, and the differences between the full-thickness group and the partial tear group was significant for both outcome measures $(P<0.001$ for both analyses). In those with arthropathy, the mean Constant score was 47 (standard deviation [SD], 23), the mean age and gender-adjusted Constant score 62 (SD, 27) and the mean WORC $58 \%$ (SD, 26). Patients with a partial tear at follow-up had mean Constant score and WORC within the normal range. In multivariable analysis with logistic regression, having a full-thickness tear at the index operation was a risk factor for arthropathy (odds ratio [OR] 37.8; 95\% confidence interval [CI], 8.2-175.0) and for tear progression (OR 6.09; 95\% CI, 1.41-26.29).

In Paper II we examined the contralateral shoulder in the same patients as in paper I and with the same methodology. Sixty-one patients were examined and 38 had had a partial tear at the index operation 21-25 years ago and 23 a full-thickness tear. The overall rate of contralateral full-thickness tears was 50.8 \%, which is higher than the $16-35 \%$ rate found in previous studies of newly diagnosed cuff patients. The rate of contralateral full-thickness tear ranged from $13.6 \%$ in patients with a partial tear in the index shoulder at follow-up, to $90 \%$ in patients with a full- 
thickness tear and arthropathy in the index shoulder. There was a significant correlation regarding conditions between shoulders in the same patient, with a Spearman coefficient of 0.72 for the number of tendons with a full-thickness tear, 0.31 for Hamada grade of arthropathy and 0.65 for Constant score. The number of tendons with a full-thickness tear in the index shoulder at follow-up was a risk factor for a contralateral fullthickness tear (OR 3.28; 95\% CI, 1.67-6.44) in a multivariable logistic regression model. We also found that cuff tear arthropathy was significantly more common in patients who had undergone an acromioplasty $(P<0.001)$, a finding which is not confirmatory but may generate a hypothesis.

Paper III addressed 17 to 20-year results after operation with a synthetic interposition graft for irreparable cuff tears. We used X-ray, ultrasonography and clinical scores at follow-up. We identified a consecutive series of 13 patients, one of whom was deceased at follow-up. Ten of the remaining 12 participated in a complete follow-up and 2 did only x-ray examination. Nine out of 12 (75 \%; 95\% CI, 43-95\%) had cuff tear arthropathy Hamada grade 2 or more in the index shoulder at follow-up. The mean Constant score was 46 (SD, 26) and the mean WORC 59 \% (SD, 20). Seven out of 12 had contralateral cuff tear arthropathy, and the difference in frequency of arthropathy between shoulders was not statistically significant $(P=0.667)$.

In Paper IV we tested whether early repair of small cuff tears, involving mainly supraspinatus, would give a superior clinical result compared to physiotherapy without repair in a prospective randomised trial with 12 months follow-up. We used Constant score as the primary outcome, and WORC, EQ-VAS and Numerical Rating Scale for pain (NRS) as secondary outcomes. We also aimed at assessing the rate of tear progression in unrepaired shoulders and the healing rate in repaired shoulders by Magnetic Resonance Imaging (MRI) performed at 12 months. With a high grade of follow-up (100 \% for 12 months Constant score and $95 \%$ for 12 months MRI), the repair group had a 12 months median Constant score of 83 (Quartile range $[\mathrm{QR}]$, 25) and the conservative group $78(\mathrm{QR}, 22)$. This between-group difference in medians of 4.5 (95\% CI,-5 to $9 ; P=0.68)$ was not statistically significant and we did not detect any significant differences in the secondary outcomes at 12 months. The retear rate was $6.5 \%$ in repaired patients and $29 \%$ of unrepaired patients had a tear enlargement $>5 \mathrm{~mm}$.

The results in this thesis indicate that patients with small, traumatic, full-thickness tears of mainly supraspinatus have no clinical benefit of early surgical repair compared to physiotherapy alone, but in the longterm, patients with full-thickness tears have an increased risk of tear progression, cuff tear arthropathy and low clinical scores. These results are 
especially important in the treatment decision of repair or not in younger patients. Having a full-thickness tear is also a risk factor for having a contralateral cuff tear, a phenomenon that underlines the importance of endogenous factors in the development of rotator cuff tears. If a cuff tear is not repairable to bone, the addition of a synthetic interposition graft does not seem to prevent cuff tear arthropathy. 
Rotator cuff tears-short and long-term aspects on treatment outcome 


\section{SVENSK SAMMANFATTNING}

Denna avhandling undersöker senskador i axlar (kuffrupturer), och de lång- och kortsiktiga utfallen av olika sätt att behandla dessa skador när det gäller symptom och strukturella förändringar. Rotatorkuffen utgörs av 4 senor som omger ledhuvudet och kuffruptur är en vanlig orsak till smärta och nedsatt funktion hos både personer i arbetsför ålder och efter pensionering och både när det gäller enkla vardagsaktiviteter och mer axelbelastande aktiviteter. Kuffruptur ses i stigande förekomst med ökad ålder, och det är även vanligt att ha en mindre kuffruptur utan symptom, men kuffruptur ses också som förmodad följd av ett större eller mindre trauma. Inom professionen finns det olika uppfattning om hur en kuffruptur ska behandlas, exempelvis om den bör lagas eller om det räcker med strukturerad sjukgymnastik. Det råder också osäkerhet om hur rupturen utvecklas på sikt, framför allt när det gäller små rupturer. Vid större kuffrupturer finns mycket som talar för att en sekundär förslitning av ledkulan kan ske, men det finns inga långtidsstudier med röntgenundersökning gjorda på oreparerade fall. Ibland hävdas att också de med en partiell kuffruptur (dvs. det finns inget hål rakt igenom hela senans tjocklek) också löper risk att få större ruptur och sekundära ledförändringar, men det saknas studier angående detta.

I studie 1 undersöktes patienter som genomgått en s.k. acromioplastik, en operation där en slemsäck tas bort och undersidan av bentaket över rotatorkuffen reduceras med en benfräs, men där man inte samtidigt gjort en lagning av senskadan. Förekomst och typ av kuffruptur fanns registrerade i operationsprotokoll från indexoperationen hos 111 patienter. Av dessa 111 hade 21 avlidit och 11 var för medicinskt sjuka för undersökning. Av resterande 78 patienter undersöktes 69, varav 24 hade en genomgående ruptur och 45 en partiell ruptur vid indexoperation. Undersökning gjordes efter 21-25 år med röntgen, ultraljud och av symptom, rörlighet och styrka. Vi fann att hos patienter som vid första operationen hade en genomgående senskada, hade i 3 av 4 fall sekundära ledförändringar utvecklats, medan detta skett hos bara $7 \%$ av de med partiell kuffruptur. Andelen som fătt en större kuffruptur efter mer än 20 år var $87 \%$ i gruppen med genomgående senskada och $42 \%$ i gruppen med partiell senskada. Att ha en genomgående kuffruptur var också en signifikant riskfaktor för att få både större ruptur och sekundära ledförändringar, när analysen korrigerade för andra faktorer. 
I studie 2 undersöktes den andra axeln (kontralaterala axeln) hos samma patienter som i studie 1. Tidigare studier har hittat förekomst av kontralateral kuffruptur hos mellan 16-35 \% av patienter med nydiagnostiserad kuffruptur i en axel. Vår hypotes var att kontralateral ruptur skulle vara ännu vanligare hos patienter som haft en känd ruptur i en axel i många år. Vi kunde vid uppföljning 21-25 år efter kuffruptur, verifierad vid titthålsoperation, påvisa att drygt hälften hade en kontralateral genomgående ruptur. Det var dessutom en stark korrelation mellan de två axlarna, således att de som fortfarande hade en partiell kuffruptur i indexaxeln, efter mer än 20 år, hade en frekvens av kontralateral ruptur på 13,6 \% och de med stor kuffruptur och sekundära ledförändringar hade kontralateral ruptur i 90 \% av fallen. I gruppen med sekundära ledförändringar i indexaxeln, hade 20 \% sekundära ledförändringar även i kontralaterala axeln. Även här var förekomst av genomgående ruptur en riskfaktor för att ha en kontralateral ruptur, när vi justerade för andra faktorer.

I studie 3 efterundersöktes patienter som p.g.a. icke reparabel kuffruptur hade opererats med en syntetisk graft (av polyesterväv). I dessa fall hade defekten mellan senstumpen och överarmsbenet överbryggats med graft med förhoppning att detta skulle hålla och därmed bidra till att minska risken för sekundära ledförändringar. Tretton patienter hade opererats och 12 av dessa kunde undersökas med röntgen efter 17-20 år. Vi fann emellertid att hos 9 av de 12 så hade sekundära ledförändringar utvecklats och att 7 av 12 hade sådana förändringar även i kontralaterala axeln, en skillnad som inte var signifikant. Vid ultraljudsundersökning fann vi att graften hos 7 av 10 inte var intakt och många hade också fått påverkan på fler senor än de hade vid första operationen.

I studie 4 lottades patienter med liten traumatisk genomgående kuffruptur till antingen senlagning (kuffsutur) eller sjukgymnastik utan lagning. Symptom och funktion jämfördes sedan vid 3, 6 och 12 månader och vid 12 månader gjordes också magnetkameraundersökning. Vid 12 månader var operationsgruppen 4,5 poäng bättre i det primära utfallsmåttet (Constant score, som mäter symtom, styrka och rörlighet), en skillnad som emellertid inte är vare sig statistiskt säkerställd eller kliniskt betydelsefull. Det förelåg heller inga statistiskt säkra skillnader när det gällde övriga utfallsmått (axelsymtom, smärta och livskvalitet). Vid magnetkameraundersökning sågs att 6,5 \% inte hade läkt sin reparerade senskada och att $29 \%$ av de icke reparerade senskadorna hade ökat i storlek med mer än $5 \mathrm{~mm}$.

Sammanfattningsvis visar denna avhandling att patienter med liten traumatisk genomgående kuffruptur, som genomgår operativ behandling med lagning av senskadan, inte får någon betydande förbättring vid 12 månader utöver den man får av axelspecifik träning. I ett 20-årigt per- 
spektiv riskerar dock patienter med genomgående kuffruptur, av både degenerativt eller förmodat traumatiskt ursprung, att utveckla större kuffruptur och sekundära ledförändringar. Personer med partiell kuffruptur löper betydligt mindre risk för större senskada och mycket liten risk för sekundära ledförändringar. Risken att ha eller få en kuffruptur i sin andra axel är ökad om man har en påvisad genomgående kuffruptur i en axel och det finns en stark korrelation mellan tillstånden i båda axlarna. Fynden stödjer hypoteser om att systemiska faktorer (snarare än faktorer specifika för en axel) är viktiga för utvecklingen av kuffruptur. Om en kuffruptur inte kan lagas, så verkar inte en syntetisk graft insatt mellan senstump och ben, skydda mot utveckling av större ruptur och sekundära ledförändringar. 
Rotator cuff tears-short and long-term aspects on treatment outcome 


\section{LIST OF PAPERS}

I. Mats Ranebo, Hanna Björnsson Hallgren, Rolf Norlin, Lars Adolfsson.

Clinical and structural outcome 22 years after acromioplasty without tendon repair in patients with subacromial pain and cuff tears. Journal of Shoulder and Elbow Surgery (2017) 26, 1262-1270

II. Mats Ranebo, Hanna Björnsson Hallgren, Lars Adolfsson. Patients with a long-standing cuff tear in one shoulder have high rates of contralateral cuff tears: a study of patients with arthroscopically verified cuff tears 22 years ago.

Journal of Shoulder and Elbow Surgery (2018) 27, e68-e74

III. Mats Ranebo, Hanna Björnsson Hallgren, Rolf Norlin, Lars Adolfsson.

Long-term clinical and radiographic outcome of rotator cuff repair with a synthetic interposition graft: a consecutive case series with 17 to 20 years of follow-up.

Journal of Shoulder and Elbow Surgery (2018) 27, 1622-1628

IV. Mats Ranebo, Hanna Björnsson Hallgren, Theresa Holmgren, Lars Adolfsson.

Surgery and physiotherapy equally successful in the treatment of small, acute, traumatic rotator cuff tears: a prospective randomised trial.

Journal of Shoulder and Elbow Surgery, accepted 20 Oct, 2019 


\section{ABBREVIATIONS}

FTT Full-thickness tear

PTT Partial thickness tear

CTA Cuff tear arthropathy

Hamada Cuff tear arthropathy classification grade 1 to $5^{112}$.

MRI Magnetic Resonance Imaging

CT Computer Tomography

CM Constant-Murley score (Constant score)

ASES American Shoulder and Elbow Society score

CSA Critical shoulder angle

AC-joint Acromioclavicular joint

CA-lig Coraco-acromial ligament

SLAP Superior Labrum Anterior to Posterior

CI Confidence Interval

SD Standard deviation

QR Quartile range

BMI Bone Mass Index

OR Odds Ratio

MMP Matrix Metalloproteinase

TIMP Tissue Inhibitors of Metalloproteinase

SPADI Shoulder Pain and Disability Index

MCID Minimal Clinically Important Difference

NRS Numerical Rating Scale

VAS Visual Analogue Scale

EQ-VAS EuroQual Visual Analogue Scale

HAD Hospital and Anxiety Scale

PACS Picture Archiving and Communication System

ANOVA Analysis of Variance

DASH Disabilities of the Arm, Shoulder and Hand questionnaire

UCLA University of California Los Angeles score

SANE Single Assessment Numerical Evaluation 


\section{INTRODUCTION}

Rotator cuff tear is, according to some, the most common reason for shoulder pain 37,236 and shoulder pain in itself is among the most frequent musculoskeletal disorders 226,228 . There are annually 250.000 rotator cuff repairs performed in the US ${ }^{182}$, and around 3000 performed in Sweden in 2017 (Swedish Board of Health and Welfare). Even if this probably is a cost-effective procedure from a societal point of view ${ }^{182}$, there is controversy over appropriate treatment 70 and we need to know more when making clinical decisions.

Perthes (1906) and Codman (1911) described the very first rotator cuff repairs more than 100 years ago $^{230}$, but the most frequent treatment strategy for a symptomatic cuff tear has probably been non-operative up until recent decades. With the advents of better imaging techniques and refined surgical techniques, the rates of cuff repairs have increased. The technical development of arthroscopic techniques may have boosted this increase, and in Sweden there has been a threefold increase from 2009 to 2014 (Swedish Board of Health and Welfare). Evolving arthroscopic techniques and newer methods of anaesthesia, like interscalene nerve block, have made it possible to perform a cuff repair as an outpatient procedure, making it easier to increase the number of repairs. The problem with easily accessible new medical techniques, that have appealing features both to clinicians and patients, is that it may be used indiscriminately and hence inflict unnecessary risks and costs before we have knowledge of the true effect of the procedure. Medical history is full of examples of how the actual effect of a surgical procedure is not shown until after the procedure has been in routine use for several years, and very often the effect is not present at all or is smaller than previously thought 255 .

Rotator cuff tear is not an easy condition to work with, neither in a clinical setting nor in research. The rotator cuff is a complex anatomical structure, with 4 distinct muscles all giving their unique contribution to shoulder function, and a defect in the cuff can sometimes be well tolerated and sometimes give rise to major problems with pain and dysfunction. In a clinical setting this is seen when two patients with seemingly identical shoulder pathology have very different symptoms.

This thesis uses various commonly accepted descriptions of a rotator cuff tear. In scientific literature, and in clinical praxis, the term partial tear (or partial thickness tear, abbreviated PTT) refers to a tear not ex- 
tending through the whole thickness of the tendon. The defect can be located on the undersurface of the tendon, an articular side tear, or on the superior surface of the tendon, a bursal side tear. A partial tear may involve more than one tendon, for example both supra- and infraspinatus. A full-thickness tear (FTT) is a defect involving the whole thickness of the tendon and hence a communication between the bursal side and the joint side. Most commonly, there is an avulsion of tendon fibres from its footprint on the greater tuberosity, but sometimes a defect more medially in the tendon may occur. A full-thickness tear may also involve more than one tendon. In large and massive cuff tears that have stood for a long time, a secondary osteoarthritis called cuff tear arthropathy (CTA) may develop.

The wording "tear" may give rise to confusion, since it implies a traumatic origin of the structural defect in the cuff, even though many patients encountered in clinical praxis have no trauma at all in their history. A non-traumatic tear is often referred to as a degenerative tear. If there is a significant traumatic event before the onset of symptoms, the tear is often referred to as a traumatic tear or a trauma-related tear ${ }^{176}$. These are not two totally separated entities and there is probably a continuum from very degenerative tendons with spontaneous rupture to healthy tendons only avulsed due to trauma, with the majority of patients belonging to the first category.

Semantics is important, since words guide our thinking. Encountering the word tear implies that something is torn and need to be fixed. On the other hand sometimes a patient with a defect in the rotator cuff may be asymptomatic, implying that continuity in the rotator cuff may not always be necessary for a well-functioning shoulder. At the other end of the disease spectrum, shoulder surgeons regularly meet patients with a massive irreparable cuff tear and a painful pseudo-paralytic shoulder, sometimes with no cartilage left in the joint. That is an end stage, cuff tear arthropathy (CTA), where only major surgery such as arthroplasty is left in our toolbox.

Rotator cuff disease has often been described as a condition progressing from tendinosis to a partial tear and further on to a full-thickness tear and finally cuff tear arthropathy4, ${ }^{209}$. How do we avoid this problem and how do we know which patient will end up in that situation? And do all patients pass each disease stage and do they all eventually end up the same way? Can we prevent this? Lack of knowledge of the true nature of a condition, and especially of its natural course, will hamper our decisionmaking.

The studies included have focused on two main areas, retrospective long-term results and prospective short-term results after various rotator cuff treatments. The first studies contain long-term results in patients 
treated with acromioplasty without cuff repair (paper I) and assessment of the contralateral shoulder in the same patients (paper II). Paper III uses the same methodology in examining long-term results after a synthetic interposition graft in irreparable cuff tears. In a prospective randomised trial, rotator cuff repair was compared to physiotherapy without repair in patients with traumatic tears and no previous shoulder complaints (paper IV). 
Rotator cuff tears-short and long-term aspects on treatment outcome 


\section{BACKGROUND}

\section{Anatomy}

\section{Osseous anatomy of the shoulder}

The shoulder joint is a ball-in-socket joint, where the socket is the pear shaped glenoid (Figure 1) and the ball is the much larger humeral head (Figure 2). The glenoid has its base on the scapula, which, in the resting position, is angulated $30-40^{\circ}$ anterior in relation to the frontal plane on the back of the thorax, covering costae II to VII. The anterior surface of the scapula, the subscapular fossa, forms the origin of the subscapular muscle. The coracoid process is situated between the upper rim of the scapula and the glenoid and constitutes a fundament for the origin of both the short head of the biceps muscle and the coracobrachialis muscle. On the backside of the scapula, the scapular spine divides the supraspinatus fossa from the infraspinatus fossa, origins of the supraspinatus and infraspinatus muscles.

The acromion is the bony roof over the rotator cuff, serving as an origin of the large deltoid muscle (Figure 1). Bigliani described three different forms of the acromion ${ }^{212}$. From a lateral view, type I is flat, type II slightly hooked downwards and type III markedly hooked. The clinical significance of a hooked acromion has been a matter of debate though ${ }^{220}$. The critical shoulder angle (CSA angle), which encompasses both the lateral extension of acromion and the tilt of the glenoid, has further been suggested to be of importance for the development of both primary osteoarthritis and rotator cuff tears ${ }^{194}$. The anteromedial aspect of the acromion is part of the articulation with the lateral clavicle, forming the acromioclavicular joint (abbreviated the AC-joint).

The hemispheric joint surface of the proximal humerus is angulated $27^{\circ}\left(+/-12^{\circ}\right)$ posterior relative to the plane of the joint surface of the distal humerus ${ }^{69}$. The collum anatomicum divides the proximal joint surface from the greater and lesser tuberosity. In the anterior part of the humeral head, the lesser tuberosity holds the insertion of the subscapularis, and it is divided from the laterally placed greater tuberosity by the intertubercular sulcus, containing the long head of the biceps. The greater tuberosity is the large insertion of the posterosuperior rotator cuff tendons of the supraspinatus, infraspinatus and teres minor. The collum chirurgicum divides the proximal humerus from the shaft. 


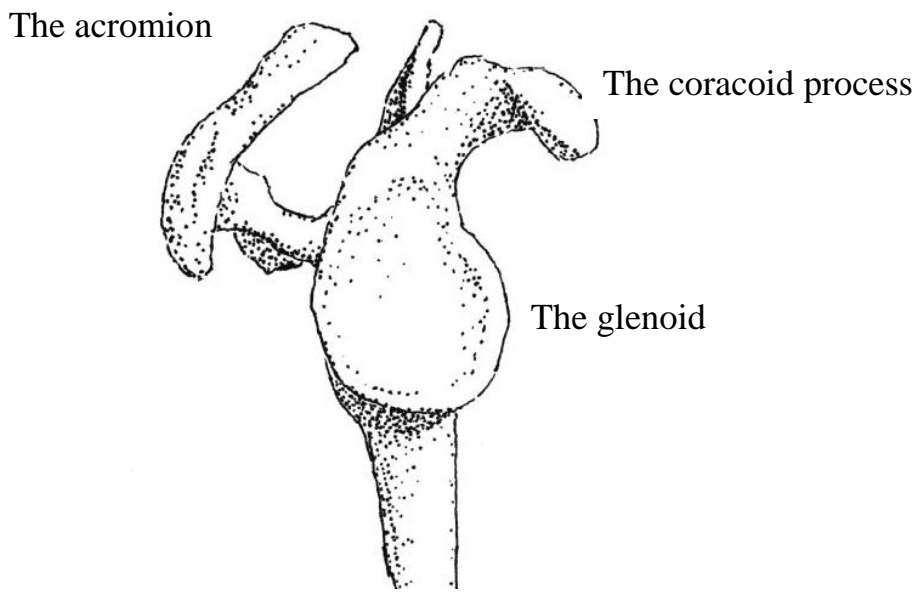

Figure 1.The bony anatomy of the scapula as seen from a lateral view.

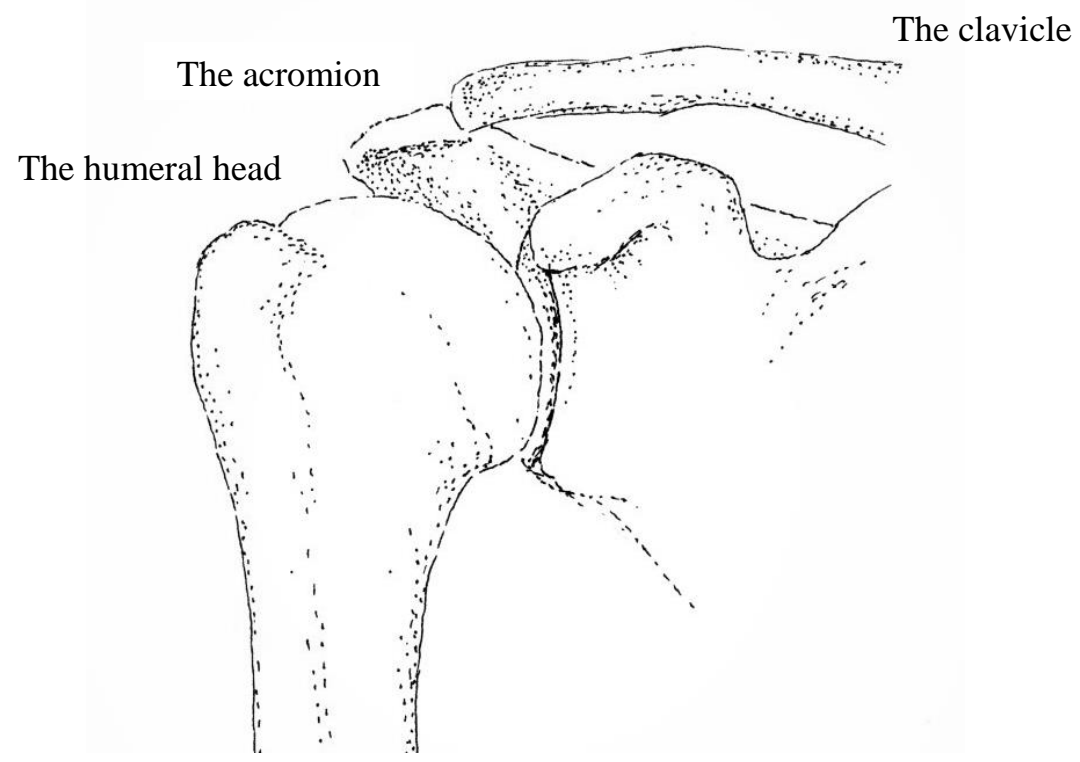

Figure 2. The bony anatomy of the anterior parts of the shoulder 


\section{The ligaments of the shoulder joint}

The relatively small glenoid articulates with the much larger humeral head, allowing a large range of motion. This potentially unstable osseous arrangement is supported by a strong capsule, reinforced by capsular thickenings, referred to as glenohumeral ligaments. The glenoid joint surface is also surrounded by the fibrocartilaginous labrum. The glenoid labrum enlarges the small joint surface and harbours the insertion of the glenohumeral ligaments, an arrangement which is fundamental to shoulder stability. The stability of the glenohumeral joint is, however, not only due to the glenohumeral ligaments, but also depends on neuromuscular control and proprioception.

The inferior glenohumeral ligament is the largest of the 3 glenohumeral ligaments. It has an anterior band, of importance in anterior stability, and a posterior band, and this inferior glenohumeral ligament covers the whole inferior part of the capsule supporting the humeral head from beneath. The middle glenohumeral ligament runs diagonally across the subscapularis, when seen from an intraarticular view. The superior glenohumeral ligament originates from the superior anterior part of the glenoid and runs spirally around the long head of the biceps to its insertion on the tendinous slip of the most superior part of the subscapular tendon ${ }^{11}$. The superior glenohumeral ligament and the uppermost part of the subscapularis insertion supports the long head of the biceps, preventing its medial dislocation ${ }^{11}$.

The coracohumeral ligament extends from the lateral part of the coracoid process medially to the supraspinatus tendon laterally with fibers both to the greater and lesser tuberosity. This ligament limits inferior translation and external rotation when the arm is adducted. A release of this ligament has been suggested to aid reduction of a retracted supraspinatus tendon during repair and maybe also prevent some postoperative stiffness ${ }^{222}$, although studies are too few to make conclusions.

The area between the anterior edge of the supraspinatus tendon and the superior edge of the subscapularis tendon is often referred to as the rotator interval. This interval contains the coracohumeral and superior glenohumeral ligaments and capsular tissue and it plays an important role for glenohumeral stability, biceps tendon stability and glenohumeral stiffness (for example in adhesive capsulitis). 


\section{The rotator cuff}

The rotator cuff consists of 4 different muscles: the subscapularis, the supraspinatus, the infraspinatus and the teres minor. They all converge into an intricate interdigitation of tendon fibres, surrounding the humeral head (Figure 3). This structure is sometimes referred to as a fibrous endoskeleton ${ }^{4}, 89$.

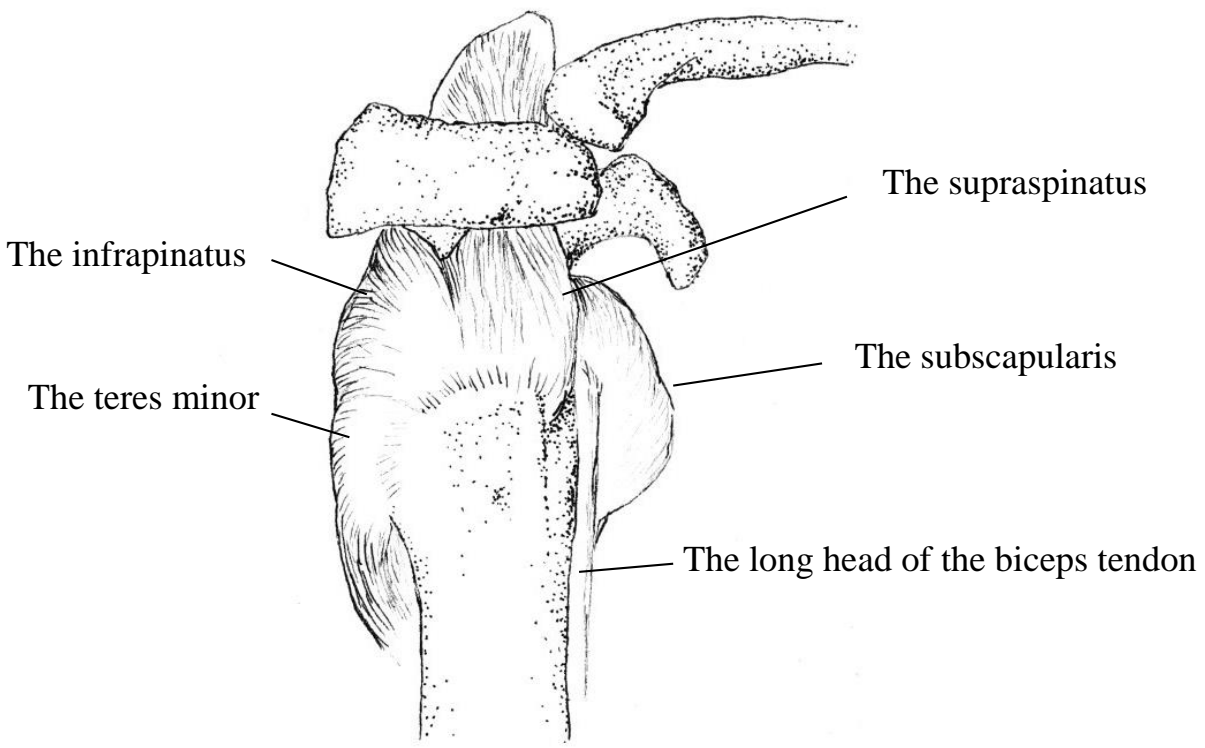

Figure 3. The rotator cuff as seen from a lateral view 


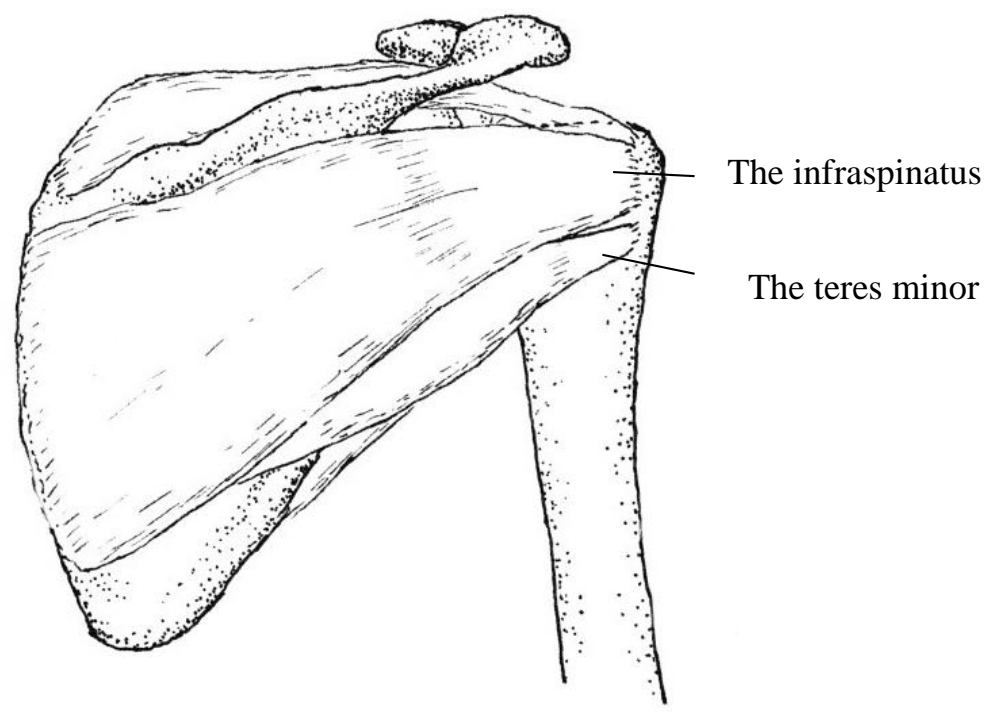

Figure 4. The posterior parts of the rotator cuff

\section{The subscapularis}

The largest muscle in the rotator cuff is the subscapularis, which has a very wide origin on the anterior surface of the scapular body (Figure 5). This muscle is innervated by the 2 subscapular nerves (upper and lower), coming from the posterior cord of the brachial nerve plexus ${ }^{64}$. In the lateral part, several distinct fascicles of tendon can be discerned before blending into one solid tendon in the upper part, inserting broadly on the upper part of the lesser tuberosity. Mean superior to inferior length of this tendinous insertion is $2,5 \mathrm{~cm}$ and mean medial to lateral width is 1,8 $\mathrm{cm}^{126}$. Below this tendinous insertion, the lower parts remain muscular to a large extent before inserting in a narrower band on the inferior lesser tuberosity. The upper part of the subscapular insertion makes up a tendinous wall in continuity with the osseous wall of the intertubercular groove, thereby contributing to biceps tendon stability ${ }^{11}$. The subscapularis functions as an internal rotator and it also aids in stability and congruence by compressing the humeral head to the glenoid, and in addition, prevents anterior displacement during elevation ${ }^{132}$. 


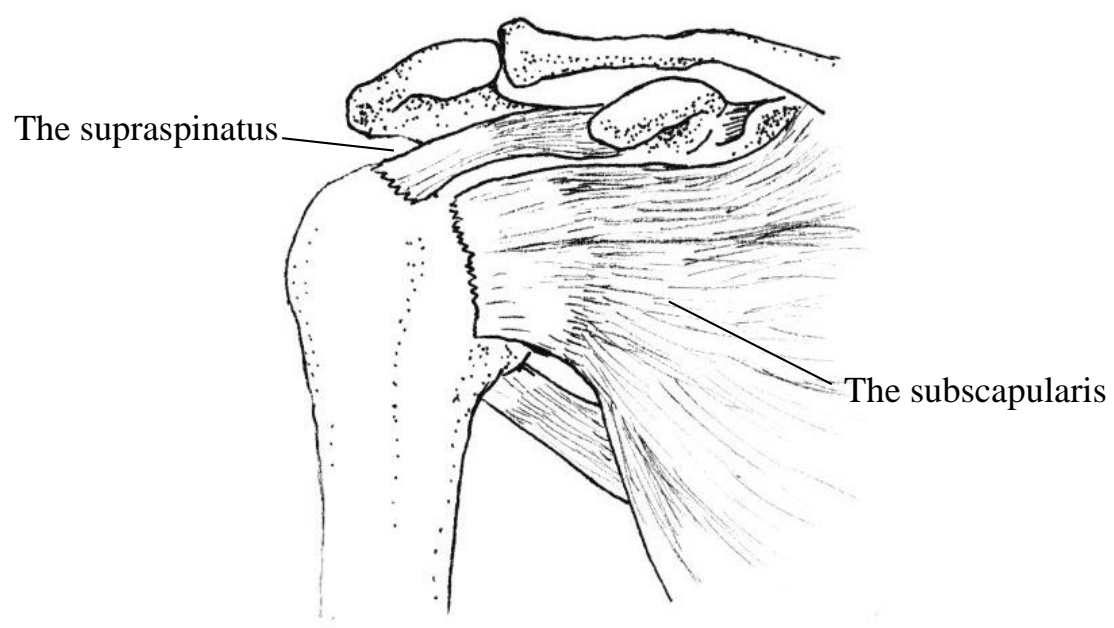

Figure 5.The anterior parts of the rotator cuff

\section{The supraspinatus}

The supraspinatus muscle originates from the supraspinatus fossa, between the scapular spine posteriorly and the upper scapular margin anteriorly. The muscle and its tendon courses anterolateral, beneath the acromioclavicular joint and the coracoacromial arch, along the plane of the scapula to its insertion on the anterior and most superior part of the greater tuberosity (Figure 3, 4 and 5). The anterior part of supraspinatus has a thicker muscle belly which is bipennate, as opposed to the unipennate thinner posterior muscle belly, and the anterior part has an intramuscular tendinous core, which is readily discernible on MRI ${ }^{235}$. Correspondingly, the anterior part of the tendon is more robust, thicker and longer than the posterior part ${ }^{192,235 .}$

The whole supraspinatus insertion is shaped in a triangular fashion ${ }^{192}$. The widest medial to lateral distance of this insertion has been measured to $6.9 \mathrm{~mm} \mathrm{(+/-1.4} \mathrm{mm} \mathrm{SD})$, and the anterior to posterior width medially to $12.6 \mathrm{~mm}$ (+/-2.0 $\mathrm{mm} \mathrm{SD})$ and laterally to $1.3 \mathrm{~mm} \mathrm{(+/-} 1.4 \mathrm{~mm} \mathrm{SD}) 192$. In a cadaver dissection of 113 shoulders, the supraspinatus fibres also inserted on the uppermost part of the lesser tuberosity in $21 \%$ of the shoul- 
ders ${ }^{192}$. In the posterior parts of the supraspinatus tendon insertion, the fusion of fibres from the neighbouring infraspinatus makes it difficult to appreciate a distinction between these tendons, in a clinical setting 49 .

Looking at the cross sectional fibre anatomy of the supraspinatus and the underlying capsule, the fibres are aligned in a multi-layered fashion, with the superficial fibres running more longitudinally and more parallel and the deeper fibres more obliquely and in a more nonlinear fashion (Figure 6) ${ }^{100}$. This explains the less echogenic nature of the supraspinatus on ultrasound, compared to tendons with longitudinal fibres, like the long head of the biceps. In a histological analysis of cross-sections, the rotator cuff is composed of five layers, where the deepest $1.5^{-2} \mathrm{~mm}$ is the capsule. The gleno-humeral capsule is a continuous sheet of collagen attached to the greater tuberosity laterally, through Sharpey fibres, and medially to the glenoid labrum ${ }^{49}$. Between the different layers of the cuff there are vessels 49 . Vascular studies show some variable results, with cadaver studies indicating a critical area of hypovascularity just proximal to the tendon insertion ${ }^{41,171,232}$ and in-vivo measurements showing hypovascularity at the very tendon insertion ${ }^{20,139}$.

The innervation of the supraspinatus is supplied by the suprascapular nerve, which originates from the $\mathrm{C}_{5}$ and $\mathrm{C} 6$ cervical roots, through the superior and lateral part of the upper trunk of the brachial plexus. The suprascapular nerve enters the supraspinatus fossa through the suprascapular notch, a potential point of nerve compression, and then courses the fossa underneath the supraspinatus muscle before making a turn around the spinoglenoid notch into the infraspinatus fossa ${ }^{180}$. This spinoglenoid turn is also a potential compression point with some anatomical variation ${ }^{180}$. The distance to the nerve from the upper glenoid rim is on average $31 \mathrm{~mm}$ (range 21-44 $\mathrm{mm}$ ) and from the posterior rim $17 \mathrm{~mm}$ (range 11-25 mm) ${ }^{105}$.

The supraspinatus contributes to flexion and abduction of the humeral head and stabilises the humeral head by aiding in compression against the glenoid. 


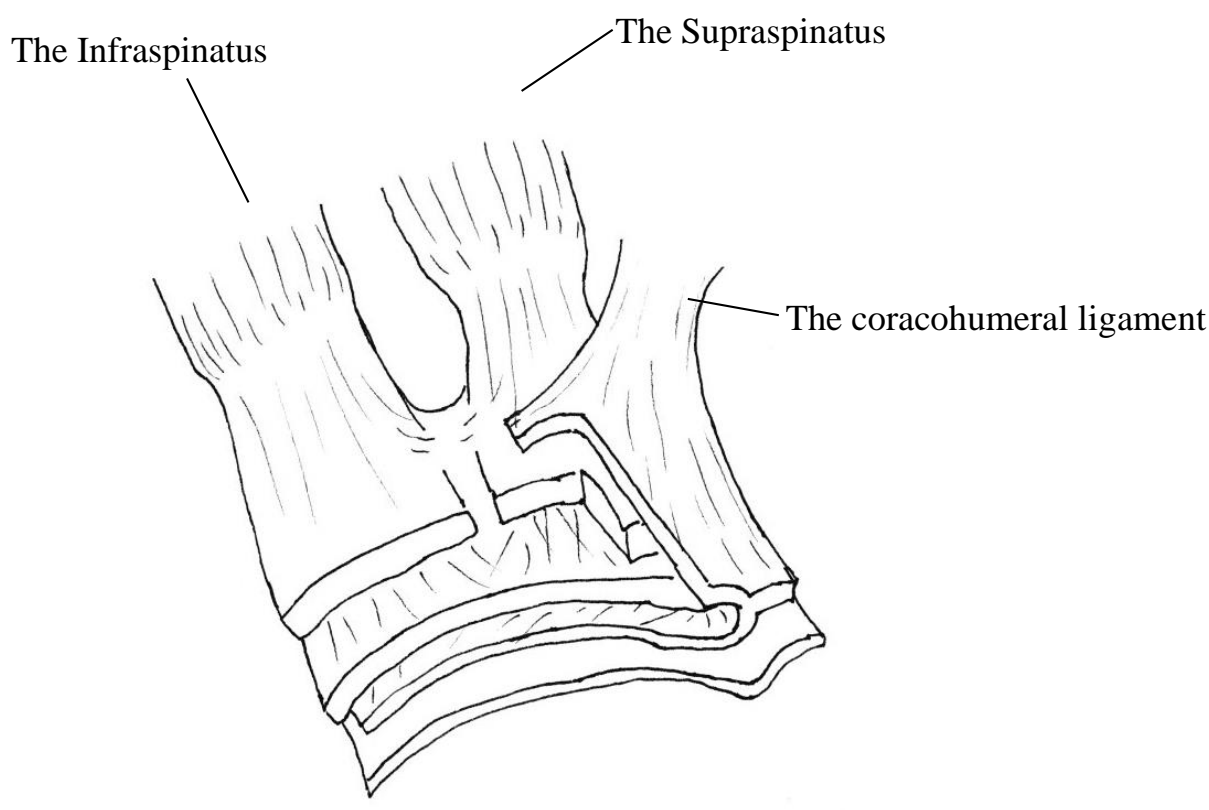

Figure 6. The multilayered structure of the supraspinatus and the infraspinatus. Adapted from Clark et al. ${ }^{49}$

\section{The infraspinatus}

The infraspinatus originates from an area inferior to the scapular spine and above the teres minor (Figure 4). The upper muscle fibres, coming from the undersurface of the scapular spine, run in a horizontal direction towards the posterior parts of the tendon, while the inferior muscle fibres from the infraspinatus fossa crosses diagonally to the upper and anterior tendon fibers ${ }^{140,192}$. The tendon itself is also divided in 2 portions, the superior part being longer and thicker and the inferior part shorter and thinner ${ }^{192}$. The infraspinatus footprint covers a trapezoidal area on the upper and posterior part of the greater tuberosity just behind the footprint of supraspinatus, with a mean maximal medial to lateral length of $10.2 \mathrm{~mm}$ and a mean maximal anterior to posterior length of $32.7 \mathrm{~mm}^{192}$. The innervation is supplied by the suprascapular nerve, through 2-4 motor branches just after the nerve has passed around the spinoglenoid 
notch into the infraspinatus fossa ${ }^{180}$. The infraspinatus is an important external rotator, contributing approximately $60 \%$ to the total external rotation force and it also contributes greatly to the concavity compression $^{126}$.

\section{The teres minor}

The teres minor originates from the dorsal area of the lateral edge of the scapula and its insertion is on the inferior and posterior area of the greater tuberosity (Figure 4). It has recently been shown that the muscle has two seemingly independent portions, each innervated by separate nerve branches originating from the axillary nerve ${ }^{111}$. The teres minor functions as an external rotator, providing approximately $40 \%$ of the external rotation force in a normal shoulder, and it also aids in concavity compression and downwards pull of the humeral head. In the face of massive posterosuperior cuff tears, the function of the teres minor is of utmost importance for results regarding both conservative treatment, tendon transfers and reverse arthroplasty54.

\section{Long head of the biceps}

The long-head of the biceps, in shoulder literature and in this thesis simply referred to as the biceps tendon, originates from the supraglenoid tubercle, where it is in continuity with the upper part of the labrum. This area of the upper labrum is often referred to as SLAP-area (Superior Labrum Anterior to Posterior)7. The biceps runs on the undersurface of the anterior part of supraspinatus into the intertubercular sulcus (Figure 3), held in place by the biceps pulley, an intricate system of fibres with contributions from the subscapularis, the supraspinatus, the superior glenohumeral ligament and the coracohumeral ligament ${ }^{11}$. The importance of the biceps for shoulder function is still not well understood and its suggested role as a humeral head depressor has not been supported by studies using electromyography ${ }^{246}$, or biomechanical in-vivo studies using flouroscopy99. A proprioceptive role has also been suggested, supported by findings of afferent nerve fibres in biceps tendon tissue ${ }^{5,253}$.

\section{The rotator cable}

A thickening in the deep parts of the capsule, going in a transverse direction, has been called the rotator cable ${ }^{31}, 49$. The anatomical name of this structure is Ligamentum Semicirculare Humeri and it has an insertion 
point on the anterior-superior greater tuberosity, just posterior to the biceps tendon, and sometimes one insertion point on the superior part of lesser tubercle. Posteriorly it inserts in the area of the inferior part of the infraspinatus and the superior border of teres minor. The rotator cable has been proposed to have a stress-shielding effect, protecting the area lateral to the rotator cable (the crescent area) and to be a mechanical link between the posterior and anterior rotator cuff (termed a "suspensionbridge mechanism")31. This concept has some support in biomechanical studies ${ }^{109,}{ }^{186}$, but these studies have often sectioned tendon tissue along with the cable tissue making it hard to conclude that the cable tissue itself has this effect ${ }^{10}$. Arai and Matsuda have noted that the cable is located at the medial edge of the contact area between the cuff and the humeral head, filling out the space between the flat cuff and the head, and suggesting a function similar to the menisci in the knee ${ }^{10}$. The rotator cable could thus be the result of compression forces and it also seems as if not all shoulders have a distinct cable structure ${ }^{10}$.

\section{The subacromial bursa}

The subacromial bursa, being the largest bursa in humans, provide a gliding surface between the coracoacromial arch and the deltoid muscle fascia superiorly and the cuff tendons and the greater tuberosity inferiorly ${ }^{146}$. The innervation of the subacromial bursa comes from one medial and one lateral branch of the suprascapular nerve ${ }^{161}$. The bursa is usually removed in both subacromial decompression and during rotator cuff repair. Even though an increase in inflammatory cytokines in patients with rotator cuff disease compared to normal controls have been described $^{28}$, it is worth noting that the bursa also seems to contain pluripotent stem cells that have superior proliferative and differentiation capabilities, compared to cells from bone marrow in the proximal humerus ${ }^{201}$. Preserving bursal tissue during repair may thus be an advantage ${ }^{205}$, but further studies are needed in this area.

\section{Rotator cuff function}

The combined effect of the rotator cuff muscles and the fibrous endoskeleton is an embracement of the humeral head and a compression against the glenoid, a concept referred to as concavity compression. Concavity compression adds stability to the humeral head. With rotator cuff muscles and tendons fully functional, allowing tension and shortening, this compression can be effectuated with any degree of elevation as opposed to the function of the ligaments, which only are under tension at 
the outer range of the movement $\operatorname{arc}^{126}$. In addition, the rotator cuff contributes with $90 \%$ of the rotational force and $45 \%$ of the abduction force $^{126}$. Halder et al. showed in a biomechanical study on cadavers, that detaching $2 / 3$ of the supraspinatus from its insertion (without retraction) resulted in only $5 \%$ decrease of the force transmission ${ }^{109}$. Simulating muscle retraction by creating a defect, similar to conditions in larger tears where the connection between the anterior and posterior cuff may be broken, resulted in loss of torque of up to $58 \%{ }^{109}$.

With impaired rotator cuff function, the unopposed massive pull of the deltoid muscle will result in superior translation of the humeral head, and this is often associated with pain and dysfunction ${ }^{144,215,262}$. This instability is probably dynamic in its early stages, but in larger and chronic cuff tears, the acromio-humeral interval may be permanently reduced ${ }^{243}$. This process gives rise to secondary cartilage wear (osteoarthritis) ${ }^{238}$.

\section{Cuff tear anatomy and classification}

A typical cuff tear initially involves the supraspinatus. With larger tears an additional involvement of the infraspinatus is most common and sometimes the subscapularis is also involved. There are also traumatic tears that involve only, or mainly, the subscapularis and the rotator interval. There are numerous ways of characterizing a cuff tear, and many classifications, but a generally accepted classification, that is based in high quality prospective data and that reliably can guide treatment decisions, does not exist. One of the early attempts was in 1944 by McLaughlin, who described transverse ruptures, vertical splits and retracted tears ${ }^{185}$. DeOrio and Cofield classified cuff tears into small $(<1 \mathrm{~cm})$, medium $(1-3 \mathrm{~cm})$, large $(3-5 \mathrm{~cm})$ and massive $(>5 \mathrm{~cm})$, based on the length of the largest diameter 65 . Several authors have instead classified cuff tears according to the number of tendons torn 93,114 . Both of these methods are used regularly, even though precise measurement of tear size on MRI is not easy. Attempts to classify tears into zones or segments in the sagittal plane ${ }^{225}$ have not come into routine use in research or clinical practice.

With arthroscopic or open examination, the morphologic and geometric appearance of tears in the cuff can be described as U-shaped, crescentshaped, L- or reverse-L shaped ${ }^{7}$. It is often necessary to make this assessment after clearance of bursal tissue and adhesions and by pulling the tendon in various directions. Davidson and Burkhart have tried to translate this to a geometric classification for MRI and suggested surgical treatment guidelines for each tear type, even though these treatment recommendations are based mainly on case-series and low-level evidence ${ }^{60}$. 
More specific tear patterns have also attracted attention recently. One such tear feature is disruption of the anterior tendinous portion of the supraspinatus. Cadaver studies indicate, that the most anterior 8-12 $\mathrm{mm}$ of the supraspinatus (i.e. the area immediately posterior to the biceps tendon) is the primary load-bearing tissue for force transmission within this tendon ${ }^{186}$. Clinical studies have also shown larger tear size and more degenerative muscle changes in cuff tears with complete disruption of this part of the supraspinatus tendon ${ }^{206}$, and retear rates after repair may be higher in such tears 45 .

For very large tears, the number of tendons and specific combinations of tendon involvement have been linked to the risk of causing pseuodparalysis ${ }^{2}$. In this classification, described by Collin et al., the upper and lower parts of the subscapularis are considered as 2 separate tendons with each having its own nerve supply and the upper being more tendinous and the lower more muscular in their respective insertions $5^{2}$. Having a full-thickness supraspinatus tear and a tear of the whole subscapularis, or a full-thickness tear involving 3 tendons, were risk factors for pseudoparalysis (defined as inability to actively elevate beyond $90^{\circ}$ ) ${ }^{2}$.

A classification of subscapularis tears based on the arthroscopic appearance together with the CT-appearance has been suggested ${ }^{159}$. A grade 1 is in this classification a partial tear of the superior one-third, grade 2 a full-thickness tear of the superior one-third, grade 3 a full-thickness tear of the upper two-thirds, grade 4 a complete tear but with centred humeral head and no fatty infiltration more than stage 3 on CT and grade 5 is a complete tear with decentralized humeral head and fatty infiltration. A weakness with this classification is that it does not allow treatment decision based on the grade until an arthroscopic examination has been performed.

\section{Prevalence and predisposing factors for rotator cuff tear}

Trauma is far from being the only etiologic factor behind a defect in the rotator cuff. Age is perhaps the most important risk factor $251,261,264$. Teunis et al. ${ }^{251}$ did a pooled estimate of prevalence of rotator cuff abnormalities (partial and full-thickness tears) in different age groups, including 30 studies based on cadaver dissections or ultrasound/MRI of both asymptomatic and symptomatic patients. In these 6112 patients and specimens, rotator cuff abnormalities ranged from $9.7 \%$ in individuals in their 20 to $62 \%$ in patients from 80 years and above ${ }^{251}$. Looking only at 
asymptomatic patients, people in their 20 s had a prevalence of $6.7 \%$ and people in their 80 s and above a prevalence of $56 \%{ }^{251}$.

Age is thus an important risk factor, but numerous other factors have also been shown to influence the occurrence of cuff tears. The two main areas where risk factors are found, are metabolic and genetic. Park et al. did a multivariable analysis of 634 shoulders in 634 rural South Korean patients and identified diabetes, hypertension, high BMI, and hypo-highdensity lipoproteinemia (hypo-HDLemia) as significant risk factors for having either a partial or a full-thickness degenerative cuff tear ${ }^{221}$. If these risk factors are grouped together as a metabolic syndrome, this risk factor was significant with an odds ratio (OR) of 1.98, together with age (OR, 1.85), dominant-side involvement (OR, 1.83) and manual labour (OR, 7.71) ${ }^{221}$. Additional studies have results supporting cardiovascular disease ${ }^{9,67}$, smoking 24,67 , dyslipidemia ${ }^{34,}{ }^{266}$, diabetes ${ }^{46,129}$, hypertension ${ }^{106}$ and obesity ${ }^{107}$ as risk factors.

Genetics also seems to influence the occurrence of cuff tears59. Harvie et al. found a more than doubled risk of full thickness tear in siblings in a case-control study, comparing siblings and spouses for patients with fullthickness tears ${ }^{116}$. In a 5 -year follow-up of the same study participants, the relative risk of tear progression was 2.08 and the relative risk of painful cuff tears was $1.44^{108}$. Tashijan et al. also described a significantly increased relatedness in subjects with rotator cuff disease, even as distant as third cousin ${ }^{250}$. In patients diagnosed before the age of 40 , the relative risk of rotator cuff tear in second degree relatives was 3.66 and in third degree relatives $1.81^{250}$. The precise genetic pathways, linking genetic changes to rotator cuff tears, are not known, but seem to include gene changes that relate to apoptosis, metabolism, angiogenesis and the extracellular matrix 43 .

Several other studies have highlighted the importance of a set of mechanically related factors. Manual labor ${ }^{191,} 221,236$, overhead work activity ${ }^{249}$, overhead sports ${ }^{245}$ and dominant-side involvement ${ }^{143}$, 221, 264, seem to have an association with rotator cuff tears ${ }^{212}$. This implies that attritional and mechanical mechanisms somehow play a role in cuff tear development, but a detailed pathway is not known.

Bony variants of the acromion and the humeral head have been suggested to be risk factors for cuff tears, and this may thus also support an extrinsic attritional pathway. Biglianis classification of the acromion as flat, curved or hooked ${ }^{212}$, as seen on a lateral scapular radiograph, has been used extensively both in justification of the diagnosis of the impingement syndrome and in justifying the surgical alteration of the problem (acromioplasty) ${ }^{220}$. The impingement syndrome, a concept proposed by $\mathrm{Neer}^{208}$, suggest that the tendons of the rotator cuff impinges under the anterior third of the acromion and the coracoacromial ligament during 
elevation and that this generates subacromial pain and perhaps also cuff tears. The scientific basis for the fundamental components of the impingement syndrome has, however, been questioned ${ }^{220}$. Increasing highlevel evidence, including placebo surgery trials, has also failed to show any clinically significant effect of the classical anterior acromioplasty above the effect seen with structured physiotherapy, both as treatment for subacromial pain ${ }^{15,147,219}$ and as an adjunct to cuff repair 36 . In recent years the lateral extension of the acromion has come into focus instead ${ }^{216}$. There are several ways of measuring this lateral extension. The most common way is called the Critical Shoulder Angle (CSA), and measures the angle between the glenoid and the most lateral part of the acromion ${ }^{194}$. Larger CSA has been found to be associated with an increased risk of rotator cuff disease in some studies ${ }^{166,194}$, but not all studies have support for this association $^{25}$. There are also other measures of the bony anatomy that may indicate an increased risk of rotator cuff tear, such as the greater tuberosity angle ${ }^{8}$ and the Y-, G- and R-angles ${ }^{233}$.

\section{Intrinsic changes in torn rotator cuff tendons}

The histopathological changes of a typical cuff tear are characterized by thinner and less organized fibres of collagen, as well as hyaline and myxoid degeneration and chondroid metaplasia ${ }^{117}$. In the normal cuff tendon, the majority of collagen is of type I and less than $5 \%$ is of type III, while the weaker type III is present in a larger proportion in degenerative and torn rotator cuff tendons ${ }^{172}$. These histopathological features may in part explain the susceptibility of the degenerative cuff to atraumatic defects or avulsions after very minor trauma. The main causative factors, and their pathways to a full-thickness cuff tear, are not known in detail and are likely multifactorial, involving extracellular matrix, cellular metabolism and vascularity 43 .

Tendon homeostasis is dependent on cells that synthesize collagen (tenocytes). Apoptosis, which is another term for controlled cell death, is needed in tendon homeostasis to remove damaged and no longer useful cells $^{18}$. Several studies, with animal models and torn human rotator cuffs, have shown increased apoptosis ${ }^{43},{ }^{190}$. Overload ${ }^{12}$, oxidative stress, hypoxia and genetic susceptibility are possible causative factors 43 .

The appropriate tendon fibre alignment and endurance needed in a well-functioning rotator cuff rely on the extracellular matrix being able to maintain its collagen structure. Matrix metalloproteinases (MMPs) are proteolytic zinc dependent enzymes that can degrade collagen and, to maintain equilibrium, there are also tissue inhibitors of MMPs, called Tis- 
sue Inhibitors of Metalloproteinases (TIMPs) ${ }^{23}$. Alterations in both MMPs and TIMPs have been found in tissue biopsies of torn rotator cuff tendons ${ }^{169}$ and in plasma from patients with rotator cuff tears ${ }^{110}$. A recent review of immonuhistochemical studies describes findings of alterations, not only in MMPs (especially MMP-1, 2 3, 9 and 13), but also in inflammatory cytokines, vascular endothelial growth factors and hypoxia inducible factors ${ }^{4}$. There is, however, uncertainty of whether all these changes are causative or are produced as an effect of a cuff tear and overall the evidence is still limited.

\section{Treatment of rotator cuff tears}

Rotator cuff tears, including arthropathy, have been described in ancient Egyptian mummies in a computer tomography study of whole bodies of 45 mummies $^{86}$. The first description of a rotator cuff tear was by Monro in 1788 and the first repair was performed by Karl Hüter in $1870^{230}$. A landmark publication, describing open cuff repair in some detail, was by Codman in $1911^{51}$. Codman sutured the avulsed tendon to the tendon stump, but in the following years transosseous sutures became the preferred method, if patients were operated on at all230. The majority of patients with cuff tears have, until recent decades, probably been treated entirely nonoperatively, some with physiotherapy and many probably without specific treatment.

\section{Physiotherapy}

Physiotherapy is in many cases the first line of treatment for symptoms associated with a rotator cuff tear. The rationale is to strengthen the remaining intact rotator cuff to compensate for the loss of torn rotator cuff fibres. In addition, correction of posture, strengthening of scapular muscles and addressing tightness of the posterior capsule are also considered important ${ }^{17},{ }^{187}$. Studies on treatment effect of physiotherapy have often included subacromial pain patients, with or without knowledge of the precise cuff pathology $2,17,124,152,187$. If the cuff status is known, a variety of cuff pathologies from intact tendon (with presumed tendinosis) to massive tears have been included and the treatment protocols also differ between studies. Several prospective randomised trials have compared physiotherapy with surgical repair in patients with mainly small fullthickness tears, without finding substantial differences $154,160,197$.

Different treatment protocols have also been tested in prospective randomised trials on patients with subacromial pain, some of whom have 
had cuff tears ${ }^{17,}{ }^{124}$. Bennel et al. could not find a difference in outcome, when comparing an active programme (with manual therapy and homeexercises) to a placebo programme, with randomisation after all participants had received 10 sessions of individualized and standardized treatment ${ }^{17}$. Holmgren et al. included subacromial pain patients on the waiting list for acromioplasty and found that a specific exercise programme was superior to a non-specific programme after 3 months and that it could reduce the need for acromioplasty ${ }^{124}$. Re-examining the same patients after 5 years showed that significantly fewer patients had chosen surgery in the specific group ${ }^{26}$.

Kuhn et al. gave an evidence-based exercise programme to a cohort of 452 patients with atraumatic cuff tears (of whom $70 \%$ had only a supraspinatus tear) and found significant improvements in clinical scores at 6 and 12 weeks with less than $25 \%$ of patients electing to undergo surgery 153 . When dichotomizing patients into those who did or did not follow the rehabilitation programme, and adjusting for covariates, thereby getting an approximation of a natural course group, those who did undergo physiotherapy had significantly better SPADI-score ${ }^{66}$. Boorman et al. have also shown that approximately $75 \%$ of patients with a chronic cuff tear, treated with physiotherapy without repair, had not elected to undergo surgery at a 5 year follow-up 29 . The CSAW study ${ }^{15}$ included patients with the diagnosis of impingement syndrome, with some patients having a partial tear (full-thickness tears were excluded). Patients were randomised to acromioplasty, placebo surgery (arthroscopy only) or only follow-up without active treatment. The no-treatment group, receiving no physiotherapy at all, had a result that was almost at the level of the acromioplasty group and the arthroscopy group, and the difference was below what was considered as clinical significant ${ }^{15}$.

Patients with massive tears have also been included in physiotherapy studies. Levy et al. ${ }^{165}$ reported on a prospective cohort of patients aged 70 96 years with 3 -tendon tears and pain with pseudoparalysis. All had cuff tear arthropathy (Hamada grade 2-4). After a physiotherapy programme, including dedicated deltoid exercises, the Constant score improved from a mean 26 to a mean of 60 after 9 months of training. Yian et al. ${ }^{267}$ tried to replicate these findings in a similar patient cohort, and extended the follow-up to 24 months, with only $40 \%$ having a successful result, defined as not abandoning the physiotherapy programme, no request for surgery and at least 20 point improvement of the ASES-score. 


\section{Surgical repair}

\section{Open cuff repair}

Golden standard for surgical repair of cuff tears has for a long time been the open cuff repair. This method includes detachment of the anterolateral deltoid from the acromion, to access the subacromial space, with subsequent reattachment through drill-holes in the acromion at the end of the procedure. Apart from the actual cuff repair, open acromioplasty, bursal resection, debridement of cuff tendon adhesions and tenotomy or tenodesis of the biceps, can be achieved through this approach. The actual reinsertion is, with this method, performed with osteosutures. Open technique is still in use today, especially for revision surgery where bone defects and anchor problems may be dealt with and augmentations more easily performed. Soon after arthroscopy had been introduced, a modified mini-open technique was described in $1990^{164}$. In this technique a diagnostic arthroscopy is performed first, including biceps tenotomy, acromioplasty and release of adhesions if needed. The anterolateral portal incision is then extended by a few centimetres and a deltoid split is performed, without detachment from the acromion. The reinsertion of the tendon is, with this technique, most frequently performed with suture anchors.

\section{Arthroscopic cuff repair}

An arthroscopic cuff repair is performed via 3-5 small stab incisions, into which arthroscopic instruments can be inserted to perform debridement, bony resection, tendon passage of sutures and insertion of suture anchors, amongst other things. The joint and the subacromial space is filled with isotonic fluid through an arthroscopic pump. The very first joint arthroscopy was performed by Nordentoft in Denmark, who used a laparoscope in a knee in $1912^{23}$. Burman tried to use arthroscopy in the shoulder in cadavers in $1931^{32}$, but it was not until the late 80 s that shoulder arthroscopy came into more widespread use. In the beginning it was primarily a diagnostic procedure ${ }^{1,230}$, but in 1985 Andrews used arthroscopy for debridement of partial supraspinatus tears and in 1987 Ellman published 1-3 year results of arthroscopic acromioplasty for impingement syndrome ${ }^{8,74}$. In the early $90 \mathrm{os}$, techniques for arthroscopic cuff repair were developed, as suture anchors came into more widespread use $\mathrm{e}^{81,252}$. 
Proponents of arthroscopic cuff repair often highlight better visualisation, less deltoid damage, quicker postoperative recovery, better cosmesis and less risk of infection as possible advantages. A meta-analysis in 2016 of 18 studies on cuff repair, amongst them 4 randomised trials, concluded that there was no overall difference in outcome between mini-open and all-arthroscopic techniques ${ }^{128}$. The large UKUFF-study, published in 2017, with 273 randomised participants from 19 hospitals, did not show a clinically relevant difference between the two techniques in a 2-year follow-up35. In clinical praxis, concern with open surgery regarding infections and post-operative deltoid deficiency have been raised, but this does not have support in comparative studies or in large case-series of both methods ${ }^{13}, 35,137$.

\section{Modern tendon fixation techniques}

Regardless of mini-open or arthroscopic approach, great efforts have been made in recent years to improve both the mechanical strength and the biologic healing capacity of cuff repairs. The classic, and probably most frequently used type of repair, is the single-row repair, in which the suture anchors are placed in the middle or lateral part of the foot print and the tendon stitch uses a locking configuration. A locking configuration, such as the Mason-Allen suture ${ }^{179}$, has been shown to have greater ultimate tensile strength ${ }^{6}$. Most suture threads are non-resorbable or partially resorbable and the knot can be a non-sliding or sliding knot, depending on surgeon preference. Published single-row series have highly variable clinical and structural results ${ }^{90,121}$ and even though it is difficult to draw conclusions regarding repair technique based on different study cohorts, the potentially high retear rate has triggered attempts to improve the mechanical strength.

In order to achieve a more stable compression and wider contact area of the tendon against bone, a double row of suture anchors has been proposed by Lo and Burkhart ${ }^{168}$. Double-row repair may have a lower retear rate compared to single-row repair ${ }^{119}$, but for small and medium sized tears there seem to be no difference in clinical outcome ${ }^{247}$. Knotless anchor is an alternative, where the thread is fixed to bone after having been passed through the tendon. This makes it possible to perform a suturebridge repair, with or without tying knots medially. The construct aims to give a compression similar to osteosutures used in the classic open anchor-less method ${ }^{223}$, 224. Arthroscopic bone tunnels for tendon fixation is a recent attempt at achieving the same fixation as in the open techniques ${ }^{85}$, 202. 
Bone marrow stimulation through microfracturing of the foot print, before tendon reinsertion, is a simple way of trying to add cells and factors to promote healing. In a meta-analysis of 4 randomised trials (365 patients) a decrease in retear rates were found with bone marrow stimulation (OR 0.42; 95\% CI, 0.25-0.73), but no difference in Constant score, DASH or UCLA-score 3 . Platelet-rich plasma, a way of adding some of the more than 1400 cytokines that may play a role, has also been tried as a healing adjunct, but results are not distinctly conclusive ${ }^{271}$. Comparison of cuff repair with or without extensive bursal resection has been made recently, and the extensive bursectomy group had more bursal thickenings at 6 months and less external rotation at 6 and 12 months follow-up, but there were no differences in pain or retear rates ${ }^{205}$.

\section{Surgical alternatives other than a complete cuff repair}

\section{Acromioplasty and other minor surgical alternatives}

Minor surgical interventions are alternatives, if a complete repair is not possible and often the immediate postoperative discomfort, the complications and the costs are substantially lower. When arthroscopic shoulder surgery was newly introduced, an arthroscopic acromioplasty in the setting of a rotator cuff tear was an accepted method $74,75,123,145$, and it is still used today. In an acromioplasty, the subacromial bursa is resected, the coracoacromial ligament released from acromion and a bony resection is performed of the antero-inferior part of the acromion. Acceptable clinical results for acromioplasty for partial tears and smaller full-thickness tears have been published ${ }^{80}{ }^{145}, 213$, but often additional procedures like biceps tenotomy or ac-joint resection have been performed as well, making it difficult to discern the procedure that is primarily responsible for the treatment results. Interpretation is also hampered by lack of control groups and poor knowledge of the natural course. An acromioplasty will include a disruption of the coracoacromial arch, something which may cause superior glenohumeral instability ${ }^{248}$ and this is potentially negative for a shoulder with a pre-existing cuff tear. Long-term studies including structural results after acromioplasty without cuff repair, are completely lacking (apart from the recently published Paper I in this thesis). Matsen et al., and others, have instead of acromioplasty advocated a smooth-andmove procedure (also called tuberoplasty or reverse acromioplasty) in patients with irreparable tears and retained elevation, simply smoothing the greater tuberosity without disruption of the coracoacromial $\operatorname{arch}^{83}, 183,257$. 


\section{Procedures adjunctive to repair}

The long head of the biceps has nociceptive nerve fibres and is thought to be a possible pain generator in conjunction with a rotator cuff tear ${ }^{5}$. The biceps tendon is surrounded by supraspinatus and subscapularis and even minor or partial cuff tears that are adjacent to the biceps sulcus, probably have the potential of generating biceps instability and, secondary to that, tendinopathy ${ }^{259}$. There are three possible ways of addressing biceps pathology in this setting: a tenotomy, a tenodesis or doing nothing. In a recent meta-analysis of 12 studies (565 patients) of cuff repair with biceps tenodesis or tenotomy, it was concluded that the small but statistically significant difference in Constant score (2.2 points better in tenodesis group; $\mathrm{P}<0.01$ ) was not clinically significant and that the rates of patient satisfaction or cramping are not different between methods ${ }^{162}$. There is, however, a difference in deformity of the biceps muscle and some advocate tenodesis in younger patients with manual labor ${ }^{259}$.

The acromioclavicular joint, which is often osteoarthritic in the age groups in which cuff tears are common, is also a possible source of pain. The surgical treatment is an excision of the distal part of the clavicle to eliminate bony contact with the acromion, a procedure that can be performed open or arthroscopically. A clinical problem is selecting the patient who may benefit from the procedure. Some predictive clinical factors found in multivariable regression analysis are local tenderness to palpation, female sex and dominant shoulder ${ }^{8}$ and when comparing MRI findings of symptomatic and asymptomatic patients, bone marrow oedema was found only in symptomatic shoulders ${ }^{25}$. Both lateral clavicle resection (open and arthroscopic) and corticosteroid injection can relieve symptoms, but directly comparative studies are lacking ${ }^{42}$.

\section{Partial repair}

In large cuff tears, which may be impossible to repair completely, it is often possible to repair some parts of the cuff (usually the infraspinatus and/or the subscapularis). The rationale behind this is to restore the force couple on the front and back to regain concavity compression and relieve symptoms. A systematic review of 11 studies, with in all 643 patients and a low to moderate methodological quality, showed that patients improve significantly with regards to pain, strength and range of motion with low rates of complications ${ }^{174}$. The lack of control groups, and the limited knowledge of the natural course, however, make it difficult to ascertain the specific effect of a partial repair. Nevertheless, other surgical alterna- 
tives, like tendon transfers and reverse arthroplasty, are much more invasive and prone to complications.

\section{Grafts and patches in rotator cuff surgery}

Grafts and patches are mainly used for bridging a defect caused by an irreparable cuff tear (interposition grafts) or for augmentation, in which the tendon is repaired and the graft is put on top of the repair to reinforce and protect the repair site ${ }^{14}$. Tissue grafts can be autologous (for example fascia lata or long head of biceps), allografts (for example fascia lata, human dermal tissue, periosteum) and xenografts (for example porcine dermal or intestinal submucosal grafts). Synthetic grafts and patches include nonresorbable material like Dacron ${ }^{\circledR}$, Teflon ${ }^{\circledR}$, Gore-Tex ${ }^{\circledR}$ and Mersilene ${ }^{\circledR}$ and resorbable materials like PLLA (Poly L-Lactic Acid).

The rationale behind bridging grafts is to allow the torn tendon to contribute to force transmission and improve the subacromial gliding surface between the greater tuberosity and the acromion. The first published results was by Nevasier et al. in $1978^{211}$, who used freeze dried allograft of rotator cuff tendon and showed good or excellent results in 14 out of 16 patients. In 1986 the first series with a synthetic graft was presented, with satisfying results in 23 out of 25 patients ${ }^{218}$. No validated outcome scores or imaging were used in these early short term studies, making it hard to compare with modern results. Thirteen more modern case series with short to medium term results all show an increase in Constant score from a mean of 42 preoperatively to a mean of 77 postoperatively with a large variability in the percentage of intact grafts ${ }^{163}$. Apart from these caseseries there are 2 comparative nonrandomised studies, both comparing against partial repair. Cho et al.47, using autologous biceps graft, reported Constant score just above 80 in both groups at 20 months of follow-up, without significant between group differences, and Mori et al. ${ }^{200}$, using autologous fascia lata graft, showed a difference of 11 points in Constant score in favour of the patch group after 35 months of follow-up and a retear rate for infraspinatus of $8,3 \%$ in the patch group and $41,7 \%$ in the non-patch group $(P=0.015)$.

A theoretical weakness with interposition grafts is that the muscle is shortened, due to tendon retraction, which changes the pennate angle of the muscle fibres in the muscle belly of a torn cuff ${ }^{272}$, making it harder for the muscle to contract and generate force. Another problem is that in order to have longevity of this graft, it will probably have to be thoroughly incorporated into an often severely degenerated tendon and into bone in the greater tuberosity. The apoptotic index (indicating a loss of tenocytes) 
has been shown to be high in degenerative tendons ${ }^{18}$, theoretically affecting medial graft healing negatively.

The rates of retears after cuff repair are highly variable, with rates ranging from $11 \%^{158}$ to $94 \%^{90}$ in the literature. The rationale for using grafts and patches as augmentation is to reinforce a cuff repair, adding mechanical strength and a more protective environment ${ }^{14}$. In a clinical setting the most common scenario for patch augmentation is probably in revision cases where a new repair is possible, but the surgeon feels the need to add something more than what was done in the previous operation. In a meta-analysis, summarizing the results from 5 studies regarding retear rates, a $61 \%$ lower odds of a retear was found when pooling the results for augmentation grafts ${ }^{14}$. A better effect of augmentation on the ASES score was also shown, but not for the UCLA-score or pain ${ }^{14}$. Overall, the level of evidence is low and there are too few studies to make solid conclusions in this area.

\section{Tendon transfer}

In the setting of an irreparable cuff tear and no osteoarthritis in younger patients, tendon transfers may improve shoulder function ${ }^{6,50,94}$. For posterosuperior tears, transfer of the latissimus dorsi 97 is the most common procedure. Careful patient selection is required and patients with pseudoparalysis and insufficient subscapularis function probably have much less gain from this procedure $6,94,214$. The variability of results, and the fact that the transferred latissimus tendon provides a quite vertical pull, have led to the development of the lower trapezius transfer ${ }^{72}$, in which the transferred lower trapezius, and the allograft that is required, provide a line of pull that is nearly identical to that of infraspinatus ${ }^{50}$. Results in selected patients have shown significant improvements in pain, function and range of motion 73 , but comparative studies and medium-term results are lacking. In irreparable anterior-superior cuff tears, both pectoralis major and latissimus dorsi have been used, with the latter having a better line of pull, but published series are few so far $5^{\circ}$.

\section{Newer surgical treatment alternatives}

In the last 7 years, both reconstruction of the superior capsule ${ }^{71,188}$ and installing a resorbable subacromial balloon ${ }^{193}$, have emerged as alternatives for patients with irreparable cuff tears. Both treatments are in early phases of development, with promising results reported, but the level of evidence is low and length of follow-up short. 
In a superior capsule reconstruction, the irreparable tendon stump is ignored and instead a graft is attached to the superior glenoid medially and to the greater tuberosity laterally ${ }^{189}$, with an open or arthroscopic technique. Often a repair of adjacent cuff tendons and a tenotomy or tenodesis of biceps is performed at the same time ${ }^{188}$. A recent review found 12 studies reporting on clinical and radiographic results after superior capsule reconstruction. Pooling and weighting the results at a mean of 42 months, there was an increase by over 40 points in mean ASES score (American Shoulder and Elbow Society score 0-100) from pre- to postoperative conditions ${ }^{71}$. The increase in ASES-scores, increase in range of motion and decrease in pain scores, were all significant and above values for Minimal Clinical Important Difference (MCID) for each score ${ }^{71}$. The level of evidence was in 95\% of cases 4 or 5 (no level 1 evidence), the median sample size was 19 patients and the total number of reported unique cases was 304 .

The In-space Balloon (OrthoSpace, Kfar, Saba, Israel) is a biodegradable inflatable balloon that is intended to be introduced in the subacromial space via arthroscopic ${ }^{244}$ or fluoroscopic assistance ${ }^{98}$. Published results of this procedure come from 7 studies of, in all, 200 patients, with 6 of those studies being case-series ${ }^{193}$. The mean Constant scores from these studies increased from 30-40 preoperatively to just above 60 postoperatively. In a few studies with longer follow-up (up to 5 years), the clinical results have been durable and comparable to early results, despite the fact that this time point is way beyond the degradation time ${ }^{193}$. Contraindications have included Hamada grade 3 (which has abrasion of the undersurface of the acromion) and subscapularis tears. Complications described, are spacer migration and synovitis without clinical significance.

When considering results from both of these methods, it has to be noted that often additional procedures have been performed (debridement, biceps tenotomy etc.), as well as dedicated rehabilitation, making it hard to determine the specific therapeutic effect. And as always, effects that are due to natural course, regression to the mean and placebo effects are not accounted for in studies like this.

\section{Reverse arthroplasty}

In a reverse shoulder arthroplasty, the convex glenosphere is fixed on the glenoid and the concave cup on the humerus. This gives a semiconstrained prosthesis with a medialized centre of rotation, leading to stability despite the absence of a rotator cuff, allowing the deltoid to generate force ${ }^{238}$. If there are an irreparable cuff tear and an osteoarthritic 
glenohumeral joint, significant improvements for this difficult patient category have been shown, but complication rates as high as $39 \%$ have also been reported 77 . Deteriorating long-term results have been reported as well and these include glenoid component loosening, which is challenging to treat ${ }^{238}$. Favard et al reported 10 year results for reverse arthroplasty for cuff tear arthropathy. Survival rate was $89 \%$ for the end point of revision, but only $72 \%$ for the end point of having a Constant score under $30^{82}$. Reverse arthroplasty is sometimes advocated in patients with massive tears and pseudoparalysis, but no osteoarthritis. On the other hand, first doing a repair, and a reverse arthroplasty only in those who have a failed repair, may be more cost-effective ${ }^{68,173}$. 


\section{Rationale for this thesis}

The multitude of treatment alternatives for a rotator cuff tear have been elaborated on in previous sections of this thesis, and they include a wide range of treatments, from non-operative treatment to major surgery. The numbers of rotator cuff repair have increased substantially in recent decades, with an increase from 41/100 ooo person years in 1996 to $96 / 100$ ooo person years in 2006 in the US (an increase of $141 \%$ )55. It may seem obvious to repair larger tears, despite a complete lack of randomised studies in patients with large cuff tears, but do we really need to operate all tears we encounter regardless of tear size? In choosing the right treatment for our patients, we need to know more about specific treatment effects and hence compare treatment to no treatment.

In the existing prospective randomised studies comparing rotator cuff repair to a treatment without repair, $89 \%$ of included patients have had degenerative non-traumatic tears ${ }^{154}, 160,197,217$. A traumatic tear could be regarded as an avulsion of a healthy tendon, due to the energy in a trauma, and it should therefore have a good healing capacity and yield a good clinical result if repaired. When something is torn, fix it! We do not know however, whether patients with a presumed traumatic tear gain more from early repair than a patient treated without repair.

If no cuff repair were a viable option in the short-term, we still need to know how such patients do in a long-term perspective. Because, as health care providers, we all see rotator cuff patients with arthropathy and question is, how did they end up in that state? Did they progress to arthropathy from starting up with a small cuff tear that was not repaired?

Patients with irreparable tears, but no arthropathy, are also a treatment dilemma. This is shown by the large amount of different patches and grafts, which all have one common feature: we do not know anything at all about the long term results! Can these devices prevent an enlargement of the irreparable tear and subsequent arthropathy? 
Rotator cuff tears-short and long-term aspects on treatment outcome 


\section{AIMS OF THIS THESIS}

The overall aim of this thesis was to increase the knowledge of both longterm and short-term results for several specific treatments for rotator cuff tears.

Specific aims in each study was:

\section{Paper I}

- To investigate if the condition of the glenohumeral joint and rotator cuff had deteriorated at a minimum of 21 years after an acromioplasty without cuff repair, in patients with partial and full-thickness tears.

- To examine the clinical results in the same patients

\section{Paper II}

- To investigate the frequency of full-thickness tear and cuff tear arthropathy in the contralateral shoulder at a minimum of 21 years after an arthroscopically documented tear in the other shoulder.

- To assess risk factors for having a contralateral cuff tear as well as symptoms and function of the contralateral shoulder.

\section{Paper III}

- To investigate the clinical and radiological results 17-20 years after repair with a bridging synthetic interposition graft for an irreparable cuff tear. We were specifically interested in whether this graft had prevented cuff tear arthropathy.

\section{Paper IV}

- To investigate if operative repair, of a fresh traumatic small full-thickness cuff tear involving mainly supraspinatus, was superior to physiotherapy without repair in a one year perspective.

- To assess healing rates in repaired patients and tear progression in unrepaired patients. 
Rotator cuff tears-short and long-term aspects on treatment outcome 


\section{MATERIALS \& METHODS}

\section{Overview of papers and their design}

The thesis is based on four papers:

Paper I - A study of treatment results 21-25 years after of acromioplasty without cuff repair in a case-series of 69 patients with partial and full-thickness rotator cuff tears. Baseline findings on x-ray and arthroscopically documented cuff tears were compared to findings on $\mathrm{x}$-ray and ultrasound in a retrospective long-term follow-up. Clinical scores were also assessed at follow-up and risk factors were analysed.

Paper II - A descriptive epidemiology study of the same study participants as in paper I, in which participants were assessed for contralateral cuff tear with ultrasound and x-ray. Clinical scores were collected and risk factors analysed as well.

Paper III -Patients with irreparable cuff tears treated with a synthetic interposition graft were examined with x-ray, ultrasound and clinical scores after 17-20 years.

Paper IV - A prospective randomised trial. Patients with small trauma-related cuff tears were randomly allocated to cuff repair or non-operative treatment with only physiotherapy. Follow-up was with clinical scores at 3, 6 and 12 months and with MRI at 12 months. 


\section{Study participants}

\section{Papers I and II}

Participants were identified through operative protocols. These protocols were mandatory to fill out after having performed a shoulder arthroscopy in the Orthopaedic Department at Linköping University Hospital. This system was adopted after introduction of this operation in the late 1980 s. In 1989, the system was fully working and the design of the protocols had settled for a layout that was then used in the forthcoming years. The operating surgeon had to fill-out the operative findings regarding joint surfaces, labrum, biceps tendon and rotator cuff tendons. For each rotator cuff tendon, the surgeon had to make a marking if the tendon was intact, had a partial tear or a full-thickness tear. It was also possible, but not mandatory, to indicate location and size on a drawing of the rotator cuff.

After review of every single protocol from 1989-1993, all patients with an operative finding of a partial or a full-thickness tear were identified and a review of medical charts was undertaken. One-hundred eleven patients were identified with a cuff tear. Twenty-one of these were deceased and 11 were considered too medically ill to be contacted. One patient could not, despite great efforts, be reached. Nine patients declined to participate, resulting in a study cohort consisting of 69 patients. A flow-chart of the inclusion process is shown in Figure 7. 


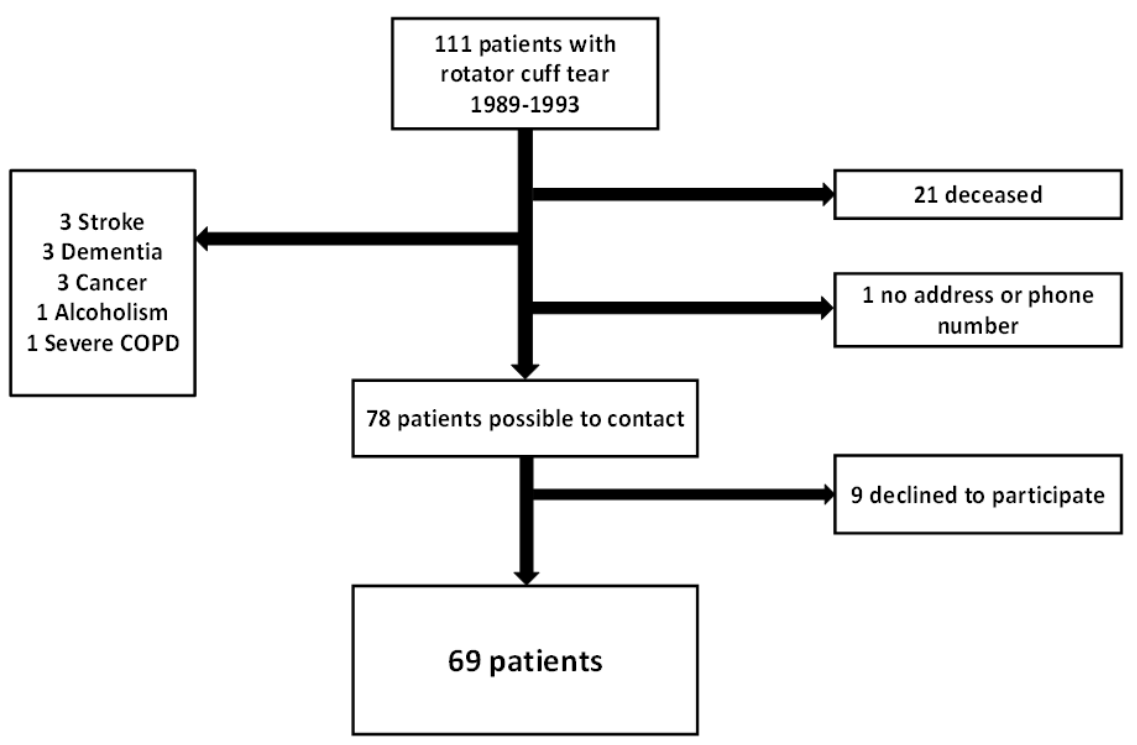

Figure 7. Flow-chart of the inclusion process in paper I.

\section{Paper III}

The orthopaedic surgeon who had performed all operations with a synthetic Dacron graft at the Orthopaedic Department in Linköping University hospital provided the names and personal identification numbers of all patients who had undergone the operation. All operations with this graft had been performed in 1992-1996. Thirteen patients were identified and one patient was deceased. We could get an x-ray and medical charts in 2 patients that lived too far away for examination and ultrasound, and in 1 patient, also living far away, we arranged for an examination with bilateral MRI and clinical scores recorded by an experienced orthopaedic surgeon. The remaining 10 patients did bilateral shoulder $\mathrm{x}$-ray, bilateral ultrasound and CM-scores on both shoulders. In summary, all 12 living patients were examined (follow-up rate $92 \%$ ) and 10 patients had a complete follow-up (follow-up rate $77 \%$ ). Mean age at follow-up was 76 years (range 64-90 years).

\section{Paper IV}

Eligible participants were recruited among patients who had been subjected to a shoulder trauma and who were seeking medical attention at emergency departments in Linköping or Kalmar. Referrals to these orthopaedic departments were also screened for possible participants. In- 
clusion criteria were shoulder pain and decreased elevation after a shoulder trauma and an MRI showing a full-thickness tear involving supraspinatus. The tear had to be within the 2 upper segments of a 12-segment division of a sagittal image of the humeral head. Exclusion criteria were previous shoulder complaints, a delay of more than 3 months between trauma and operation, glenohumeral osteoarthritis, symptomatic ACjoint arthritis, shoulder fracture or dislocation, previous shoulder operations, systemic joint disease, malignancy, fibromyalgia, shoulder instability, frozen shoulder, neurological disease affecting arm function, inability to understand Swedish, drug abuse and cognitive impairment. Onehundred sixty four patients were screened and 58 included. A flow-chart of the enrollment in paper IV is shown in Figure 8.

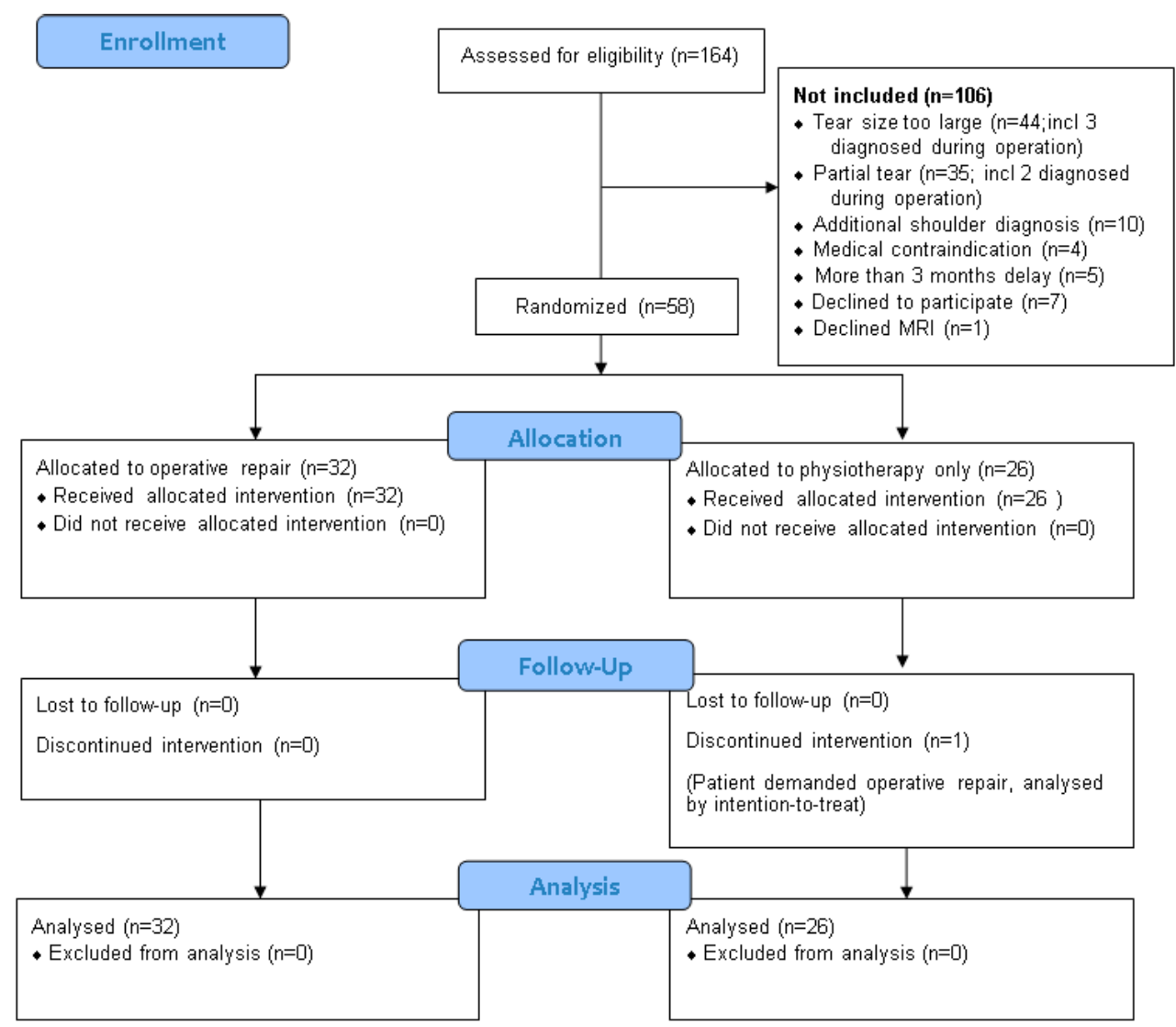

Figure 8.Flow-chart of the inclusion process paper IV 


\section{Methods}

\section{Surgical treatments}

\section{Acromioplasty}

In paper I and II, the operations were performed by one of 4 well experienced shoulder surgeons, as part of routine care in 1989-1993. The arthroscopic procedure was performed in lateral decubitus and began with an intraarticular diagnostic part, where all intraarticular structures were identified for later documentation in the operative protocols. The status of each rotator cuff tendon was documented, but not precise tear size in millimetres. The arthroscope was then withdrawn from the joint and introduced into the subacromial space, where a bursectomy, release of the coracoacromial ligament and an acromioplasty was performed with a shaver. The bony resection aimed at a distance of twice the diameter of the $6 \mathrm{~mm}$ shaver blade. If there were osteophytes of the AC-joint protruding inferiorly, they were also resected.

\section{Interposition graft}

In paper III, all operations had been performed by the same experienced shoulder surgeon from 1992-1996. The operation was done through a superolateral skin incision with detachment of the anterolateral deltoid from the acromion. The non-reparability of the tear was ascertained and the tip of the greater tuberosity resected. The Dacron graft was medially sutured to the tendon edge and laterally fixed with a screw and washer, without any partial repairs. After completion of the construct, the deltoid was reattached to the acromion with osteosutures. The repair was protected with an abduction brace for 5 weeks and the brace was removed gradually over several days with the help of a physiotherapist.

\section{Rotator cuff repair}

Arthroscopically assisted mini-open repair was done by 5 different shoulder surgeons. There are no substantial differences in clinical results between mini-open and arthroscopic techniques35, 254 and we chose mini- 
open technique to avoid effects from learning curves or lack of experience. The arthroscopic part was diagnostic, with the addition of a subacromial bursectomy and a small acromioplasty according to surgeon preference. The approach was a superolateral incision and a split between the anterior and middle portions of the deltoid. The footprint was then prepared and the torn tendon assessed for most appropriate way of suturing. The fixation used double loaded metallic suture anchors with Orthocord ${ }^{\circledR}$ suture threads (Fast-in $\mathrm{RC}^{\circledR}$ or Super QUICKANCHOR Plus ${ }^{\circledR}$ ), in one case supplemented with osteosutures. A sling was used post-operatively for 4 weeks.

\section{Physiotherapy}

The rehabilitation programme was based on specific exercises, that in a previous randomised trial had been shown to be more effective than unspecific exercises ${ }^{124}$. The rehabilitation programme was delayed 4 weeks in the operative group, due to the sling and the post-operative restrictions, but was otherwise the same for both groups. The programme contained 3 phases, each with a set of recommended exercises that the physiotherapist could choose from. The first phase emphasized information, good posture and scapula stabilizers. Active and assisted exercises that unload the rotator cuff, like the wall slide and flexion on a table using a ball92, was also used in this phase. Phase 2 used active unloaded exercises in full can elevation and external and internal rotation, as well as isometric strengthening exercises ${ }^{124}$, 153. Phase 3 introduced dynamic strengthening exercises for the rotator cuff and scapula stabilisers ${ }^{124}$.

\section{Imaging modalities}

\section{Radiographic imaging}

In all papers, plain radiographs including a standard frontal and a lateral projection of the shoulder were used, in papers I, II and III for arthropathy classification of follow-up images and in paper IV at inclusion, screening for exclusion criteria.

In papers I, II and III, the original preoperative images from 19891993 were not available (destroyed and no longer in storage). The radiography report in the medical charts was used to ascertain that there were no pre-operative osteoarthritis changes. The follow-up images of both the index shoulder and the contralateral shoulder were classified according to the Hamada classification ${ }^{112}$. Two orthopaedic shoulder surgeons and one experienced radiologist independently classified the images and consen- 
sus discussion was used for final classification. Kappa statistics was used for quantification of assessor agreement.

\section{The Hamada classification}

The Hamada classification ${ }^{112}$ is intended to be used for classifying cuff tear arthropathy. It takes into account the superior migration and the accompanying bony changes of the humeral head seen in later stages in shoulders with long-standing rotator cuff tears. Incorporating these presumed temporal changes, that seem to be specific to the secondary osteoarthritis seen in cuff tear arthropathy, makes the classification theoretically appropriate. The Hamada classification is described as having fair to moderate intra- and interrater agreement, with kappa values ranging from 0.407 to $1.0^{30}, 130,138$. Limitations include inability to specifically describe anterosuperior escape and morphologic changes of the glenoid. When compared to 3 other osteoarthritis classifications, it fared well and has been recommended for use in research and everyday practice ${ }^{138}$. The different stages are displayed in Figure 9.

The acromio-humeral interval is essential for distinguishing between grade 1 and 2. This interval is measured from the most superior part of the subchondral bone of the humeral head to the undersurface of the acromion. Grade 1 is defined by an acromiohumeral interval of $6 \mathrm{~mm}$ or more and grade 2 by $5 \mathrm{~mm}$ or less. An acromio-humeral distance of $7 \mathrm{~mm}$ or less has been strongly associated with the presence of a full-thickness tear and tear size and fatty infiltration of infraspinatus correlate to a reduced acromio-humeral distance ${ }^{243}$. In Grade 3 there is a concavity deformity of the undersurface of the acromion (called acetabulization), indicative of frequent and severe contact between the major tuberosity and acromion. In grade 4 the joint surface is also reduced and in grade 5 there is, in addition, a deformity of the humeral head (a head collapse). 


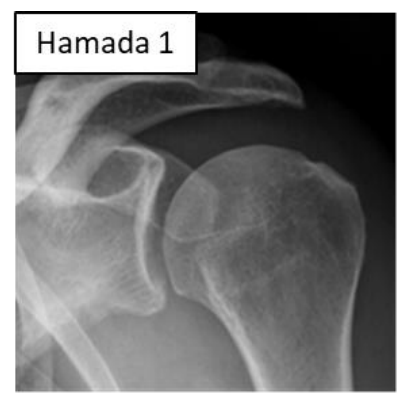

Acromiohumeral interval $(\mathrm{AHI}) \geq 6 \mathrm{~mm}$

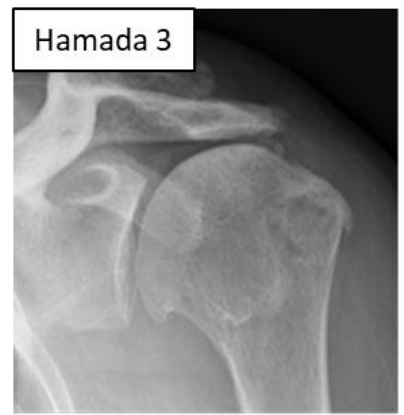

+ acetabulization

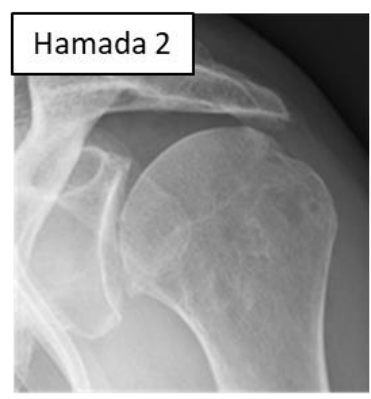

$\mathrm{AHI} \leq 5 \mathrm{~mm}$

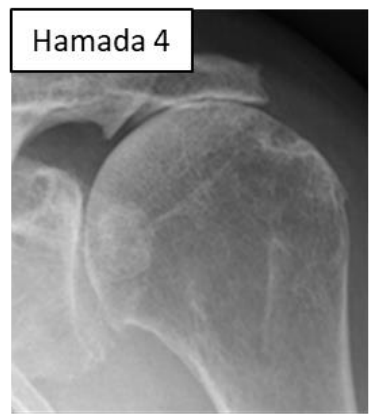

+ reduced joint space

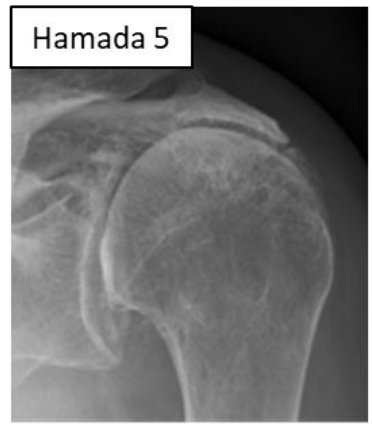

+ head collapse

Figure 9. The Hamada classification 


\section{Ultrasound}

Shoulder ultrasound is well established as an easily accessible and cheap method of assessing the rotator cuff ${ }^{16,178}$. Ultrasound was used in papers I-III to assess rotator cuff status and we used the technique described and recommended by the European Society for Musculoskeletal Radiology ${ }^{178}$. In using this standardized technique, the examiner positions the arm in several specific positions and each tendon of the rotator cuff is scanned longitudinally and transverse to the tendon fibres. Intact tendon fibres are hyperechoic and a defect and fluid is hypoechoic. We diagnosed a fullthickness tear when there was a hypoechoic defect through the whole thickness of the tendon, visible in both planes. Similarly, a partial tear was diagnosed when there was a defect on the bursal or articular side, not extending through the entire thickness of the tendon. We used a BK Medical Flex focus 500 (BK Medical, Peabody, MA, USA) with a 6-18 MHz linear transducer.

It has been shown that orthopaedic surgeons, that are not previously familiar with the technique, can achieve a high degree of accuracy on detection of full-thickness tears using ultrasound, after a short formal training course ${ }^{203}$. In a meta-analysis of 65 studies, ultrasound was found to have a sensitivity of $92.1 \%$ and a specificity of $92.9 \%$ in diagnosing a fullthickness cuff tear ${ }^{61}$.

The accuracy is lower for partial tears, with a sensitivity of $66.7 \%$ and a specificity of $93.5 \%$, but there are no significant differences in accuracy for partial tears (or for full-thickness tears) between ultrasound and MRI ${ }^{61}$. The sensitivity for detecting subscapularis tears is also considerably lower (39.5\%), especially for the smaller articular side tears, but the specificity is $93.1 \%^{207}$.

In paper I, tear progression (increased tear size) was defined as either having a partial tear at index operation and a full-thickness tear at followup or having a full-thickness tear at index operation and a full-thickness tear in an additional tendon at follow-up.

\section{Magnetic Resonance Imaging (MRI)}

MRI was used at baseline in study 4 to diagnose full-thickness tears compliant with the inclusion and exclusion criteria. We also used MRI at follow-up to assess tear size increase in non-operated patients and retear in operated patients. In both groups we also looked at atrophy and fatty infiltration. Three orthopaedic shoulder surgeons assessed the MRI-images 
independently and consensus discussion was used to definitely classify the tear regarding tear size, atrophy and fatty infiltration.

MRI of the shoulder is by many regarded as the primary tool for imaging shoulder disorders ${ }^{131}$. It has the advantage of visualizing both bone and soft tissues and the deeper structures, like cartilage, labrum, muscle bellies etc., are visualized more easily than with ultrasound. It is also an advantage in a multicentre study to be able to send images between centres. All MRI images were taken according to local routine at each radiology department, without any study specific alterations. The majority of images were taken with a 3.0 Tesla MRI, but in a smaller proportion of cases a 1.5 Tesla machine was used.

We wanted to include cuff tears which mainly involved the supraspinatus tendon, i.e. the superior rotator cuff. Since the precise anatomy is very intricate, especially the overlapping of fibres from supra- and infraspinatus ${ }^{192}$, there are difficulties in relying on tendon nomenclature for inclusion. Instead we used a custom made digital 12-segment template called the Cuff Clock (Figure 10).

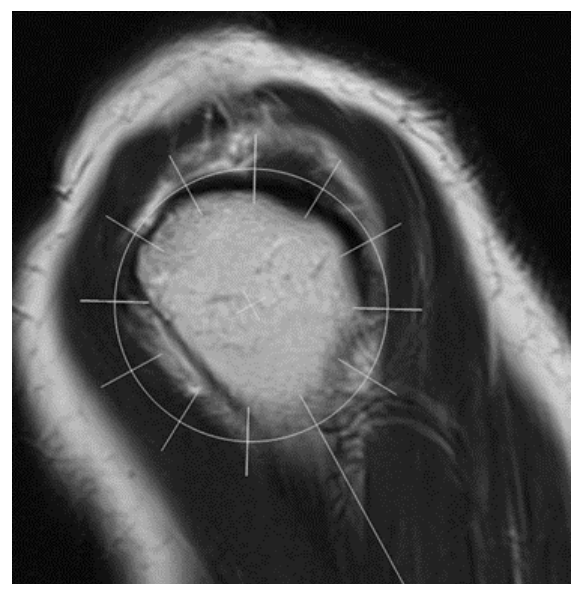

Figure 10. Sagittal oblique MRI with Cuff Clock

The Cuff Clock was designed with the help of Sectra and constructed with the same technique as used for preoperative planning with templates and measurement tools in PACS. The sagittal oblique image in which the tear is at its widest is used for application of the template, which can then be rotated, so that the long $6 o^{\prime}$ clock line is in line with the humeral shaft. In paper IV the tear had to be within the 2 upper segments (from $11 \mathrm{o}^{\prime}$ clock to $1 o^{\prime}$ clock).

We also measured tear size at inclusion and at 12-month follow-up in paper IV. Tear size was measured in two planes. In the longitudinal plane 
(medial to lateral), we measured from middle of tendon edge to middle of footprint and in the transverse plane (anterior to posterior) from tendon edge to tendon edge or, if the whole tendon was avulsed, to the posterior edge of the biceps sulcus.

We used the Tangent sign ${ }^{268}$ to determine if atrophy was present or not. In a shoulder with atrophy of the supraspinatus (a positive Tangent sign), the muscle belly does not extend superior to a line drawn between the superior borders of the scapular spine and the coracoid process. The Tangent sign has been shown to have a good intraobserver and interobserver reliability and it seems to be a good predictor of repairability ${ }^{151}$. Sensitivity is $93.3 \%$ and specificity $95.3 \%$, and if pre-test prevalence of irreparable tears is $18.9 \%$, the positive predictive value is $82.4 \%$ and negative predictive value $98.4 \%{ }^{151}$.

Fatty infiltration is another factor that has an impact on reparability and healing ${ }^{102}$. The very commonly used Goutallier classification ${ }^{101}$, was developed for CT, but has been adapted to MRI by Fuchs et al. ${ }^{88}$. The Goutallier classification grades the fatty streaks within the muscle belly as seen on the most lateral parasagittal image, where the scapular body is in contact with the scapular spine ${ }^{101}$. The stages are: normal (stage o), some fatty streaks (stage 1), still more muscle than fat (stage 2), equal amounts of fat and muscle (stage 3 ) and more muscle than fat (stage 4). Traditionally, it has been stated that fatty infiltration occurs mainly as a result of a full-thickness tear or denervation, and this holds true for the more advanced stages of fatty infiltration. For low-grade fatty infiltration however, both age ${ }^{104}$ and obesity ${ }^{184}$ may be associated with fatty infiltration up to stage 2. 


\section{Clinical outcome measures}

\section{Constant-Murley score (CM)}

The Constant-Murley score ${ }^{6}$ was used in all studies to assess shoulder symptoms and function and is probably the most widely used shoulder specific outcome score. It is recommended by the European Society of Shoulder and Elbow Surgery (ESSSE). It combines a patient assessed part, which accounts for 35 points of the total score of 100 points, and an objective part in which an assessor measures range of motion and strength. A possible reason for the popularity and recommendations is probably the inclusion of range of motion and strength, which adds clinically relevant information compared to purely patient reported outcome scores. Like many other shoulder outcome scores, the Constant-Murley score lacks evidence for many of its measurement properties ${ }^{127}$. It has moderate evidence for reliability 57,127 and limited evidence for responsiveness ${ }^{62,127}$. In papers I-III, the age- and gender adjusted Constant score (called relative Constant score) was also calculated 56 .

The Constant scores in paper IV were collected by an independent physiotherapist, who was not otherwise involved in the care of the patients in the study. Clothing covering the scar area was used in all patients to keep the assessor blinded as far as possible, but we did not evaluate if this blinding was successful.

\section{Western Ontario Rotator Cuff index (WORC)}

WORC is a patient reported outcome score designed specifically for patients with rotator cuff disorders and contains 21 questions in 5 subdomains ${ }^{150}$. Each question is answered on a visual analogue scale $0-100 \mathrm{~mm}$ and relates to symptoms as perceived during the last week. The subdomains are Physical symptoms (6 questions), Sports/Recreation (4 questions), Work (4 questions), Lifestyle (4 questions) and Emotions (3 questions). The millimetre-measurements are recalculated to points (total scale $0-2100$ points) and a percentage, and this can be done for the whole score and for each subdomain. Compared to 16 other outcome scores for shoulder disorders, WORC has been ascribed the best overall psychometric properties ${ }^{127}$, even though quality of studies in this area is generally low. There are evidence for good or acceptable responsiveness, internal consistency, reliability, content validity and hypothesis testing ${ }^{127}$. 


\section{Numerical Rating Scale (NRS)}

NRS is a measure of pain intensity, in which the respondent chooses the whole number that gives the most accurate reflection of his or her pain. The 11-point scale goes from o ("no pain") to 10 ("worst pain imaginable"). NRS is thus similar to the well-known pain VAS scale and they are highly correlated when tested together ${ }^{118}$. An advantage is its simplicity. It does, for example, not require administration of a blinded VAS ruler and it can be delivered verbally or in writing. In paper IV, we used NRS asking for pain at rest, during activity and at night, as perceived during the last week. The NRS has been found to have a high test-retest reliability and a high acceptability ${ }^{118}$. NRS has also been validated for acute pain and may be more responsive than $\mathrm{VAS}^{84}$.

\section{EQ-VAS}

We used the EQ-VAS as a measure of overall health in paper IV. This score gives a self-reported value of $0-100 \mathrm{~mm}$ of overall health. Qualityof-life measures contribute with an important aspect of medical treatments, but the responsiveness (the ability to capture clinically meaningful change over time) in shoulder surgery can be questioned for EQ-5D78, 127 . The EQ-5D-3L has also been noted to have a ceiling effect of $46 \%{ }^{78}$, and an acceptable ceiling effect is considered to be $15 \%$ of scores at the highest levels of functioning. In a test of external responsiveness against Oxford Shoulder score in rotator cuff patients, EQ-VAS showed a weak but significant external responsiveness, while the EQ-5D-3L showed no responsiveness ${ }^{78}$.

\section{Hospital Anxiety and Depression score (HAD)}

Comorbidities such as anxiety and depression have been shown to be present in patients scheduled for rotator cuff repair and to have a significant correlation with post-operative clinical scores and pain scores44. The Hospital Anxiety and Depression score (HAD score) ${ }^{269}$ has a depression subscale and an anxiety subscale, with 7 questions each. There are 4 alternatives (o to 3) to each question, rendering up to 21 points for each subscale. A value of 0-7 is considered normal, 8-10 a mild case, 11-15 a moderate case and $16-21$ a severe case 44 . HAD has good psychometric properties and has been recommended for screening patients with musculoskeletal disorders ${ }^{115}$. We screened the participants in paper IV with the HAD score to have a better baseline characteristic of these potentially influential factors, but we did not use a high HAD score as exclusion criterion. 


\section{Statistical methods}

Paper I: We used both mean values with standard deviation (SD) and median values with quartile range $(\mathrm{QR})$, even though distribution in some cases was non-parametric. The mean and standard deviation were included anyway in such cases (even if it is less correct from a statistical standpoint) to allow comparison with other published studies, where mean values are most frequently used. Frequencies are given as percentage of patients with available data. We used Fischer's test for comparison of categorical data and Mann-Whitney U-test for numerical data and considered $\mathrm{P}>0.05$ as significant. All tests were 2-sided, when applicable.

We also analysed risk factors for having cuff tear arthropathy and tear progression with logistic regression, a method well suited for a binary outcome such as having or not having a disease. Stepwise forward and backward selection methods were used when performing logistic regression. Data in paper I was analysed with Statistica 12.0 (Statsoft, Tulsa, OK, USA).

Paper II: The same statistical methods were used as in paper I, but in addition, analysis of 3 groups was performed with one-way analysis of variance (ANOVA), with Duncan's test for post-hoc analysis. We used Spearman's rank correlation, a non-parametric method, to assess correlation between the index shoulder and the contralateral shoulder regarding structural changes and clinical scores. The risk factor analysis for having a contralateral cuff tear was performed with logistic regression, with forward and backward selection of variables. Statistica 12.0 was used for analyses.

Paper III: We used descriptive statistics with mean values and standard deviation and Fischer's test for group comparisons. We also calculated the confidence intervals for proportions, which gives the reader an indication that with $95 \%$ probability the results will be at least at the lower level of the interval (if the same method was used on the same kind of patients). Both Statistica 12.0 and Excel were used for analyses.

Paper IV: The basis for calculations of sample size used results from a previous study of traumatic tears, in which the difference between those with a healed repair and a retear was 18 points in Constant score and the standard deviations was 21 and $20^{27}$. Using the conventional power of $80 \%$ and significance level $5 \%$, the required sample size would be 42 patients. At the time of planning the study, only a few suggestions of Minimal Clinical Important Difference (MCID) for Constant score had been 
published and interpretation and use of such values are still under debate and without consensus in the literature. MCID values of 10, 17 and 24 had been published for the Constant score ${ }^{125},{ }^{156}$. We took this into account, as well as the possibility of losses to follow-up, and decided to include at least 56 patients.

The analysis was based on testing the null hypothesis that there was no difference in primary or secondary outcomes between the groups at the 12-month follow-up. One patient crossed over from the physiotherapy group to the repair group and the results from this patient were analysed in the physiotherapy group, i.e. an intention-to-treat analysis was performed.

The continuous data at baseline and at follow-up were checked for normality with visual inspection of histograms, normal quantile-quantile plots (Q-Q plots), the Kolmogorov-Smirnov test and the Shapiro-Wilks test. In the baseline variables, mean with SD or min-max range was used in case of parametric distribution and medians with interquartile range or min-max range for non-parametric distribution. The corresponding comparisons were made with the independent T-test or Mann-Whitney U-test for continuous variables. For categorical variables we used Fischer's test or $\mathrm{Chi}^{2}$-test.

Considering the non-parametric distribution, the median value was the most correct measure of the central tendency, but to allow comparison with other studies (which predominantly have used mean values), the means were shown as well. We chose to display the 12-month results in great detail, including mean, standard deviation, min-max range, median and interquartile range for the absolute scores of all primary and secondary outcomes.

The same principle was used for differences between the groups, where the median values were used, but the differences in mean values were also accounted for, in order to facilitate comparison with other studies. The confidence interval for difference between means is readily available in SPSS, when performing independent t-test, but not the confidence interval for the difference in medians. For this calculation, we instead used Excel with add-ins containing formulas for this calculation, downloaded from www.real-statistics.com. The effect size allows comparison with other interventions and was calculated as the standardized test statistic (from the Mann-Whitney analysis) $/ \sqrt{ } \mathrm{N}$ (where $\mathrm{N}$ is number of participants).

The amount of results with several follow-up time points is potentially very large. We therefore chose to display the remaining results from the 3 and 6 month time-points as line graphs of the median values and corresponding 95\% confidence intervals. 
All analyses in paper IV were performed with SPSS 24.0 (IBM, Armonk, NY, USA), except as already described. 


\section{RESULTS}

\section{Paper I: Long-term results of unrepaired cuff tears.}

After 21-25 years we had a follow-up rate of $88 \%$ for patients who were possible to examine (Figure 7). Out of the 69 patients examined, 45 had had a partial tear at the index operation and 24 a full-thickness tear. The mean age at index operation was 49 years (range 19-69) and the mean age at follow-up 72 years (range 43-92). Patient characteristics are shown in Table 1. At follow-up, patients with partial tears (mean age 69 years) were significantly younger than those with a full-thickness tear (mean age 77 years; $P=0.003$ ).

We found very different conditions in patients who had a fullthickness tear at the index operation compared to those who had a partial tear. The rate of tear progression was $87 \%$ in the full-thickness group and $42 \%$ in the partial tear group $(P<0.001)$. Tear progression according to tendon status at index operation is shown in Table 2.

The frequency of cuff tear arthropathy (CTA) was also markedly different between the groups. In the full-thickness tear group $74 \%$ had arthropathy (Hamada grade $\geq 2$ ), with $30 \%$ having Hamada grade 4, while in the partial tear group, $7 \%$ had arthropathy $(P<0.001)$. The numbers and frequencies of cuff tear arthropathy according to tendon status at the index operation are shown in Table 3. In 2 patients the follow-up x-ray showed decreased joint space and inferior osteophytes but no acetabulization or decrease of the acromiohumeral interval. These images were interpreted as Hamada stage 1. The Hamada classification showed kappa values of $0.83,0.76$ and 0.75 for the 3 assessors. 
Table 1. Patient characteristics in paper I

\begin{tabular}{|c|c|c|c|c|}
\hline & $\begin{array}{l}\text { PTT } \\
n=45\end{array}$ & $\begin{array}{l}\text { FTT } \\
n=24\end{array}$ & $\begin{array}{l}\text { All cases } \\
\mathrm{n}=69\end{array}$ & $\begin{array}{l}\text { Missing } \\
\text { info }\end{array}$ \\
\hline \multicolumn{5}{|l|}{ At surgery: } \\
\hline Mean age in years (range) & $46(19-66)$ & $54(37-69)$ & $49(19-69)$ & - \\
\hline \multicolumn{5}{|l|}{ Gender (n; \%) } \\
\hline Male & $31(69 \%)$ & $21(88 \%)$ & $52(75 \%)$ & - \\
\hline Female & $14(31 \%)$ & $3(13 \%)$ & $17(25 \%)$ & - \\
\hline Dominant shoulder op (n; \%) & $36(80 \%)$ & $20(83 \%)$ & $56(81 \%)$ & - \\
\hline Manual labourer (n; \%) & $27(60 \%)$ & $16(67 \%)$ & $43(62 \%)$ & 8 \\
\hline Trauma (n; \%) & $18(40 \%)$ & $14(58 \%)$ & $32(46 \%)$ & 2 \\
\hline \multicolumn{5}{|c|}{ Tendon status at surgery (n): } \\
\hline \multicolumn{5}{|l|}{ SS only } \\
\hline Partial articular side tear & $36^{*}$ & & & - \\
\hline Partial bursal side tear & 1 & & & - \\
\hline Full-thickness tear & & $20^{\dagger}$ & & - \\
\hline \multicolumn{5}{|l|}{$\mathrm{SS}+\mathrm{IS}$} \\
\hline Partial articular side tear & 8 & & & - \\
\hline Full-thickness tear & & 4 & & - \\
\hline Proximal biceps tear (n; \%) & $1(2 \%)$ & $4(17 \%)$ & $5(7 \%)$ & 1 \\
\hline \multicolumn{5}{|l|}{ Follow-up data available (n) } \\
\hline Complete & & & 61 & \\
\hline X-ray and WORC & 2 & 2 & 4 & \\
\hline Unilateral x-ray and WORC & & 1 & 1 & \\
\hline WORC only & 2 & 1 & 3 & \\
\hline
\end{tabular}

${ }^{*} 1$ patient also had a partial articular side tear of the subscapularis. ${ }^{\dagger} 3$ patients also had partial articular side tear of subscapularis.

Abbreviations: FTT, Full-thickness tear; PTT, Partial thickness tear; SS, Supraspinatus; IS, Infraspinatus; US, Ultrasound; CM, Constant-Murley score; WORC, Western Ontario Rotator cuff index; ASD, Arthroscopic subacromial decompression; RC, Rotator Cuff; AC, acromioclavicular joint; Index op, the first acromioplasty. 
Table 2.

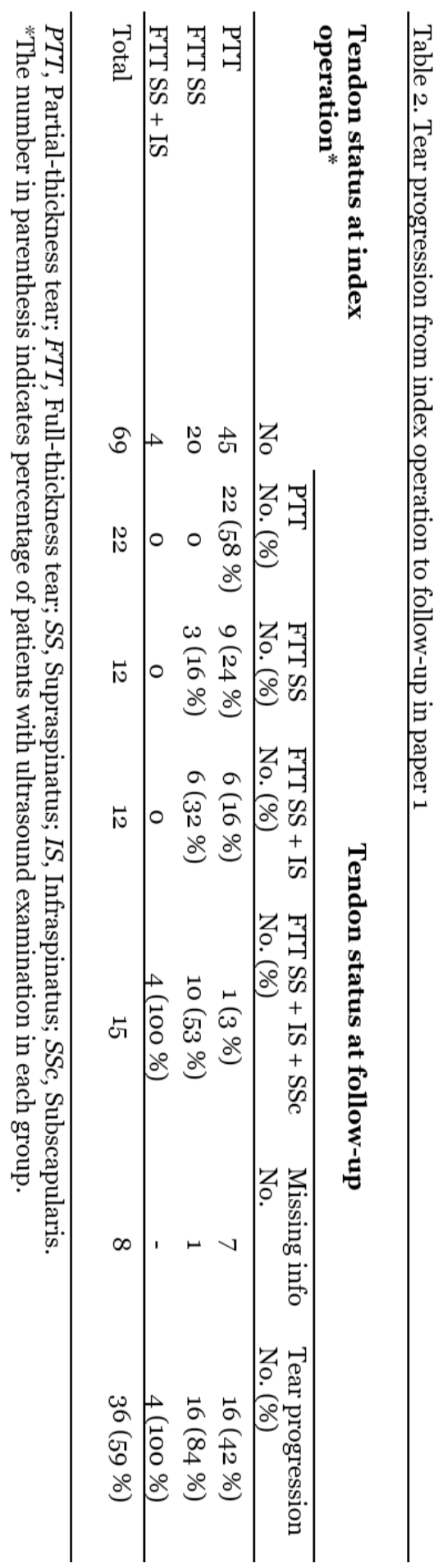


Table 3. Comparison of number of cases in each Hamada category between patients with partial and full-thickness tears at the index operation.

\begin{tabular}{|c|c|c|c|}
\hline \multirow{3}{*}{$\begin{array}{l}\text { Radiographic cuff tear ar- } \\
\text { thropathy classification* }\end{array}$} & \multicolumn{3}{|c|}{ Tendon status at index operation } \\
\hline & PTT & FTT & P-value \\
\hline & $\mathrm{n}=45$ & $\mathrm{n}=\mathbf{2 4}$ & \\
\hline & No. $(\%)^{\dagger}$ & No. $(\%)^{\dagger}$ & \\
\hline Hamada 1 & $40(93)$ & $6(26)$ & $<0.001$ \\
\hline Hamada 2 & $2(5)$ & $7(30)$ & 0.007 \\
\hline Hamada 3 & o & $3(13)$ & 0.039 \\
\hline Hamada $4 \mathrm{~b}$ & $1(2)$ & $7(30)$ & 0.002 \\
\hline Missing $\mathrm{x}$-ray & 2 & 1 & \\
\hline Hamada $\geq 2$ & $3(7)$ & $17(74)$ & $<0,001$ \\
\hline Hamada $\geq 3$ & $1(2)$ & $10(43)$ & $<0,001$ \\
\hline $\begin{array}{l}\text { FTT, full-thickness tear; } P T T, \mathrm{p} \\
{ }^{*} \text { Hamada: radiographic cuff tea } \\
\text { were no Hamada grade } 4 \text { a or } 5 \text {. } \\
{ }^{+} \text {The number in parenthesis ind } \\
\text { group. }\end{array}$ & $\begin{array}{l}\text { hickness tear. } \\
\text { opathy accordi } \\
\text { the percentage }\end{array}$ & $\begin{array}{l}\text { la classific } \\
\text { ith availa }\end{array}$ & $\begin{array}{l}\text { There } \\
\text { ay in each }\end{array}$ \\
\hline
\end{tabular}

There were differences in clinical scores according to severity of structural changes in the shoulder. Patients with full-thickness tear and Hamada grade 2 or more had the lowest clinical scores, with a mean absolute CMscore of 47 (standard deviation [SD], 23), a mean relative CM-score of 62 $(\mathrm{SD}, 27)$ and a mean WORC of $58 \%(\mathrm{SD}, 26)$. Sixty percent of these patients had shoulder pain.

The full-thickness tear patients who did not have arthropathy, had a mean absolute CM-score of 65 (SD, 28), a mean relative CM-score of 88 $(\mathrm{SD}, 38)$ and a mean WORC of $72 \%(\mathrm{SD}, 26)$. Fifty percent of these patients had shoulder pain.

In the patients who still had a partial tear at follow-up, after a mean of 22 years, no one had arthropathy and the mean absolute CM-score was 80 (SD, 17), the mean relative CM-score 101 (SD, 22) and mean WORC $81 \%$ (SD, 20). The detailed clinical scores, including mean and median values and separate pain assessments, are shown in Table 4.

A reoperation had been performed in a total of 15 cases (22\%). In the full-thickness group, 2 acromioplasties, 2 cuff repairs and 3 interposition grafts had been performed. Neither the cuff repairs nor the interposition grafts were intact at follow-up. In the partial tear group, 5 acromioplasties, 1 AC-resection, 1 diagnostic arthroscopy and 1 open capsular shift had been performed.

In the long follow-up period, 4 patients with a full-thickness tear at the index operation had sustained a trauma and 3 of those had tear pro- 
gression. Corresponding numbers in the partial tear group was 5 patients, 3 of whom had tear progression at follow-up.

In risk factor analyses with multivariate logistic regression, and arthropathy and tear progression as dependent variables, the following factors were tested: age, gender, reoperation, tendon status at the index operation, biceps status at index operation, traumatic tear and manual labour. Only having a full-thickness tear at index operation was a significant factor in both analyses, and odds ratio for arthropathy was 37.8 (95\% CI, 8.2-175.0; $P<0.001$ ) and for tear progression 6.09 (95\% CI, 1.4126.09; $P=0.016)$. Age was also a significant factor for tear progression with an odds ratio of 1.07 (95\% CI, 1.00-1.15; $P=0.043$ ). 
Table 4.Clinical scores including pain domains of WORC at follow-up in relation to tear type and radiographic outcome at follow-up

\begin{tabular}{|c|c|c|c|c|c|c|}
\hline \multirow[b]{3}{*}{ Clinical scores } & \multirow{3}{*}{$\begin{array}{c}\begin{array}{c}\text { PTT at } \\
\text { follow-up }\end{array} \\
\begin{array}{c}\text { Hamada } \\
1 \\
\mathrm{n}=21^{*}\end{array} \\
\end{array}$} & \multicolumn{5}{|c|}{ FTT at follow-up } \\
\hline & & $\begin{array}{c}\text { Hamada } \\
1\end{array}$ & $\begin{array}{c}\text { Hamada } \\
2\end{array}$ & $\begin{array}{c}\text { Hamada } \\
3\end{array}$ & $\begin{array}{c}\text { Hamada } \\
4 \mathrm{~b}\end{array}$ & $\begin{array}{c}\text { Hamada } \\
\geq 2\end{array}$ \\
\hline & & $\mathrm{n}=18^{*}$ & $\mathrm{n}=9$ & $\mathrm{n}=3$ & $\mathrm{n}=8$ & $n=20$ \\
\hline \multicolumn{7}{|l|}{ CM absolute } \\
\hline Mean (SD) & $80(17)$ & $65(28)$ & $53(29)$ & $58(13)$ & $36(14)$ & $47(23)$ \\
\hline Median (QR) & $83(18)$ & $72(46)$ & $63(52)$ & $62(26)$ & $37(17)$ & $42(39)$ \\
\hline \multicolumn{7}{|l|}{ CM relative } \\
\hline Mean (SD) & $101(22)$ & $88(38)$ & $70(34)$ & $71(13)$ & $51(20)$ & $62(27)$ \\
\hline Median (QR) & $103(24)$ & $102(72)$ & $84(56)$ & $62(26)$ & $47(21)$ & $57(49)$ \\
\hline \multicolumn{7}{|l|}{ WORC (\%) } \\
\hline Mean (SD) & $81(20)$ & $72(26)$ & $65(32)$ & $62(19)$ & 48 (19) & $58(26)$ \\
\hline Median (QR) & $88(20)$ & $79(47)$ & $72(34)$ & $71(36)$ & $45(35)$ & $63(39)$ \\
\hline \multicolumn{7}{|l|}{ WORC pain † } \\
\hline Question nr. 1 & $13(18)$ & $18(26)$ & $32(39)$ & $41(45)$ & $31(39)$ & $33(38)$ \\
\hline Question nr. 2 & $12(17)$ & $15(25)$ & $27(35)$ & $28(38)$ & $25(29)$ & $26(31)$ \\
\hline \multicolumn{7}{|l|}{ Question 1 ‡ § } \\
\hline No pain, No. (\%) & $11(52)$ & $9(50)$ & $4(44)$ & $1(33)$ & $4(50)$ & $9(45)$ \\
\hline Any pain, No. (\%) & $10(48)$ & $9(50)$ & $5(56)$ & $2(67)$ & $4(50)$ & $11(55)$ \\
\hline Mild pain & $7(33)$ & $7(39)$ & $2(22)$ & $1(33)$ & $1(13)$ & $4(20)$ \\
\hline Moderate pain & $3(14)$ & $1(6)$ & $1(11)$ & - & $1(13)$ & $2(10)$ \\
\hline Severe pain & - & $1(6)$ & $2(22)$ & $1(33)$ & $2(25)$ & $5(25)$ \\
\hline \multicolumn{7}{|l|}{ Question 2 ‡ } \\
\hline No pain, No. (\%) & $12(57)$ & $10(56)$ & $4(44)$ & $1(33)$ & $3(38)$ & $8(40)$ \\
\hline Any pain No. (\%) & $9(43)$ & $8(44)$ & $5(56)$ & $2(67)$ & $5(63)$ & $12(60)$ \\
\hline Mild pain & $7(33)$ & $6(33)$ & $2(22)$ & $1(33)$ & $3(38)$ & $6(30)$ \\
\hline Moderate pain & $2(10)$ & $1(6)$ & $2(22)$ & $1(33)$ & $2(25)$ & $5(25)$ \\
\hline Severe pain & - & $1(6)$ & $1(11)$ & - & - & $1(5)$ \\
\hline
\end{tabular}

Note: WORC question nr. 1: "How much sharp pain do you experience in your shoulder (in the last week)?". WORC question nr. 2: "How much constant nagging pain do you experience in your shoulder (in the last week)?".*1 patient with primary osteoarthritis is not included.† mean VAS o-100 mm (Standard deviation). $¥$ Number of patients (percentage per column).§ Pain scores divided according to Jensen ${ }^{136}$ : no pain $=0-4 \mathrm{~mm}$ VAS, mild pain 5-44 $\mathrm{mm}$, moderate pain $45-74$ $\mathrm{mm}$, severe pain 75-100 mm. Abbreviations: SD, Standard deviation; QR, quartile range; FTT, Full-thickness tear; PTT, Partial-thickness tear; Hamada, radiographic cuff tear arthropathy according to Hamada classification $1-5^{112}$; CM abs, absolute Constant score; CM rel, age- and gender adjusted Constant-Murley score; VAS, Visual Analog Scale. 


\section{Paper II: The status of the contralateral shoulder in patients with long-standing cuff tears}

Patients from paper I were also examined in the contralateral shoulder at a mean of 22 years after the first operation on the other shoulder. Eight patients out of 69 did not have an ultrasound examination of the contralateral shoulder, since they were unable to visit the clinic. The remaining cohort of 61 patients comprised $78 \%$ of patients possible to examine. The patient characteristics are shown in Table 5 .

Table 5. Demographic data of study population in paper II.

\begin{tabular}{lc}
\hline Mean age at follow-up (years; range) & $72(43-92)$ \\
Gender & \\
$\quad$ Male & $45(73.8 \%)$ \\
$\quad$ Female & $16(26.2 \%)$ \\
Dominant side operated & $52(85.2 \%)$ \\
Manual labourer & $43(70.5 \%)$ \\
Diabetes* & $11(18.0 \%)$ \\
Smoking* $^{*}$ & $7(11.5 \%)$ \\
Trauma-related tear (index shoulder) & $30(49.2 \%)$ \\
Rotator cuff tear in index shoulder & \\
$\quad$ Partial tear & $38(62.3 \%)$ \\
$\quad$ Full-thickness tear & $23(37.7 \%)$ \\
Operations in contralateral shoulder & \\
$\quad$ Acromioplasty & $9(14.7 \%)$ \\
$\quad$ Cuff repair & $3(4.9 \%)$ \\
\hline *at follow-up & \\
tat index operation. &
\end{tabular}

\section{Tendon status in the contralateral shoulder}

In the contralateral shoulder, full-thickness tears were found in $50.8 \%$ (31/61), with a group mean age of 76.4 years (SD, 8.2 years). The frequency of partial tears was $32.8 \%(20 / 61)$ and the mean age in this group 67.8 years $(\mathrm{SD}, 10.6)$. This age difference was significant $(P=0.010)$. The total prevalence of some kind of rotator cuff abnormality on ultrasound was $83.6 \%$. Remaining 10 patients with intact tendons had a mean age of 64.6 
years (SD, 9.8 years), and the difference in age from patients with fullthickness tears was significant $(P=0.001)$, but not the difference in age from those with a partial tear $(P=0.385)$. The detailed tendon status in the contralateral shoulder is shown in table 6 .

The frequency of contralateral full-thickness tear was very different depending on the conditions in the index shoulder at follow-up. The frequency of contralateral full-thickness tear was $13.6 \%$, with the index shoulder having a partial tear, $71.8 \%$ with a full-thickness tear in the index shoulder and $90 \%$ with CTA in the index shoulder.

\section{Radiographic status in contralateral shoulder}

There were CTA changes (Hamada $\geq 2)$ in $8.2 \%(5 / 61)$ of contralateral shoulders, all of whom had a concomitant contralateral full-thickness tear, and CTA in the contralateral shoulder was significantly more common if there was CTA in the index shoulder $(P=0.036)$. Details of contralateral radiographic outcome are shown in Table 7.

As can be seen in Table 7, of 39 patients who had a full-thickness tear in the index shoulder, 20 also had CTA in the index shoulder (51.3\%) and they had all had an acromioplasty in this shoulder. Only 5 out of these 39 (12.8 \%) had CTA in the contralateral shoulder and 2 of those 5 had undergone a previous acromioplasty. When comparing both shoulders, CTA was significantly more common if an acromioplasty had been performed $(\mathrm{P}<0.001)$.

\section{Clinical status in the contralateral shoulder}

The absolute and relative CM scores were a mean 43 (SD, 23) and 57 (SD, 24) in patients with full-thickness tears and CTA, mean 64 (SD, 24) and $87(\mathrm{SD}, 32)$ in patients with full-thickness tears without CTA and mean 88 $(\mathrm{SD}, 13)$ and $114(\mathrm{SD}, 14)$ respectively, in patients with partial tears. The CM scores were significantly lower in patients with a full-thickness tear, compared to those with a partial or no tear $(P=0.001)$.

Pain was also different depending on the structural conditions. In the 31 patients with contralateral full-thickness tear, 17 (54.8\%) were painful and 10 (32.2 \%) had moderate or severe pain, as compared to 3 out of 20 $(15 \%)$ being mildly painful with a partial tear $(P=0.033)$. 
Table 6.
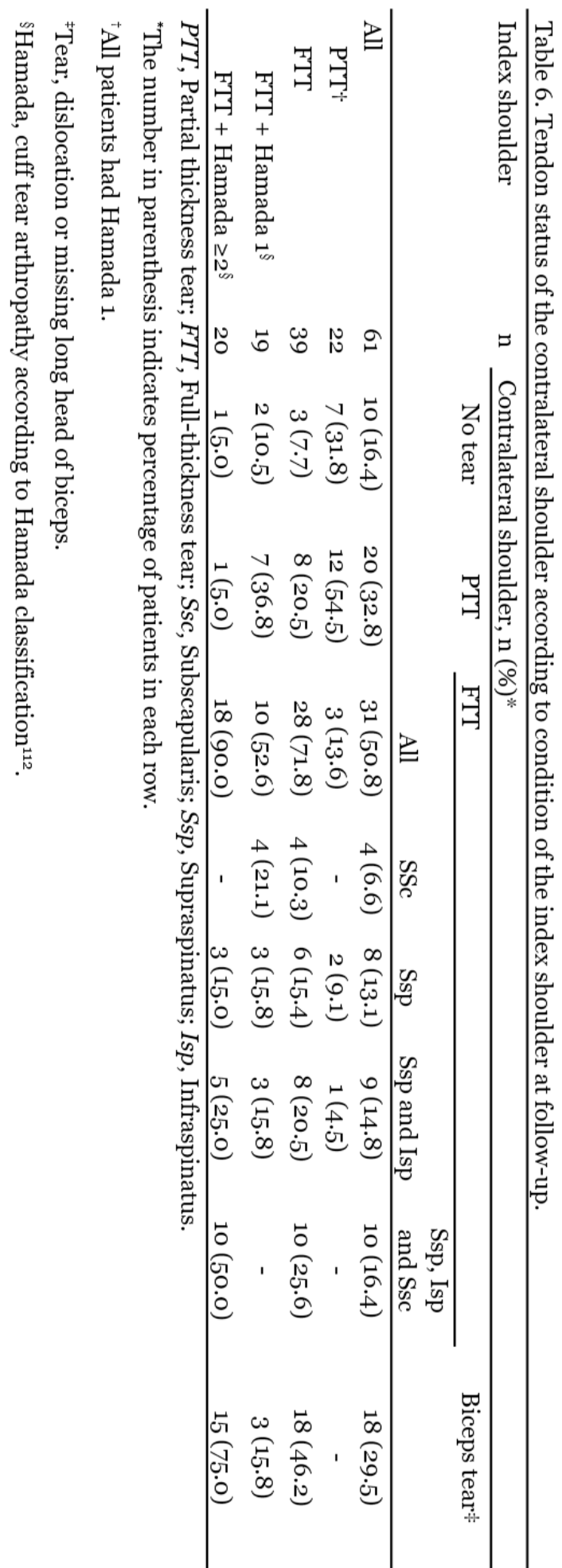
Table 7 .

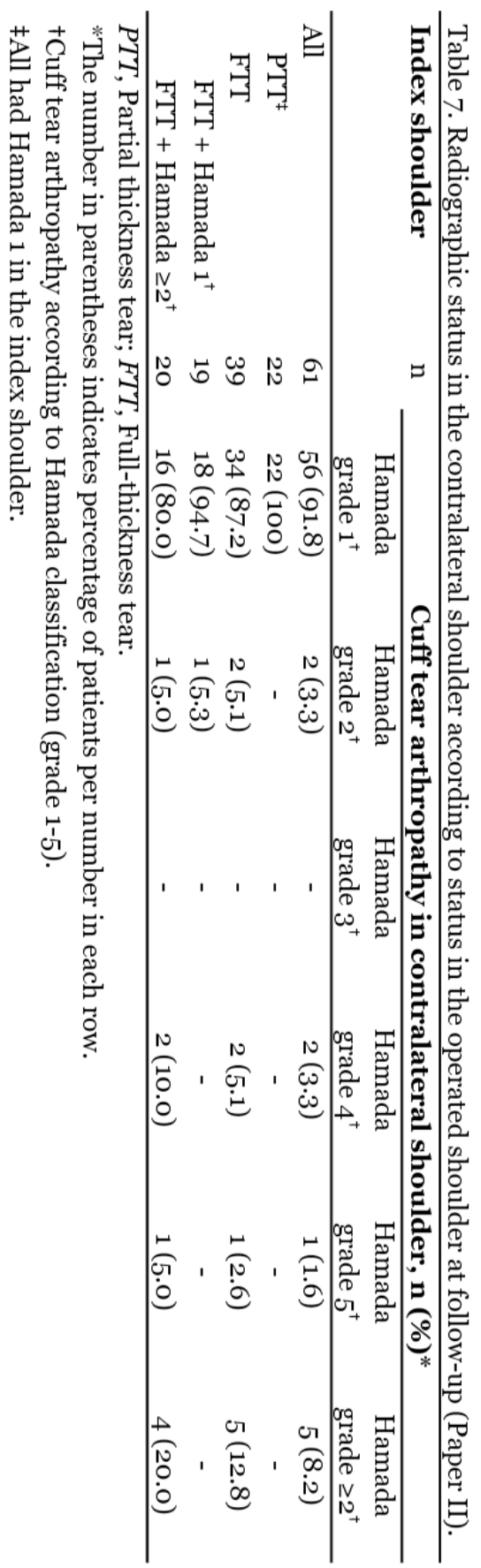




\section{Correlation between shoulders and risk factor analysis}

There was a significant correlation between the conditions in the index shoulder and the contralateral shoulder. Spearman's correlation coefficient was $0.72(P<0.001)$ for number of tendons with full-thickness tear, $0.31(P=0.016)$ for Hamada grade, 0.65 for absolute CM score $(P<0.001)$ and 0.61 for relative $\mathrm{CM}$ score $(P<0.001)$.

Index shoulder variables were analysed with univariate and multivariate logistic regression for risk factors of having a contralateral fullthickness rotator cuff tear (Table 8). Only number of tendons with fullthickness tear was a significant factor in the multivariate analysis (OR 3.28; 95\% CI, 1.67-6.44; $\mathrm{P}<0.001$ ).

Table 8. Multivariate logistic regression analysis of risk factors for having contralateral full-thickness rotator cuff tear (Paper II)

\begin{tabular}{lcccccc}
\hline & \multicolumn{2}{c}{$\begin{array}{c}\text { Univariate logistic } \\
\text { regression* }\end{array}$} & & \multicolumn{2}{c}{$\begin{array}{c}\text { Multivariate logistic } \\
\text { regression }\end{array}$} \\
\cline { 2 - 3 } \cline { 5 - 6 } Variable for index shoulder & OR $(95 \% \mathrm{CI})$ & $P$-value & & OR (95\% CI) & $P$-value \\
\hline Age & $1.12(1.04-1.22)$ & 0.004 & & $1.09(0.99-1.19)$ & 0.068 \\
No. of tendons with FTT at index op. & $6.15(1.94-19.53)$ & $<0.001$ & & - & - \\
Hamada grade & $4.14(1.51-11.37)$ & 0.007 & & - & - \\
No. of tendons with FTT at follow-up & $3.94(2.05-7-59)$ & 0.003 & & $3.28(1.67-6.44)$ & $<0.001$ \\
Tear progression & $10.40(2.94-36.80)$ & $<0.001$ & & - & - \\
CM abs & $0.09(0.01-0.77)$ & 0.029 & & - & - \\
CM rel & $0.24(0.05-1.25)$ & 0.089 & & - & - \\
\hline
\end{tabular}

$O R$, Odds ratio; CI, Confidence interval; FTT, Full-thickness tear; $C M$ abs, absolute Constant-Murley score; $\mathrm{CM}$ rel, relative age- and sex-adjusted Constant-Murley score.

*Only variables with $\mathrm{p}<0.1$ is included. 


\section{Paper III: Long-term results of synthetic interposition grafts for rotator cuff tear}

\section{Clinical and structural results}

Cuff tear arthropathy (Hamada grade 2 or more) was found in 9 out of 12 patients (75 \%; 95\%CI, 43-95\%), including 3 patients reoperated with arthroplasty. Kappa values for the 3 assessors were 0.76 , 0.82 and 0.92 . An example of an x-ray with Hamada grade 4 is shown in Figure 11. The graft was interpreted as not intact in 7 out of 10 patients (70 \%) and all patients except 1 had either a partial or a full-thickness tear in subscapularis and a biceps tear. Mean absolute CM-score was 46 (SD, 26), mean relative CMscore 61 (SD, 35) and mean WORC 59 \% (SD, 20). Hamada grades, ultrasound findings and clinical scores of all patients are shown in Table 9.

\section{Complications and reoperations}

Four patients had had a transient fever, and patient $\mathrm{nr} 8$ and 13 received antibiotics, but no infection could be detected in wound cultures. A loose screw was removed in patient 13 but perioperative cultures were negative. Three reoperations with arthroplasty were performed: patient 1 had a hemiarthroplasty after 13 years at another hospital, patient 8 an anatomic total arthroplasty after 2 years and patient 9 a reverse prosthesis at another hospital after 16 years. According to medical charts from the last two operations, remnants of torn graft was removed. 
Table 9

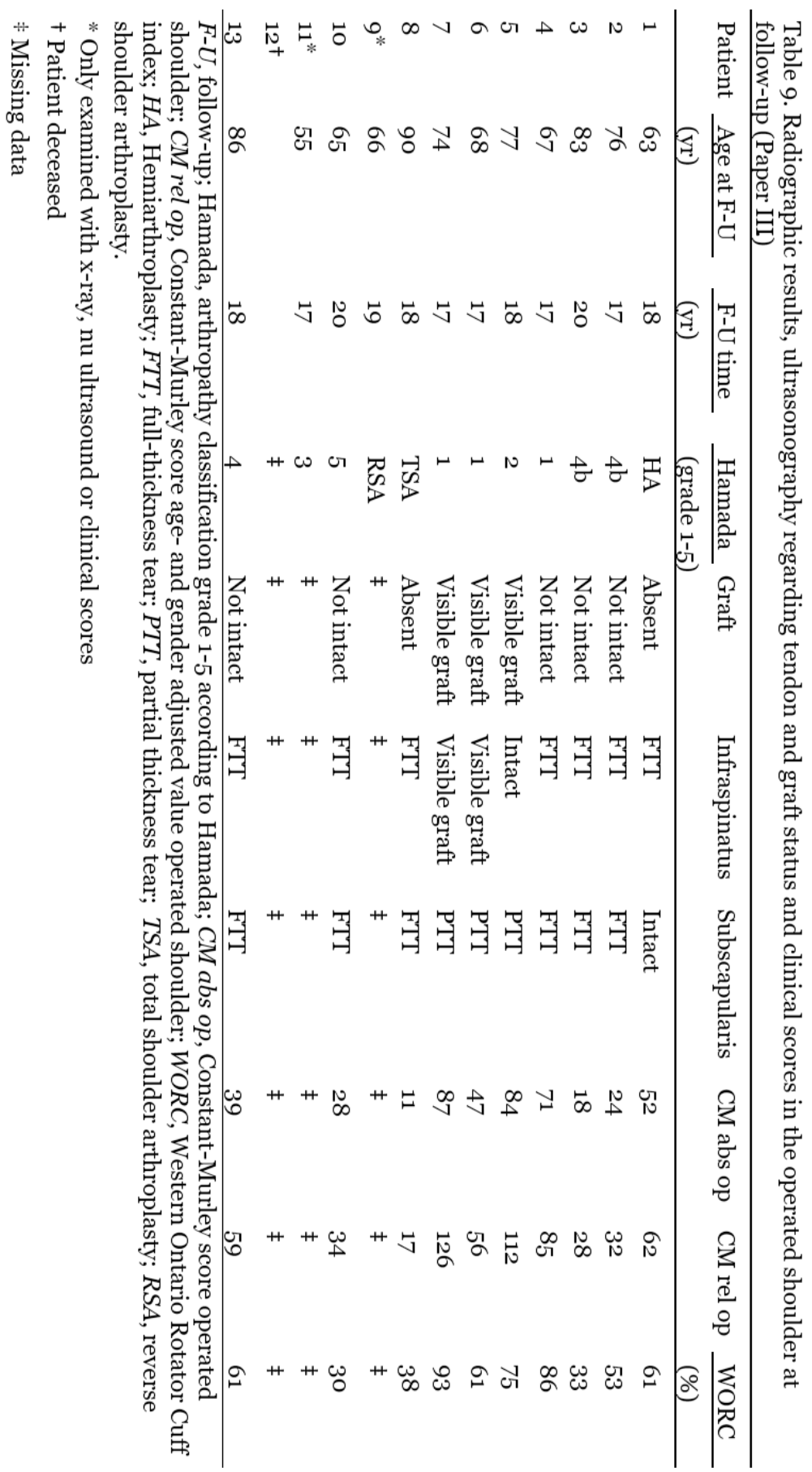




\section{Contralateral shoulder at follow-up}

All patients, in whom tendon status was examined, had a full-thickness tear in at least one tendon and 9 out of 10 (90 \%; 95\%CI, 55-100 \%) had full-thickness tears in 2 or more tendons. CTA (Hamada grade $\geq 2$ ) was found in 7 out of 12 patients ( $58 \%$; 95\%CI, 28-85\%). In addition, patient 4 had signs of osteoarthritis but no decrease in the acromiohumeral distance and was thus classified as Hamada 1. The difference between shoulders in proportion of patients with CTA was not significant $(P=0.667)$. Structural conditions and clinical scores for the contralateral shoulder are shown in Table 10.

Table 10. Status of contralateral shoulder at 17 to 20 years of follow-up after synthetic interposition graft operation of index shoulder (Paper III).

\begin{tabular}{lllll}
\hline Case & Full thickness tear & Hamada & CM abs & CM rel \\
\cline { 3 - 3 } & & (grade 1-5) & & \\
\hline 1 & Ssp & 1 & 80 & 96 \\
2 & Ssp + Isp + Ssc & 3 & 58 & 77 \\
3 & Ssp + Isp + Ssc & 1 & 44 & 69 \\
4 & Ssp + Ssc & 1 & 31 & 37 \\
5 & Ssp + Isp & 2 & 46 & 61 \\
6 & Ssp + Isp + Ssc* & 4 & 2 & 2 \\
7 & Ssp + Isp + Ssc* & 2 & 83 & 120 \\
8 & Ssp + Isp + Ssc & 4 & 18 & 27 \\
$9^{\ddagger}$ & \& & 1 & & \\
10 & Ssp + Isp + Ssc & 5 & 18 & 22 \\
$11^{\ddagger}$ & $\S$ & 1 & & \\
$12^{\dagger}$ & $\S$ & & 32 & 49 \\
13 & Ssp + Isp & 4 & $41(27)$ & $56(36)$ \\
All, mean (SD) & & & \\
\hline
\end{tabular}

Hamada, arthropathy classification grade 1-5 according to Hamada classification; $C M$ abs, Constant-Murley score absolute value; $C M$, Constant-Murley score age- and sex-adjusted value; $S s p$, supraspinatus; Isp. Infraspinatus; $S s c$, Subscapularis; $S D$, standard deviation.

*Partial tear of subscapularis

†Patient deceased

‡ Only x-ray, no ultrasonography or clinical scores

$\S$ Missing data 


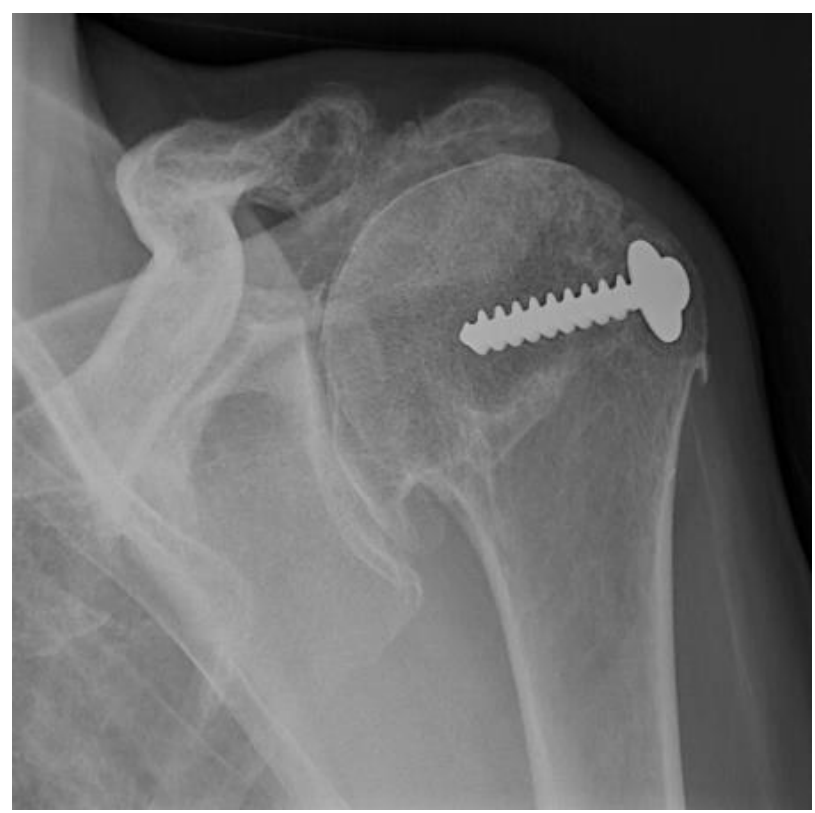

Figure 11.Frontal projection of a left shoulder 17 years after operative repair with a synthetic interposition graft. The graft was fixed laterally on the greater tuberosity with a metal screw and washer (Paper III) 


\section{Paper IV: Randomised trial of acute traumatic cuff tears.}

There was an almost complete 12 month follow-up of the 58 patients, who had been randomised to surgical repair $(n=32)$ or physiotherapy without repair $(n=26)$. Exceptions were 3 patients, who did all the clinical 12month scores but declined MRI, and 1 patient who had missing data for WORC and NRS at 12 months. Mean age was 59.7 years (range, 44-77). Baseline variables were well balanced between groups and patient characteristics are shown in Table 11.

The median sagittal tear size was $9.7 \mathrm{~mm}$ (range, 4-21) for the whole group and the tear size in categories are shown in Figure 12.

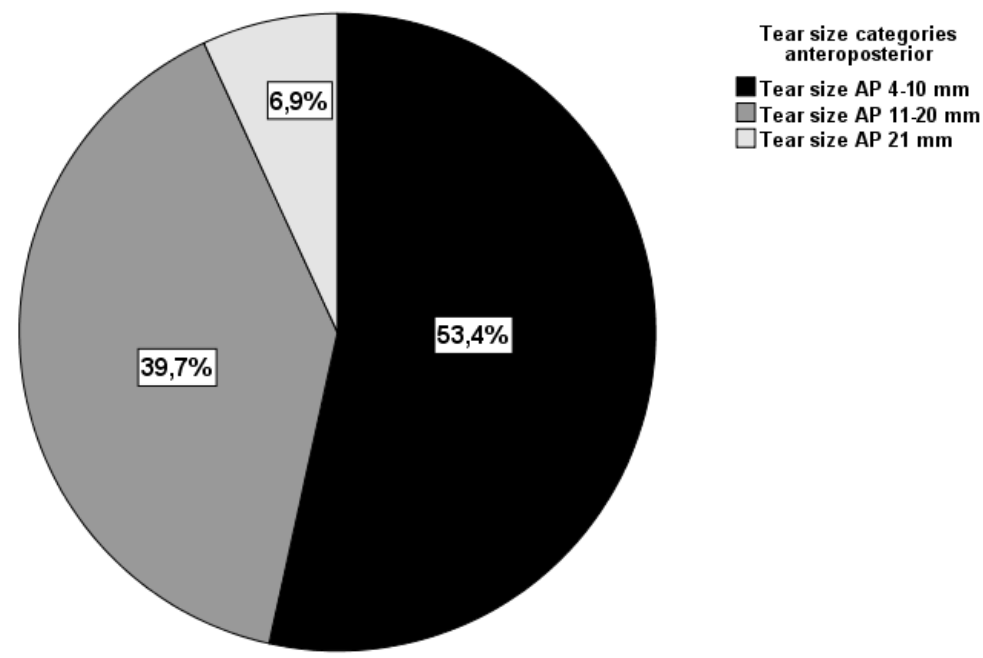

Figure 12. Pie-chart of the sagittal tear size in categories for the whole cohort at inclusion (Paper IV) 
Table 11. Patient characteristics at enrollment (Paper IV)

\begin{tabular}{|c|c|c|c|}
\hline Variables & $\begin{array}{l}\text { Cuff repair } \\
(\mathrm{n}=32)\end{array}$ & $\begin{array}{l}\text { Physiotherapy } \\
(\mathrm{n}=26)\end{array}$ & $P$ value \\
\hline Age, mean (min-max) & $58(44-77)$ & $62(46-77)$ & 0.12 \\
\hline Sex male, No. (\%) & $18(56)$ & $14(54)$ & 0.86 \\
\hline Dominant side, No. (\%) & $15(47)$ & $17(65)$ & 0.16 \\
\hline Manual labour, No. (\%) & $17(53)$ & $8(31)$ & 0.09 \\
\hline Current smokers, No. (\%) & $2(6)$ & $o(0)$ & 0.30 \\
\hline Hypertensive medication, No. (\%) & $7(22)$ & $6(23)$ & 1.00 \\
\hline Diabetes mellitus, No. (\%) & $\mathrm{o}(\mathrm{o})$ & $1(4)$ & 0.45 \\
\hline Time to intervention, days (min-max) & $58(21-98)$ & $53(12-83)$ & 0.42 \\
\hline Flexion, $\operatorname{median}^{\circ}$ (min-max) & $90(30-180)$ & $90(40-180)$ & 0.93 \\
\hline Abduction, $\operatorname{median}^{\circ}$ (min-max) & $85(30-180)$ & $65(30-180)$ & 0.67 \\
\hline External rotation, $\operatorname{median}^{\circ}(\min -\max )$ & $60(30-80)$ & $70(45-90)$ & 0.06 \\
\hline Internal rotation, median $(\min -\max ) *$ & $5(3-6)$ & $4(2-6)$ & 0.66 \\
\hline Sagittal tear size, median (min-max) & $10.0(5-21)$ & $8.7(4-15)$ & 0.15 \\
\hline Coronal tear size, median (min-max) & $9.1(4-24)$ & $10.2(3-20)$ & 0.89 \\
\hline \multicolumn{4}{|l|}{ Pain, NRS o-10, median (QR) } \\
\hline Activity & $8(3)$ & $8(1)$ & 0.68 \\
\hline Rest & $4(6)$ & $3(4)$ & 0.19 \\
\hline At night & $7(4)$ & $5(5)$ & 0.16 \\
\hline HAD-score total points, median (QR) & $5(3)$ & $5(5)$ & 0.85 \\
\hline HAD-score anxiety & $3(3)$ & $4(3)$ & 0.64 \\
\hline HAD-score depression & $1(1)$ & $1(2)$ & 0.81 \\
\hline WORC total \%, mean (SD) & $36(14)$ & $39(16)$ & 0.44 \\
\hline Physical symptoms & $49(16)$ & $51(13)$ & 0.65 \\
\hline Sport/recreation & $27(16)$ & $27(17)$ & 0.97 \\
\hline Work & $21(12)$ & 24 (19) & 0.95 \\
\hline Lifestyle & 39 (23) & $40(24)$ & 0.96 \\
\hline Emotions & $53(16)$ & $60(19)$ & 0.14 \\
\hline
\end{tabular}

NRS, Numerical Rating Scale; HAD, Hospital Anxiety and Depression scale; QR, Interquartile range; $\mathrm{SD}$, standard deviation

* $1=$ Thigh, $2=$ =luteus, $3=$ Lumbosacral level, 4=Lumbar process 3, 5=Thoracic process 12,6 Thoracic process 7 .

\section{Clinical results}

The median Constant score at 12 months in the operative repair group was 83 (quartile range [QR], 25) and in the physiotherapy group 78 (QR, 22 ), and the between group difference of 4.5 (95\%CI, -5 to $9 ; P=0.68$ ) was not significant. Corresponding values for the secondary outcome measure WORC was $91 \%(\mathrm{QR}, 24)$ vs. $86 \%(\mathrm{QR}, 24)$, with between group difference of 5.0 (95\%CI, -4 to $9 ; P=0.62$ ). There were no significant differences 
for pain or EQ-VAS. The detailed scores for primary and secondary outcome measures at 12 months are shown in Table 12.

The proportion of patients having a CM-score of 70 or more at 12 months, was $68.8 \%$ in the operative repair group and $69.2 \%$ in the physiotherapy group $(P=0.97)$. Corresponding numbers for CM-score 80 or more was $59.4 \%$ and $46.2 \%(\mathrm{P}=0.43)$.

The 3, 6 and 12 months results of all outcome variables, including the between group differences in medians (with 95\% confidence intervals), are shown in Figure 13. The difference in CM-score between the 2 groups was significant in favour of the physiotherapy group at 3 months, but differences between the other outcome measures were not significant at 3 months and there were no significant differences in any outcome score at 6 or 12 months.

\section{Morphological results}

In the unrepaired group, an increase of more than $5 \mathrm{~mm}$ in any plane was found in 7 out of 24 patients (29.2 \%) at 12 month MRI. Fatty infiltration to a grade 1 had developed in 8 out of 24 (33.0 \%) and 4 patients had developed muscle atrophy with a positive Tangent sign in the unrepaired group. The healing rate was $93.5 \%$, with 2 patients out of 31 having a retear (Sugaya 4 or 5). Details on the morphological results are shown in Table 13.

\section{Complications and unexpected events}

There were 2 post-operative wound infections.

One 68 year old man was operated with open revision at 5 weeks postoperatively, where 1 loose anchor was removed and 1 anchor and osteosutures were left in situ. The infection resolved with antibiotics. MRI showed a healed tendon at 12 months and the CM-score was 89.

A 64 year old woman randomised to physiotherapy decided to crossover to repair at 6 months. A suspected infection was diagnosed at 2.5 months and was operated with 4 revisions and prolonged antibiotic treatment but the infection had not completely resolved at 12 months. The tendon appeared healed at 12 month MRI and at revision operations. CMscore at 12 months was 74 .

A 49 year old man with manual labour randomised to repair had an extensive amount of scar tissue over the otherwise healed cuff at 12 months and complained of impaired abduction. An open resection was 
performed just after end of study but deep cultures did not show bacterial growth. The 12 month CM-score was 57 .

A 66 year old woman, randomised to physiotherapy, had a very complicated femur fracture 1.5 months after start of the intervention. She did not hurt her study shoulder and performed her shoulder exercises as instructed. The 12 month CM-score was 88 . 
Table 12.
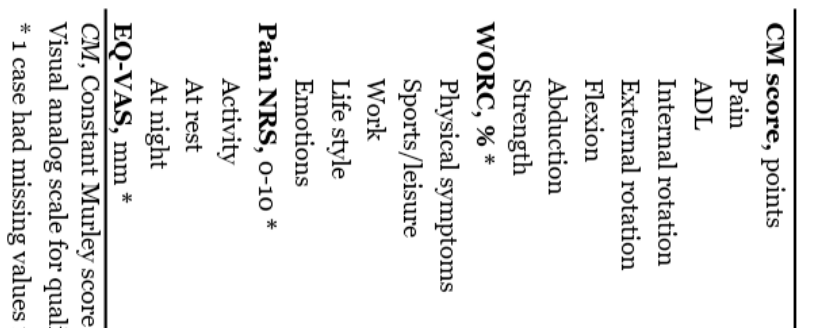

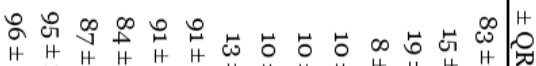

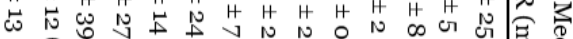

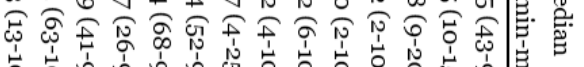

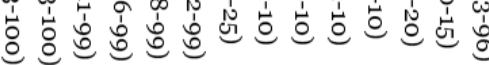
T.

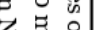
贫志思早

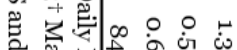
D

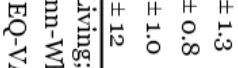
空

$\infty$

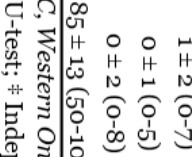

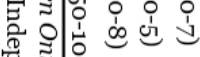

范

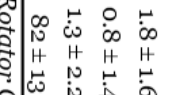
ह

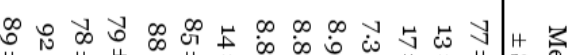

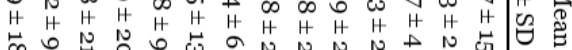
is o H H H H H

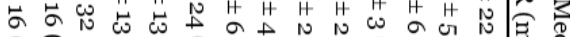

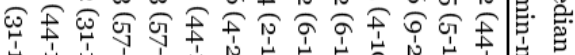

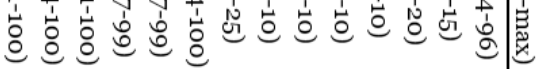<smiles>[CH]</smiles>

8

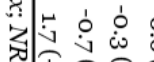

I

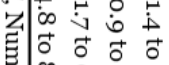

$\begin{array}{llll}\infty & 0 & 0 & 0 \\ 0 & 0 & 0 & 0\end{array}$

تص

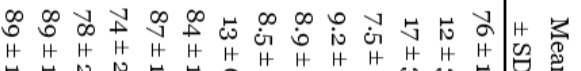

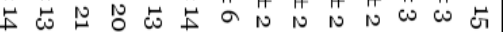

突|

象

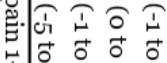

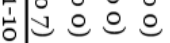

म

○

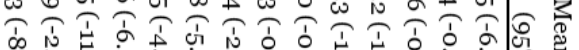

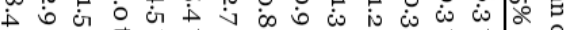

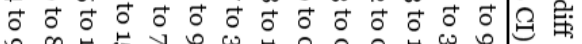

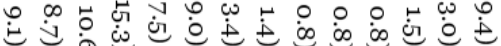

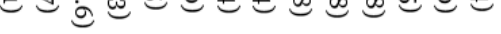

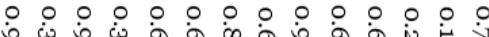

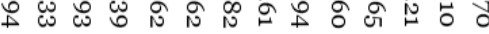

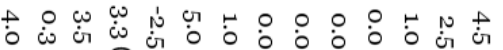

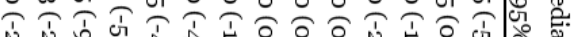

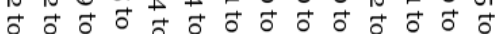

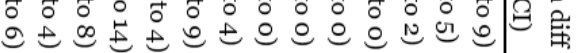
तิ है। 四

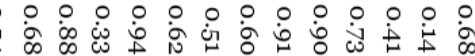
○)

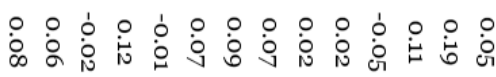


Table 13. MRI findings at 12 months (Paper IV)

\begin{tabular}{|c|c|c|c|}
\hline Variables & $\begin{array}{l}\text { Cuff repair } \\
\mathrm{n}=31\end{array}$ & $\begin{array}{l}\text { Physiotherapy } \\
\mathrm{n}=24\end{array}$ & $P$-value \\
\hline Sagittal tear size, median (min-max) & $0(0-30.0)$ & $11.3(0-22.2)^{*}$ & $<0.001$ \\
\hline Coronal tear size, median (min-max) & $\mathrm{o}(0-25 \cdot 3)$ & $13(0-32.5)^{*}$ & $<0.001$ \\
\hline Tear progression $>5 \mathrm{~mm}$, No. $(\%)^{\dagger}$ & & $7(29.2)$ & \\
\hline Tear progression $>10 \mathrm{~mm}$, No. $(\%)^{\dagger}$ & & $2(8.3)$ & \\
\hline Retears (Sugaya 4-5), No. (\%) & $2(6.5)$ & & \\
\hline Tangent sign, No. (\%) & $2(6.5)$ & $4(16.7)$ & 0.39 \\
\hline \multicolumn{4}{|l|}{ Fatty infiltration, No. (\%) $\ddagger$} \\
\hline Grade 1 & $6(19.4)$ & $8(33)$ & 0.35 \\
\hline Grade 2-4 & 0 & 0 & \\
\hline
\end{tabular}

* Analysed by Intention-to-treat, and the minimum value of o at 12 month follow-up in the physiotherapy group represents the only cross-over patient

$\dagger$ An increase in tear size from baseline to 12 month follow-up in mediolateral or anteroposterior plane.

¥ According to classification by Goutallier ${ }^{101}$ 


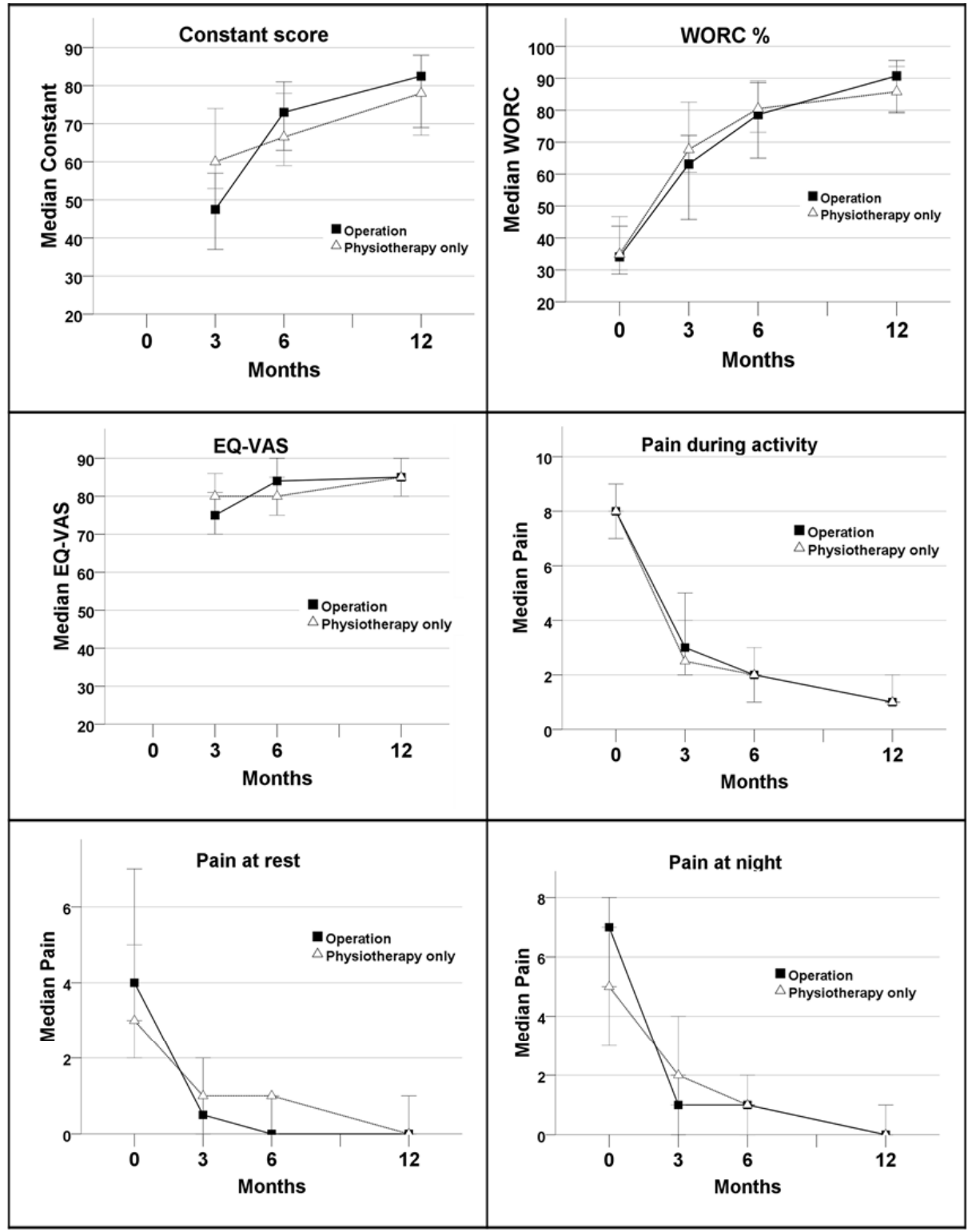

Figure 13.Line graphs displaying outcome scores at all follow-up points. Error bars indicate $95 \%$ confidence intervals. Missing data: Constant score, 1 patient at 6 months; WORC, 1 patient at 6 months, 1 patient at 12 months; EQ-VAS, 2 patients at 3 months, 1 at 6 months and 1 at 12 months; Pain NRS, 2 patients at 3 months, 1 patient at 6 months and 1 patient at 12 months. 


\section{DISCUSSION}

Treatment of rotator cuff tears has evolved immensely in recent years, but a multitude of questions remain to be answered. The spectrum of rotator cuff pathology is wide, from the intact but possibly painful tendon with tendinosis to the massive irreparable cuff tear with secondary osteoarthritis (cuff tear arthropathy). A very large number of treatment alternatives have been described and used for these pathologies. This thesis has focused on a subset of tear types and treatment alternatives.

The papers in this thesis have shown long-term consequences of adopting a non-repair strategy, such as acromioplasty without repair, to partial and full-thickness tears with both a traumatic and non-traumatic origin. We found that some patients do not fare well if treated with a nonrepair strategy. Having a full-thickness tear at presentation indicated a risk of a poorer outcome and the likelihood of a contralateral rotator cuff problem was high in these patients. We could not, however, in paper IV detect a significantly positive effect of an early repair of small traumatic cuff tears in patients with previously symptom-free shoulders. In patients with irreparable tears, bridging the defect with a synthetic interposition graft did not prevent arthropathy development. These findings raise questions and the findings and methodology used have both strengths and limitations.

\section{What are the long-term consequences regarding tear size enlargement and symptoms of not repairing a tear in the rotator cuff?}

Paper I showed that treating full-thickness tears with acromioplasty without cuff repair resulted in a high frequency of tear progression (i.e. tear size enlargement), with $87 \%$ of patients having a larger tear after 21-25 years and $74 \%$ having developed some degree of cuff tear arthropathy. The Constant and WORC-scores were low and $60 \%$ of these patients had pain. In paper IV, in which follow-up is 12 months, around one third of the patients had an increase in size of the unrepaired tear.

Tear progression can be defined with different levels of precision. Some studies have measured tear size in longitudinal studies with ultrasound ${ }^{141}, 199,{ }^{241}$ or MRI ${ }^{177}$, comparing measurement at baseline with the 
same measurement at follow-up, most often with the same examiner utilizing the same technique and the same definitions at each measuring occasion. This method has a high scientific value, when it comes to assessing the true and detailed rate of progression. A methodological drawback though, is the time needed prospectively in order to show the true impact of progression on clinically relevant measures. Our method of assessing tear progression at baseline in paper I, was to rely on the assessment done by the shoulder surgeon, who had filled out the pre-specified operative protocol. It is likely, that the definitions and ways of assessing tendon involvement at baseline are the same as those used at follow-up with ultrasonography. Our method does not, however, allow the same precision and sensitivity to small changes as those used in recent prospective studies and it does not allow precise measurements in millimetres. We also used a conservative definition of tear progression (from partial tear to fullthickness tear or from full-thickness tear to full-thickness tear of an additional tendon). This conservative definition is more appropriate, considering that different methods were used at baseline and at follow-up, and this definition should reduce the risk of over-diagnosing tear progression.

Prospective studies with short to medium term follow-up of patients with full-thickness tears have shown that a there is a risk of tear progression. In a study by Maman et al. of 33 patients with full-thickness tears treated nonoperatively, $52 \%$ had an increase in tear size on MRI at a mean of 24 months follow-up ( $24 \%>5 \mathrm{~mm}$ ) ${ }^{177}$. In 51 patients under the age of 60 years, Safran et al. found a tear size increase $>5 \mathrm{~mm}$ in $49 \%$ after a mean of 29 months of follow-up after nonoperative treatment and of those who had pain at follow-up, $56 \%$ had an increase in tear size as opposed to $25 \%$ in the non-painful group $(P=0.002)^{241}$. Moosmayer has in a prospective study examined a cohort of asymptomatic patients with cuff tears, and after 3 years, around one third of the patients had become symptomatic ${ }^{199}$. The mean tear size increased significantly more in symptomatic compared to asymptomatic patients $(10.6 \mathrm{~mm}$ vs $3.3 \mathrm{~mm}$; $P=0.02$ ). In a subsequent 8.8 year follow-up, the majority of patients had an increase in tear size, with $32.6 \%$ of all patients having an increase of $>10 \mathrm{~mm}^{196}$. Kim et al. did MRI after 24 months (+/- 19 months) in symptomatic cuff tear patients treated without repair and, similar to our findings in paper I, $82 \%$ of patients with full-thickness tears and $26 \%$ of patients with partial tears had an increase in tear size ${ }^{149}$.

What amount of tear progression that is clinically relevant is not known in detail, but when comparing tear size between symptomatic and asymptomatic shoulders in patients with bilateral cuff tears, a tear size difference of $5.4 \mathrm{~mm}$ was found ${ }^{261}$. The true clinical significance of tear progression, including which tear size increase that is clinically relevant, remains to be better defined. It is also possible that the tear anatomy is 
more important than pure tear size. An involvement of the anterior tendinous portion of the supraspinatus has been linked to more advanced fatty infiltration ${ }^{148}$, but tears with or without anterior rotator cable disruption seem to have similar risks and magnitudes of tear progression ${ }^{142}$.

Partial tears may also progress to full-thickness tears and this progression is associated with development of symptoms ${ }^{175}$. In paper I the rate of tear progression in patients with partial tears was low, despite the long follow-up period, and the rate of tear progression was lower when compared to patients with full-thickness tears ( $42 \%$ vs. $87 \%$; $\mathrm{P}<0.001$ ). Lower rates of tear progression for partial tears compared to fullthickness tears, and full-thickness tear being a risk factor in multivariable analysis, have also been found in a retrospective 24 month follow-up of cuff patients treated nonoperatively ${ }^{149}$. This challenges the idea that a majority of patients with partial tears are at risk of tear progression. The absolute numbers of patients with partial tears in paper I (and paper II and III) should, however, be interpreted with caution, considering the lower accuracy for detecting partial tears with ultrasound ${ }^{61}$.

The results from paper I, and from previous studies evaluating tear progression in unrepaired patients, indicate that full-thickness tears increase in size in some patients and that this increase is associated with development of symptoms. These results are of importance in deciding on repair or not, favouring repair in younger patients. The rate of progression seem however to be slow and require several years in many patients, and, estimated from 8 studies on asymptomatic and symptomatic patients, has been suggested to be $0.91 \%$ per month ${ }^{157}$. Another estimate of progression rate is $2 \mathrm{~mm} /$ year for width and $3.8 \mathrm{~mm} /$ year for length ${ }^{265}$. Most studies have been performed on patients with small tears however, and the progression rate may differ depending on tear size ${ }^{204}$. The passing of several years may also allow coping strategies and age-related decrease in activities to have an effect on the symptomatic state of a patient. An informed decision on repair or not should thus take age and activity into account.

It would aid clinical decision-making substantially, if the subgroup of patients with cuff tears who will progress to poorer shoulder conditions could be easily identified. In paper I, we identified age and having a fullthickness tear as significant factors in multivariable logistic regression. Both age ${ }^{177}$ and full-thickness tear'141, 177, 265, have been identified in other studies as well and additional factors identified include pain ${ }^{175}, 199,241$, smoking 265 and dominant side ${ }^{141}$. It is likely, but not convincingly shown as of yet in prospective studies, that identifying known risk factors for rotator cuff tear may aid in identifying patients at risk for tear progression with non-operative treatment, but factors that are currently unknown or 
unreachable to clinicians (like genetic factors) may be of greater importance.

\section{Do patients with rotator cuff tears develop arthropa- thy in the long term and which are the clinical impli- cations?}

Cuff tear arthropathy, the degenerative osteoarthritic changes secondary to rotator cuff tears, is something that we, as shoulder clinicians, should try to prevent as far as possible. Some patients can achieve an acceptable function without much pain, as illustrated by the $40 \%$ of patients who were pain free with Hamada grade 2 or more in paper I. On the other hand, for those who require surgery, the alternatives have a high degree of variability in clinical results, a risk of complications and a limited time before revisions are necessary.

Paper I showed a frequency of $74 \%$ Hamada grade 2 or more in patients who had been treated with acromioplasty without repair for a fullthickness tear at a mean of 22 years earlier and a frequency of only $7 \%$ in patients who had had a partial tear at index operation. Approximately one third of patients with a full-thickness tear at the index operation had Hamada grade 4. The mean absolute Constant score was 47 (relative Constant score 62) among patients with Hamada grade 2 or more and 60\% had a painful shoulder.

One must bear in mind that the follow-up is very long in paper I and there has been a lack of studies with this length of radiographic follow-up. Studies with shorter follow-up have also found arthropathy progression. In a prospective median 8-year follow-up of patients with asymptomatic partial and full-thickness cuff tears of small sizes, these patients had a statistically significant progression of osteoarthritic changes, compared to normal controls, but the progression was limited in most ${ }^{40}$. Those results may be valid for asymptomatic patients with small tears, but it is not straightforward to compare with the patients in paper I, who were symptomatic at baseline and perhaps had a more severe disease condition from the beginning. Zingg et al. did a 48 month follow-up of 19 patients, with 2 or 3 -tendon tears treated nonoperatively, and found significant progression of osteoarthritic changes and decrease of acromiohumeral distance on radiographs, with patients with 3-tendon tears having more progression $^{270}$. Despite these changes the mean relative Constant score was 83 and the mean Subjective Shoulder Value $68 \%$. 
A tentative answer to the question above is that a substantial proportion of patients with a full-thickness tear seem to develop arthropathy, even though not all of them have pain or severe dysfunction. The risk for a patient presenting with a partial tear to develop cuff tear arthropathy, seems to be very low according to paper I. One possible interpretation of these findings, is that progression to arthropathy may, in some cases, be a slow process that allows coping strategies and age related activity changes to keep symptoms at a reasonable level. When considering a non-repair treatment strategy for patients with full-thickness tear however, the age and anticipated number of active years are important factors for this decision.

\section{Assessment and classification of cuff tear arthropathy on radiographs and its clinical implications}

In paper I, II and III, we used the Hamada classification ${ }^{112}$ to grade the arthropathy (Figure 9). One major weakness with this classification is the difficulty in differentiating between grade 1 (no decrease of the acromio-humeral interval) and 2 (an acromio-humeral interval of $5 \mathrm{~mm}$ or less). Measurement accuracy of this interval has been shown to be acceptable when using standardized radiographs ${ }^{103}$, but variability between assessors increased when non-standardized images were used ${ }^{19}$. Difficulties may depend on how the images have been taken, sometimes the undersurface of the acromion appears less well defined. It is also possible that the acromio-humeral interval varies depending on the muscular tone and/or the position of the patient as the image is taken. When plain radiographs have been compared to CT or MRI (where the patient usually is positioned supine), Werner et al. found that measurement of the acromiohumeral interval appeared larger on radiographic images ${ }^{258}$. For practical reasons, we used images taken with the technique routinely used at the radiology departments in papers I, II and III. On one hand, this may have increased the variability, and some true grade 2 cases may thus have been diagnosed as grade 1 . On the other hand the external validity may be better, since images like the ones used are of the same kind as those used for decision making and follow-up in normal clinical routine. We also used 3 different assessors and showed good or acceptable agreement according to Kappa values in papers I-III.

The most frequently used classification of osteoarthritis in the shoulder is the Samilson-Prieto classification, which originally was designed to assess glenohumeral osteoarthritis after recurrent dislocations ${ }^{242}$. Here emphasis lies on measurement of inferior osteophytes and a reduced joint 
space. Cuff tear arthropathy is in earlier stages more characterised by static superior translation and alterations of the coracoacromial $\operatorname{arch}^{238}$, while joint space narrowing and osteophytes occur much later ${ }^{112}$. This makes the Samilson-Prieto classification less appropriate for assessing cuff tear arthropathy. In a comparison of 4 different classification systems for cuff tear arthropathy ${ }^{138}$, the Hamada classification was recommended for use (along with the Visotsky-Seebauer classification ${ }^{260}$ ).

The different grades of Hamada may have implications for the choice of treatment, but the evidence base for this is weak. In Hamada grade 2, a cuff repair seems to have an increased risk of a retear compared to Hamada grade $1^{113}$. Some have cautioned against using Latissimus-Dorsi transfer in Hamada grade 3 cases $^{214}$, where bony contact between the greater tuberosity and the acromion (seen on x-ray as the acetabulization) may make the conditions challenging to the integrity of the transferred tendon. The same arguments can be used when it comes to using a subacromial balloon or a superior capsule reconstruction in patients with Hamada grade 2 or 3 . Better results with superior capsule reconstruction have been reported in patients with Hamada grade 1 and 2, compared to those with Hamada grade 3 or $4^{63}$. In Hamada grade 4 or 5 , if surgery is required, a reverse prosthesis is usually the method of choice ${ }^{238}$.

\section{The contralateral cuff tear}

The presence of a contralateral cuff tear may have clinical implications and it may tell us something about the nature of the rotator cuff syndrome. In paper II, the overall prevalence of a contralateral full thickness cuff tear was $50.8 \%$ at a mean of 22 years after an arthroscopically verified partial or full-thickness tear in one shoulder. There was also a substantial correlation in the conditions between shoulders in the same patient, with the prevalence of a contralateral tear ranging from $13.6 \%$, in those who still had a partial tear in the index shoulder, to $90 \%$ in those having arthropathy in the index shoulder at follow-up. Our findings are higher than those of previous studies, in which the prevalence of contralateral tears has been in the range of $16-35 \%{ }^{167}, 234,261$. The most important reason for this difference is that the long follow-up in paper II may have allowed a tear to develop in all those with a predisposition for rotator cuff problems, while previous studies have examined newly diagnosed patients. We also had a slightly older cohort (mean 72 years vs. 60-68 years) and comparison of small cohorts taken from different contexts (with an unknown composition of risk factors) should be done with caution.

We did a risk factor analysis with multivariable logistic regression, identifying tear size (expressed as number of tendons with full-thickness 
tear) as a significant factor with an odds ratio of 3.28 (95\% CI, 1.67-6.44). This was done to assess which of the factors in this study that may have had an influence of the occurrence of a contralateral tear, but to have a more precise and more generalizable estimate, a much larger cohort is probably needed. To obtain a good estimate, in ideal conditions, all factors that may influence the occurrence of contralateral tears should be included, but factors likely to be of considerable importance (like genetic factors) are not known in detail in this case.

The high frequency of bilateral pathology, and the strong correlation between the two shoulders, indicate that a trauma, or repetitive overuse of a dominant shoulder, cannot be the only etiologic factors and that systemic factors must have a significant role for the development of many cuff tears. These systemic factors may be both genetic59 and acquired ${ }^{221}$ and affect tendon homeostasis. Patients who have an increased amount of predisposing factors will perhaps develop a bilateral disease with initial involvement of the dominant shoulder and a subsequent involvement of the contralateral shoulder. The index operation was performed in the dominant shoulder in $81 \%$ of the cases in paper I.

Identifying a contralateral cuff problem will, in a clinical setting, make it possible to initiate treatment or prevention at earlier stages of this probably progressive condition. It is a problem though, that we have very little knowledge of how to prevent the occurrence or progression of a cuff tear with non-operative means. It is possible that shoulder and posture exercises, and addressing metabolic factors, may have an impact, but this remains to be shown.

\section{Acromioplasty without cuff repair}

Earlier studies with short to medium term results after acromioplasty without cuff repair for rotator cuff tears have shown symptomatic improvement $91,181,213,237$. The majority of studies are retrospective caseseries with a mix of intact tendons, partial tears and full-thickness tears. Without a control group, and with poor knowledge of the natural history of cuff tears, it is difficult to ascertain a specific effect of the acromioplasty itself. When it comes to comparative studies, there is only the 3 armed randomised study by Kukkonen et al.154, in which acromioplasty was compared to physiotherapy (and to cuff repair) for patients with small degenerative cuff tears and a significant difference could not be detected.

Long-term effects of acromioplasty for this indication is needed, and question is, if the symptomatic improvement is durable and if the procedure can prevent tear progression and ultimately reduce the risk of cuff 
tear arthropathy. If a cuff tear is caused or aggravated by abrasion of the cuff against the underside of the acromion, an acromioplasty could theoretically have a positive effect. Jaeger et al. published a 20 year follow-up of acromioplasty as sole treatment for a mix of intact tendons and partial and full-thickness tears in $2015^{133}$. They identified 166 randomly selected patients out of 302 eligible candidates, but only 95 (57\%) were examined. Outcome was defined as successful if age- and gender adjusted Constant score was over 70 and no reoperation had been performed. In patients with partial tears, $91 \%$ had a good result and in patients with fullthickness tears, $71 \%$. Corresponding numbers in Paper I are $64 \%$ and $39 \%$. This difference may be due to our much higher follow-up rate and/or different indications for reoperation. The rates of tear progression and arthropathy cannot be assessed in Jaegers et al. study, since they did not perform imaging at follow-up. Paper I is the only study in this area with structural outcome included and 20 years or more follow-up. The study showed that an acromioplasty will likely not prevent tear progression or prevent cuff tear arthropathy in a long-term perspective.

Biomechanical studies have indicated a possible antero-superior escape of the humeral head if a CA-ligament release and an acromioplasty are performed in a shoulder with a cuff tear79, 195. There are no studies specifically aiming to examine if an acromioplasty can actually have a negative effect in the long-term. In paper II, we observed that patients who had had an acromioplasty had developed arthropathy in larger numbers than those who had not. In the index shoulder, where all patients had had this procedure, $51 \%$ of patients with a full-thickness tear at follow-up had arthropathy and in the contralateral shoulder, where only 9 shoulders had been treated with acromioplasty, the frequency of arthropathy was 13 $\%$. Even if this question was not a pre-specified aim in paper II, and the findings should therefore be assessed with caution, it is an interesting finding that could be the focus of future studies. It is also worth noting however, that we do not know when the contralateral cuff tear occurred and it is possible that the lower frequency of arthropathy is merely due to a shorter time period with a cuff tear.

\section{Can cuff tear arthropathy be prevented with an in- terposition graft in shoulders with irreparable cuff tears?}

Paper I has shown, that an acromioplasty without repair in patients with full-thickness tears does not prevent tear progression or cuff tear arthropathy. Paper IV did not show a significant difference between repair and 
physiotherapy without repair of acute full-thickness tears, but the followup is too short to assess any preventive effect regarding arthropathy. Paper III addressed the question of prevention of arthropathy in patients in which it is of utmost importance, i.e. in those with a large and irreparable tear.

Theoretically, an interposition graft could aid in keeping tension in the torn cuff, thereby perhaps counteracting tear progression. In a study on sheep, with a device applying continuous tension after detaching the infraspinatus, progression to muscle atrophy and fatty infiltration seemed to be arrested 95 . A graft could also assist in force transmission between the cuff and humerus, counteracting superior translation, and it could protect the joint by closing the pathological connection between the joint and the subacromial space. To achieve all of this, there has to be healing between an artificial material and a degenerative tendon stump medially and bone laterally. Lack of tenocytes from the degenerative tendon, which is characterized by increased apoptosis ${ }^{190}$, and the potential lack of cells from the osteopenic greater tuberosity 33 , in conjunction with very challenging extracellular conditions ${ }^{48}$, could be suspected of impairing this healing process in both ends of the construct. The tendon-graft interface is also probably subjected to significant stress from superior translation of the humeral head. In a cadaver study by Mihata et al. ${ }^{189}$, in which a cuff defect was created, the addition of a tendon interposition graft only reduced the superior translation partially (compared to normal state or superior capsule reconstruction).

Studies with short to medium-term follow-up of interposition grafts have shown improvement in pain and function, with a mean of 77 in Constant score at follow-up in published studies ${ }^{163}$. The frequency of healed grafts is, however, highly variable and there are no reports with long-term results and radiographic outcome regarding arthropathy. In paper III, we did not find that a synthetic interposition graft could prevent cuff tear arthropathy at 17-20 years follow-up. There are no other studies on interposition grafts (or any type of graft) with this length of follow-up and the follow-up rate was high in paper III. Even though the study has a small sample size, the results (75\% arthropathy, 95\% CI 46-95\%) state that if you do this procedure, in the same kind of patients, at least half of the patients (and most likely 75\%) would end up with arthropathy in the longterm. The procedure seems also not to have been able to prevent tears in adjacent tendons. The results on integrity of the graft in paper III should be interpreted with caution, since assessment with ultrasound is difficult and the method of ultrasound assessment of grafts is not validated. The fact that the grafts did not prevent progression and arthropathy, supports the findings of a high rate of not intact grafts. 
On the other hand, the results from paper III does not mean that grafts should never be used. As has been reviewed in the background section (Grafts and patches in rotator cuff surgery, pp. 37-38), a positive effect on retear rates and clinical scores has been found, even if this is based on few studies and a low level of evidence ${ }^{14}$.

\section{Are the results after cuff repair of a full-thickness ro- tator cuff tear superior to physiotherapy without re- pair in a short-term perspective?}

Paper IV tries to address this question, which in its simplicity hides a large complexity. The rotator cuff is a very large tendinous structure with an intricate detailed anatomy $49,89,192$ and patients may have a defect without any symptoms 199,263 . In a survey from 2005 it has been shown to be common, especially among American high volume surgeons, ta advocate repair of rotator cuff tears, but the variation in decision making was high $^{70}$. Since then several prospective randomised trials have been conducted, most of them focusing on degenerative non-traumatic tears.

In paper IV we wanted to include traumatic tears involving only supraspinatus and we used the Cuff Clock to make sure only superior cuff tears were included. Considering the significant interdigitation of fibres from supra- and infraspinatus ${ }^{192}$, there may have been some patients, in whom some infraspinatus fibres were torn as well. Considering the small tears included (Figure 12), cases like that are probably few. We also aimed at including only acute traumatic tears and hence only included patients without previous shoulder complaints. There is, however, a possibility that some patients with an asymptomatic tear and a trauma that did not increase the tear size were included. After initiation of study IV, Loew and colleagues published a study, in which they tried to find MRI-signs that reliably could distinguish between acute traumatic and chronic degenerative tears ${ }^{170}$. Findings of oedema, kinking of tendon and atrophy may aid in correct diagnosis, but no absolutely distinguishing features could be identified. If a few patients in paper IV had tears of the above mentioned type, they could be expected to have a better result from non-operative treatment, since an easy return to good shoulder function would be expected in case of no or small additional tendon damage.

There was a difference of around 5 points in both Constant score and WORC\% in favour of repair, but the difference is not statistically significant. Nonsignificant differences can be the result of a sample size being too small to detect a real difference (a type II error). If, hypothetically, the 
sample size had been much larger, a difference of around 5 points would still, probably, not be of clinical importance. Measures of Minimal Clinically Important Difference (MCID, a change or difference considered important by patients) have been calculated for Constant score to be 2, 10, 17 and $24^{125,156}$, with the most cited value being 10 points.

Four previous prospective randomised studies have published 12month results, in which comparisons were made between repair and nonrepair treatment $154,160,197,217$. Moosmayer et al. randomised 103 patients to mini-open repair or physiotherapy and included both traumatic and degenerative tears, with $38 \%$ having an adequate trauma ${ }^{197}$. In an intentionto-treat analysis, in which 9 patients who underwent secondary surgery were included in the physiotherapy group, a significant difference in improvement was found in favour of primary repair. The 12 months Constant score in the repair group (mean Constant score 76.8) was comparable to the findings in paper IV (median 83) but the Constant score in the physiotherapy group (mean 66.8) was lower than in paper IV (median 78). The better result in the physiotherapy group in paper IV may be due to a larger proportion of very small tears, differences in the rehabilitation programmes and better prerequisites for training in patients without previous shoulder complaints. In the study by Kukkonen et al.154, only degenerative non-traumatic tears were investigated and 3 groups were compared: arthroscopic cuff repair, acromioplasty and physiotherapy. The repair group also had a higher Constant score (77.9) than the physiotherapy group (74.1), but the difference of 4 points was not statistically significant. Similar patterns are seen in the other 2 studies. Lambers-Heerspink at al. examined degenerative non-traumatic tears and found Constant scores of mean 81.9 in the repair group vs. 73.7 in the non-repair group $(P=0.08)^{160}$. Odak et al. also included degenerative non-traumatic tears with a mean tear size of $17.6-18.3 \mathrm{~mm}$, finding a mean Constant score of 76.4 in the repair group vs. $65.3(P=0.06)$ in the acromioplasty group ${ }^{217}$.

In studies with 12-month follow-up, there have been differences in some of the secondary outcome scores used and they have all been in favour of repair. Moosmayer et al. found differences in ASES-score (American Shoulder and Elbow Society score), pain free abduction and pain ${ }^{197}$, Lambers-Heerspink et al. found a difference in pain ${ }^{160}$ and Odak et al. found differences in ASES-score and DASH ${ }^{217}$.

Structural integrity of repaired cuff tendons are reported at 12 months of follow-up in some studies as well. Compared to the finding of a retear rate of $6.5 \%$ in paper IV, all other studies have higher rates. Moosmayer et al. reported an $8 \%$ full-thickness retear rate ${ }^{197}$, Odak et al. a retear rate of $38 \%^{217}$ and Lambers-Heerspink a retear rate of $73.7 \%{ }^{160}$. Kukkonen et al. did not report structural integrity at 12 months, but a $31 \%$ retear rate was found at 24-month follow-up ${ }^{155}$. The number of retears in all these 
studies should be interpreted with caution, since authors seldom have reported precisely how they defined a retear.

Attempts to summarize results of existing RCTs with 12-month results have been made in 2 recent systematic reviews and meta-analyses ${ }^{227,} 240$. Both studies have included results from the same 3 studies (Moosmayer, Kukkonen and Lambers-Heerspink). Piper et al. ${ }^{227}$ found a significant between group difference of 5.6 in Constant score (95\% CI 2.06-9.21; $P=0.002$ ) in favour of repair. Ryösä et al. also found a between-group difference of 5.6, but with wider confidence intervals ( $95 \%$ CI -0.41 to 11.62; $P=0.068$ ). Regardless of statistical significance or not, a difference of around 5 points in Constant score may be regarded as below a level of clinical significance. The results from paper IV is in line with these previous findings.

It is very important not to discard the method of cuff repair for all patients with a cuff tear, based on the results from above mentioned studies and the results in paper IV. The tear sizes per group in each study is 8.7$10 \mathrm{~mm}$ in paper IV, 14.3-15.6 mm in Moosmayer et al. ${ }^{197}$, 8.5-9.6 in Kukkonen et al. ${ }^{154}$, "supraspinatus" in Lambers-Heerspink et al. ${ }^{160}$ and 17.618.3 in Odak et al. ${ }^{217}$. Consequently the results are mainly applicable to small tears, and the 2 studies with slightly larger tears ${ }^{197,} 217$, also have a larger between-group difference in Constant score.

Existing randomised trials, including paper IV, also have a limitation in the relatively small sample sizes. This is not surprising, since trials like that are time- and resource consuming. One attempt to overcome these problems was recently published by Ramme et al.229. They compared 107 patients, who had chosen operative cuff repair, with 107 patients who had chosen nonsurgical treatment, matching the 2 groups with propensity score analysis regarding age, sex, symptom duration, comorbidity, tear size, injury mechanism and atrophy. About $1 / 3$ in each group, had a tear size above $30 \mathrm{~mm}$. The repair group did better regarding all outcome measures (WORC, ASES, SANE and pain VAS) at all time points. At the final 2 year follow-up, the repair group had a WORC of $81.4 \%$ vs. $68.8 \%$ for the nonoperative group, a statistically and clinically significant difference. Jain et al. also used the same methodology, with propensity score matching of a prospective cohort of 55 patients with cuff tears treated with repair and 77 treated nonoperatively ${ }^{134}$. The operative group had significantly better pain and functional outcome scores up to 18 months of follow-up.

One question is, if there is a tear size, above which pain is more likely to be present? Fucentese et al. have shown that patients with supraspinatus tears, with a mean size of $16 \mathrm{~mm}$, did well in a prospective 3.5 -year follow-up ${ }^{87}$. These tears were treated non-operatively after patients had chosen this, despite a recommendation of repair. Hinsley et al. did bilat- 
eral shoulder ultrasound of 464 women and found that a tear size above $25 \mathrm{~mm}$ indicated a greater likelihood of having shoulder pain ${ }^{122}$. The majority of patients with full-thickness tears having participated in randomised studies of cuff repair, including patients from paper IV, have had tear sizes well below these suggested thresholds.

Despite the fact that paper IV has focused exclusively on traumatic tears, as opposed to previous studies, the results are in line with those studies. In a 12-month perspective, patients thus seem to be able to function with a defect in the cuff, but the mechanisms for this compensation are poorly understood. Mechanical reasons, like the remaining cuff being able to uphold relevant biomechanics, may play a role, along with strengthening of the intact cuff on the front and back, as well as achieving a stronger deltoid muscle through rehabilitation. Psychological coping mechanisms and activity modifications may also be of importance.

\section{What is the natural long-term course of rotator cuff tears, with and without repair?}

Traditionally, the natural course of rotator cuff disease has been described as starting with an impingement of the rotator cuff under the acromion, leading to subacromial bursitis, cuff tendinopathy and eventually to partial and full-thickness rotator cuff tears ${ }^{22,208}$. A tear in the rotator cuff is also believed to possibly cause cuff tear arthropathy in the end ${ }^{210}$, but the literature have a paucity of data on the details of progression from a rotator cuff tear to arthropathy.

In paper I, we found a high frequency of $87 \%$ progression to a larger tear in patients with full-thickness tears, despite a conservative definition of progression, and also a high frequency of $74 \%$ cuff tear arthropathy. The mean Constant score in those with arthropathy was 47, and mean 65 in those with full-thickness tear without arthropathy. A recent review by Chalmers et al. from 2018 found a total of 289 patients with mid to longterm results for unrepaired rotator cuff tears (including those from paper I) and the mean duration of follow-up was 14.9 years (95\% CI, 11.5-18.3 years) 39 . Paper I therefore seems to have the longest follow-up of unrepaired tears published until now. In this review, 1294 patients from 23 studies with outcome after repair were compared to 289 patients with unrepaired tears from 8 studies 39 . The repair group had a larger tear size at inclusion and the duration of follow-up was longer in the unrepaired group. The authors adjusted for differences in age, sex, duration of followup and tear size and concluded that the frequency of patients requiring additional surgery and the final tear size was significantly lower in the re- 
pair group, but the estimated mean difference in Constant scores between the groups was not significant. This review did not analyse arthropathy.

Three additional studies with long-term results53, 120, 231 have been published after this review. Radiographic results 20 years after rotator cuff repair was published recently by Hervé et al. and a frequency of $29 \%$ osteoarthritis was reported ${ }^{120}$, but their definition of osteoarthritis did not include Hamada grade 2 and 3. If these Hamada grades are also included, the frequency would be $35 \%$, which is substantially lower than the findings in paper I ( $74 \%$ arthropathy). The low follow-up rate of $47 \%$, as well as different definitions between the studies, add to difficulties when comparing with results in paper I.

In another recent report of 20 year results after cuff repair of supraspinatus tears53, the total Constant score at follow-up was 71 (as compared to 52 pre-operatively) and the subjective shoulder value was $77 \%$, despite a retear rate of $42 \%$. Analysis of this study is hampered by a low followup rate (66 out of 137). The mean Constant scores (overall 71, in healed repairs 75) seem however to be substantially higher than in paper I. The authors do not report the numbers for each Hamada grade, but 12 out of 53 radiographs (23\%) showed Hamada grade 4, as compared to 7 out of 24 (30 \%) in paper I. It seems likely that these arthropathy cases are among those with a retear, although this is not clearly stated in the article.

Randelli recently reported 10 year results after arthroscopic cuff repair, including complete follow-up of 102 out of 169 patients (6o \%) ${ }^{231}$. Despite a retear rate of $51 \%$, the mean Constant score was 78 for the whole cohort, 81 for small tears $(<2 \mathrm{~cm})$ and 70 for larger tears. Patients with a small tear, had Hamada grade 2 or more in $14 \%$ of cases, and corresponding rate in patients with larger tears was $53 \%$. Again, results regarding clinical scores and frequency of cases with arthropathy seem better in these repaired patients compared to the findings in paper I.

Comparing separate cohorts from different contexts, as has been attempted above, is difficult since the group distribution of known and unknown factors that may influence the results is not known in detail. It is also possible, that patients chosen for repair in non-comparative studies, may have been worse in some aspects than those chosen for non-repair treatment in other studies. If repaired patients then do as well or slightly better than unrepaired patients, the treatment effect of repair may be underestimated. Only a well-performed prospective randomised study with long follow-up can overcome some of these difficulties. Ten year results with $88 \%$ follow-up from such a study were recently published by Moosmayer et al. ${ }^{198}$. The repair group had a better result for Constant score (by 9.6 points), as well as better scores for ASES, pain, pain-free abduction and pain-free flexion, with all differences being statistically significant. These differences were larger at 10 years compared to previous follow-up 
points, probably due to a progression of tear size and deteriorating clinical results in the unrepaired patients.

In a 5 to 11 year follow-up of the cohort from Odak et $\mathrm{al}^{217}$, a mean Constant score of 78 in the repair group and 61 in the acromioplasty group was found, a difference which was not significant ${ }^{21}$. This study may, however, have been underpowered to detect a real difference, with a follow-up of only 33 of the original 42 patients.

The overall impression, although not relying on extensive high-level evidence, is that a repaired and healed rotator cuff may increase the chance of less pain, better function and less secondary osteoarthritis in the long-term. The altered tendon biology in rotator cuff tears, described earlier in this thesis, may be the driving-force of both progression of unrepaired tears and recurrence of tears despite repair. A repair cannot be expected to change these underlying alterations in tendon biology. Perhaps a repair can only slow-down the deterioration, but not eliminate it.

A person with an intact infraspinatus, but a ruptured supraspinatus, will still possibly have a functioning shoulder. This shoulder will, however, probably have an increased susceptibility to pain after overhead loading and an increased susceptibility to a subsequent traumatic injury of remaining rotator cuff tendons. Such an additional injury (a so called acute-on-chronic injury) may also have more severe consequences than if a normal shoulder sustained a trauma of equivalent proportions. 
Rotator cuff tears-short and long-term aspects on treatment outcome

98 


\section{CONCLUSIONS}

Results from paper I indicate that treating patients with a full-thickness cuff tear with an acromioplasty without cuff repair, does not prevent the tear from progressing to a larger tear size, or the joint from developing cuff tear arthropathy after more than 20 years. The frequency of tear progression and arthropathy was high in patients with full-thickness tears and the clinical scores low in the presence of arthropathy at long-term follow-up. Very few patients with partial-thickness tears developed arthropathy and the clinical scores were high on a group level, even though 4 out of 10 had progressed to a full-thickness tear. The findings indicate that a rotator cuff tear is a potentially progressive condition, and that a fullthickness tear at presentation indicates an increased risk of both tear progression and arthropathy.

In paper II, we found that the frequency of contralateral cuff tears was high, in patients with an arthroscopically verified cuff tear more than 20 years earlier. There also seems to be a high correlation between the conditions between shoulders, regarding both tendon status, arthropathy and clinical scores. Having a full-thickness tear in one shoulder, and age, are risk factors for having a contralateral full-thickness tear. An increased frequency of cuff tear arthropathy was observed in patients having previously undergone acromioplasty, but this finding is hypothesis-generating rather than confirmatory.

Results from paper III indicate that covering an irreparable cuff defect, by suturing a synthetic interposition graft to the tendon stump medially and fixing it with a screw laterally, do not seem to prevent cuff tear arthropathy or tear progression in adjacent tendons.

In a prospective, randomised, parallel group comparison, with one year follow-up, between early repair and physiotherapy without repair in paper IV, clinical results seem equally good in patients with small traumatic cuff tears with a median tear size of approximately $1 \mathrm{~cm}$. The retear rate in repaired patients was low, but almost one third of unrepaired patients had a small progression in tear size of $5 \mathrm{~mm}$ or more. No clinically relevant fatty infiltration was observed in any of the groups. 
Rotator cuff tears-short and long-term aspects on treatment outcome 


\section{FUTURE PERSPECTIVES}

The indications for a cuff repair remain to be better defined. It would be preferable with larger prospective randomised studies, incorporating larger tear sizes and various tear types, which may make subgroup analysis possible. If existing, and future research, were to say that we need to operate cuff patients, in order to avoid a negative outcome in some of them, it would improve decision making substantially if we could identify those who really need the operation. Shoulder joint degeneration will, for example, progress in some patients with nonoperative treatment, and the ability to identify these rapid progressors would enhance clinical decisionmaking. If we do not have this information, we may be inclined to do unnecessary operations in some patients. One study which may provide information like this is the ongoing ARC-trial ${ }^{135}$, which aim to include 700 patients with all kinds of cuff tears (except isolated subscapularis tears and tears due to severe trauma).

In paper I, and in other studies ${ }^{153}, 196$, some patients progress more rapidly, and to more extensive joint pathology, than others. Finding factors associated with rapid progression would be of value. Such factors could be related to tear geometry or to metabolic and genetic factors. Finding risk factors for tear progression in tear geometry or metabolic factors, through larger prospective studies, is feasible, but finding genetic factors is more difficult, since candidate genes are currently not well defined.

Surgery has a potential for generating placebo effects 255 , something which has been explored in shoulder surgery concerning impingement syndrome (i.e. patients with subacromial pain but not a full-thickness tear), with the CSAW-trial 15 and the FIMPACT-trial 219 . The ACCURATEtrial is an ongoing similar randomised trial, comparing arthroscopic cuff repair to sham surgery (diagnostic arthroscopy), in patients with traumarelated cuff tears up to $30 \mathrm{~mm}$ in width ${ }^{239}$. We aim to include 180 patients and do follow-up at 1, 2, 5 and 10 years.

A superior cuff tear has the potential to increase the superior translation of the humeral head. This may be possible to measure with fluoroscopy, and we plan to publish results comparing repaired cuff patients to unrepaired patients with traumatic tears. Data has been collected, from the same patients as in paper IV, and analysis is under way. 
In the discussion section of this thesis, some focus has been on tear size, since it is important to know what kind of patients that have been the focus of comparative studies. Measuring tear size on MRI is, however, not easy, and we are now planning to compare measurements on MRI with measurement during both open and arthroscopic repair. 


\section{ACKNOWLEDGEMENTS}

I would like to thank everyone who have contributed to this thesis and who have helped me in my thesis work. Named or unnamed, without you this thesis would never have been possible. First of all, I would especially like to thank all the participating patients in these studies, many of whom travelled far to be able to contribute.

I also specifically would like to thank the following:

Lars Adolfsson, professor, main supervisor. For the good answers to all my questions, for the great patience and for the ability to question things in order to understand them. I am so grateful, Lars!

Hanna Björnsson Hallgren, co-supervisor and co-author of all papers in this thesis. You have brought energy and hard work into our studies and your social skills have persuaded many patients to take part in studies. And from the very beginning you made me feel welcome in Linköping!

Rolf Norlin, co-supervisor and co-author of papers I and III. Your early work in Linköping has laid the foundation for doing the research that resulted in several of the papers in this thesis.

Theresa Holmgren, physiotherapist in Linköping and co-author of paper IV. The friendly and energetic enthusiasm you bring into our common projects makes it all a lot easier. I hope we can continue doing projects.

Lars Brudin, for statistical advice. I have truly had a great time in your company and I didn't know I liked statistics as much as I did, it was not until you got me started. I hope you can keep up the good work for a long time to come.

Terez Zara Hanqvist, research nurse in Linköping. For helping me getting in contact with all these patients. Without you, our follow-up rate would have been much lower! Always swift and friendly help throughout the whole PhD-period.

Anna Petersson, former research nurse in Kalmar. For all the help in getting started, handling patients, keeping track of things.

Kim Thorsen, present head of Orthopaedic Department in Kalmar, and Anders Linge and Dan Johannesson, former heads of department in Kalmar. For giving me the time and the resources to do this thesis. 
Research Committee Region Kalmar (Forskningskommittén). For giving me the time to do this thesis.

Anne Dettmer, colleague and friend in Kalmar. For all the help with managing and including patients for our studies. I hope we can keep on helping each other!

Lisa Stolth, Emma Nattfogel, Rebecca Nobin, Stefan Wetterstad, Johan Christiansson and all the other colleagues and friends at the Orthopaedic Department in Kalmar. You are all contributing to an open atmosphere and interesting discussions, as well as being supportive of my research.

Annika Hjortenkrans, Carina Nilsson and Jenny Hultenius, physiotherapists in Kalmar. For doing a great job in handling and training our patients inside and outside of studies and for collecting research data.

Anna Berglund, Anna Petersson, Maria Öberg, physiotherapists in Linköping. For handling, training and collecting research data.

Jens Nestorsson, Johan Scheer, Ida Dånmark and all the other colleagues at the Orthopaedic Department in Linköping. You have always made me feel welcome in Linköping! And for help with finding and operating patients from paper IV.

Lena Törnqvist, radiologist in Linköping. For helping with radiographic analysis in papers I and II.

Per Ranebo, my brother. For the great anatomical drawings, the proofreading and for being the best imaginable brother!

Stellan Ranebo, my father. For always being there, no matter where or when, giving me support and help, in life and in the work with this thesis!

Many friends, knowingly or unknowingly, helping me in different ways. A special thanks to Daniel Bengtsson, Fredrik Ellin, Jonas Bonnedahl, and Olle Björneld i.e. the Cavemen of Tegnérgatan and to Dödeviligan (you know who you are).

And at last, but not least, my family: Charlotte, Ida and Oscar Ranebo. You are more important than anything else in my life! Thank you for the patience and for keeping my priorities straight. And Ida: Thank you for the nice photo for the cover! 


\section{REFERENCES}

1 Adolfsson L, Lysholm J. Arthroscopy and stability testing for anterior shoulder instability. Arthroscopy 1989;5:315-320.

2 Ainsworth R, Lewis JS. Exercise therapy for the conservative management of full thickness tears of the rotator cuff: a systematic review. Br J Sports Med 2007;41:200-210. 10.1136/bjsm.2006.032524

3 Ajrawat P, Dwyer T, Almasri M, Veillette C, Romeo A, Leroux T et al. Bone marrow stimulation decreases retear rates after primary arthroscopic rotator cuff repair: a systematic review and meta-analysis. J Shoulder Elbow Surg 2019;28:782-791. 10.1016/j.jse.2018.11.049

4 Al-Hakim W, Noorani A, Lambert S. Assessment and treatment strategies for rotator cuff tears. Shoulder Elbow 2015;7:76-84. $10.1177 / 1758573214557143$

5 Alpantaki K, D. M, Karagogeos D, Hadjipavlou A, Kontakis G. Sympathetic and sensory neural elements in the tendon of the long head of the biceps. J Bone Joint Surg Am 2005;87-A:1580-1583. doi:10.2106/JBJS.D.02840

6 Anastasopoulos PP, Alexiadis G, Spyridonos S, Fandridis E. Latissimus Dorsi Transfer in Posterior Irreparable Rotator Cuff Tears. Open Orthop J 2017;11:77-94. 10.2174/1874325001711010077

7 Andrews J, Carson WG, Jr., McLeod WD. Glenoid labrum tears related to the long head of the biceps. Am J Sports Med 1985;13:337-341.

8 Andrews JR, Broussard TS, Carson WG. Arthroscopy of the shoulder in the management of partial tears of the rotator cuff: a preliminary report. Arthroscopy 1985;1:117-122.

9 Applegate KA, Thiese MS, Merryweather AS, Kapellusch J, Drury DL, Wood E et al. Association Between Cardiovascular Disease Risk Factors and Rotator Cuff Tendinopathy: Cross-Sectional Study. J Occup Environ Med 2016. 10.1097/jom.0000000000000929

10 Arai R, Matsuda S. Macroscopic and microscopic anatomy of the rotator cable in the shoulder. J Orthop Sci 2019;Article in press. 10.1016/j.jos.2019.03.014

11 Arai R, Mochizuki T, Yamaguchi K, Sugaya H, Kobayashi M, Nakamura T et al. Functional anatomy of the superior glenohumeral and coracohumeral ligaments and the subscapularis tendon in view of stabilization of the long head of the biceps tendon. J Shoulder Elbow Surg 2010;19:58-64. 10.1016/j.jse.2009.04.001

12 Arnoczky SP, Tian T, Lavagnino M, Gardner K, Schuler P, Morse P. Activation of stress-activated protein kinases (SAPK) in tendon cells following cyclic strain: the effects of strain frequency, strain magnitude, and cytosolic calcium. J Orthop Res 2002;20:947-952. 10.1016/sO7360266(02)00038-4

13 Asaid R, Eng K, Brown G, Page R. Long-term outcomes after infected miniopen rotator cuff repair: results of a 10-year review. J Shoulder Elbow Surg 2018;27:751-755. 10.1016/j.jse.2017.09.003 
14 Bailey JR, Kim C, Alentorn-Geli E, Kirkendall DT, Ledbetter L, Taylor DC et al. Rotator Cuff Matrix Augmentation and Interposition: A Systematic Review and Meta-analysis. Am J Sports Med 2018:363546518774762. 10.1177/0363546518774762

15 Beard DJ, Rees JL, Cook JA, Rombach I, Cooper C, Merritt N et al. Arthroscopic subacromial decompression for subacromial shoulder pain (CSAW): a multicentre, pragmatic, parallel group, placebo-controlled, three-group, randomised surgical trial. Lancet 2018;391:329-338. 10.1016/s0140-6736(17)32457-1

16 Beggs I. Shoulder ultrasound. Semin Ultrasound CT MR 2011;32:101-113. 10.1053/j.sult.2010.10.003

17 Bennell K, Wee E, Coburn S, Green S, Harris A, Staples M et al. Efficacy of standardised manual therapy and home exercise programme for chronic rotator cuff disease: randomised placebo controlled trial. BMJ 2010;340:c2756. 10.1136/bmj.c2756

18 Benson RT, McDonnell SM, Knowles HJ, Rees JL, Carr AJ, Hulley PA. Tendinopathy and tears of the rotator cuff are associated with hypoxia and apoptosis. J Bone Joint Surg Br 2010;92:448-453. 10.1302/0301620X.92B3.23074

19 Bernhardt GA, Glehr M, Zacherl M, Wurnig C, Gruber G. Observer variability in the assessment of the acromiohumeral interval using anteroposterior shoulder radiographs. Eur J Orthop Surg Traumatol 2013;23:185-190. 10.1007/s00590-012-0942-y

20 Biberthaler P, Wiedemann E, Nerlich A, Kettler M, Mussack T, Deckelmann $S$ et al. Microcirculation associated with degenerative rotator cuff lesions. In vivo assessment with orthogonal polarization spectral imaging during arthroscopy of the shoulder. J Bone Joint Surg Am 2003;85A:475-480.

21 Bidwai AS, Birch A, Temperley D, Odak S, Walton MJ, Haines JF et al. Medium- to long-term results of a randomized controlled trial to assess the efficacy of arthoscopic-subacromial decompression versus mini-open repair for the treatment of medium-sized rotator cuff tears. Shoulder Elbow 2016;8:101-105. 10.1177/1758573215620571

22 Bigliani LU, Levine WN. Subacromial impingement syndrome. J Bone Joint Surg Am 1997 dec;79:1854-1868.

23 Birkedal-Hansen H, S. Y, Windsor J, Pollard A, Lyons G, Stetler-Stevenson W et al. Matrix metalloproteinases. Curr Protoc Cell, Biol 2008 Sep;Chapter 10:Unit 10.18.

24 Bishop JY, Santiago-Torres JE, Rimmke N, Flanigan DC. Smoking Predisposes to Rotator Cuff Pathology and Shoulder Dysfunction: A Systematic Review. Arthroscopy 2015;31:1598-1605. 10.1016/j.arthro.2015.01.026

25 Bjarnison AO, Sorensen TJ, Kallemose T, Barfod KW. The critical shoulder angle is associated with osteoarthritis in the shoulder but not rotator cuff tears: a retrospective case-control study. J Shoulder Elbow Surg 2017;26:2097-2102. 10.1016/j.jse.2017.06.001

26 Bjornsson Hallgren HC, Adolfsson LE, Johansson K, Oberg B, Peterson A, Holmgren TM. Specific exercises for subacromial pain. Acta Orthop 2017;88:600-605. 10.1080/17453674.2017.1364069

27 Bjornsson HC, Norlin R, Johansson K, Adolfsson LE. The influence of age, delay of repair, and tendon involvement in acute rotator cuff tears: 
structural and clinical outcomes after repair of 42 shoulders. Acta Orthop 2011;82:187-192. 10.3109/17453674.2011.566144

28 Blaine TA, Kim YS, Voloshin I, Chen D, Murakami K, Chang SS et al. The molecular pathophysiology of subacromial bursitis in rotator cuff disease. J Shoulder Elbow Surg 2005;14:84s-89s. 10.1016/j.jse.2004.09.022

29 Boorman RS, More KD, Hollinshead RM, Wiley JP, Mohtadi NG, Lo IKY et al. What happens to patients when we do not repair their cuff tears? Fiveyear rotator cuff quality-of-life index outcomes following nonoperative treatment of patients with full-thickness rotator cuff tears. J Shoulder Elbow Surg 2018;27:444-448. 10.1016/j.jse.2017.10.009

30 Brolin TJ, Updegrove GF, Horneff JG. Classifications in Brief: Hamada Classification of Massive Rotator Cuff Tears. Clin Orthop Relat Res 2017;475:2819-2823. 10.1007/s11999-017-5340-7

31 Burkhart SS, Esch JC, Jolson RS. The rotator crescent and rotator cable: an anatomic description of the shoulder's "suspension bridge". Arthroscopy 1993;9:611-616.

32 Burman MS. Arthroscopy or the direct visualization of joints: an experimental cadaver study. 1931. Clin Orthop Relat, Res 2001;390:5-9.

33 Cadet ER, Hsu JW, Levine WN, Bigliani LU, Ahmad CS. The relationship between greater tuberosity osteopenia and the chronicity of rotator cuff tears. J Shoulder Elbow Surg 2008;17:73-77. 10.1016/j.jse.2007.04.017

34 Cancienne JM, Brockmeier SF, Rodeo SA, Werner BC. Perioperative Serum Lipid Status and Statin Use Affect the Revision Surgery Rate After Arthroscopic Rotator Cuff Repair. Am J Sports Med 2017;45:2948-2954. 10.1177/0363546517717686

35 Carr A, Cooper C, Campbell MK, Rees J, Moser J, Beard DJ et al. Effectiveness of open and arthroscopic rotator cuff repair (UKUFF): a randomised controlled trial. Bone Joint J 2017;99-b:107-115. 10.1302/0301-620x.99b1.Bjj-2016-0424.R1

36 Chahal J, Mall N, MacDonald PB, Van Thiel G, Cole BJ, Romeo AA et al. The role of subacromial decompression in patients undergoing arthroscopic repair of full-thickness tears of the rotator cuff: a systematic review and meta-analysis. Arthroscopy 2012;28:720-727. 10.1016/j.arthro.2011.11.022

37 Chakravarty K, Webley M. Shoulder joint movement and its relationship to disability in the elderly. J Rheumatol 1993;20:1359-1361.

38 Chalmers PN, Granger E, Ross H, Burks RT, Tashjian RZ. Preoperative Factors Associated With Subsequent Distal Clavicle Resection After Rotator Cuff Repair. Orthop J Sports Med 2019;7:2325967119844295. $10.1177 / 2325967119844295$

39 Chalmers PN, Ross H, Granger E, Presson AP, Zhang C, Tashjian RZ. The Effect of Rotator Cuff repair on Natural History. JBJS Open Access 2018:e0043. 10.2106/JBJS.OA.17.00043

40 Chalmers PN, Salazar DH, Steger-May K, Chamberlain AM, Stobbs-Cucchi G, Yamaguchi K et al. Radiographic progression of arthritic changes in shoulders with degenerative rotator cuff tears. J Shoulder Elbow Surg 2016;25:1749-1755. 10.1016/j.jse.2016.07.022

41 Chansky HA, Iannotti JP. The vascularity of the rotator cuff. Clin Sports Med 1991;10:807-822. 
42 Chaudhury S, Bavan L, Rupani N, Mouyis K, Kulkarni R, Rangan A et al. Managing acromio-clavicular joint pain: a scoping review. Shoulder Elbow 2018;10:4-14. 10.1177/1758573217700839

43 Chaudhury S, Carr AJ. Lessons we can learn from gene expression patterns in rotator cuff tears and tendinopathies. J Shoulder Elbow Surg 2012;21:191-199. 10.1016/j.jse.2011.10.022

44 Cho CH, Seo HJ, Bae KC, Lee KJ, Hwang I, Warner JJ. The impact of depression and anxiety on self-assessed pain, disability, and quality of life in patients scheduled for rotator cuff repair. J Shoulder Elbow Surg 2013;22:1160-1166. 10.1016/j.jse.2013.02.006

45 Cho NS, Moon SC, Hong SJ, Bae SH, Rhee YG. Comparison of Clinical and Radiological Results in the Arthroscopic Repair of Full-Thickness Rotator Cuff Tears With and Without the Anterior Attachment of the Rotator Cable. Am J Sports Med 2017;45:2532-2539. 10.1177/0363546517709772

46 Cho NS, Moon SC, Jeon JW, Rhee YG. The influence of diabetes mellitus on clinical and structural outcomes after arthroscopic rotator cuff repair. Am J Sports Med 2015;43:991-997. 10.1177/0363546514565097

47 Cho NS, Yi JW, Rhee YG. Arthroscopic biceps augmentation for avoiding undue tension in repair of massive rotator cuff tears. Arthroscopy 2009;25:183-191. 10.1016/j.arthro.2008.09.012

48 Cipollaro L, Sahemey R, Oliva F, Maffulli N. Immunohistochemical features of rotator cuff tendinopathy. Br Med Bull 2019. 10.1093/bmb/ldz016

49 Clark JM, Harryman DT, 2nd. Tendons, ligaments, and capsule of the rotator cuff. Gross and microscopic anatomy. J Bone Joint Surg Am 1992;74:713-725.

50 Clark NJ, Elhassan BT. The Role of Tendon Transfers for Irreparable Rotator Cuff Tears. Curr Rev Musculoskelet Med 2018;11:141-149. 10.1007/s12178-018-9468-1

51 Codman EA. Complete rupture of the supraspinatus tendon. Operative treatment with report of two successful cases. 1911. J Shoulder Elbow Surg 2011;20:347-349. 10.1016/j.jse.2010.10.031

52 Collin P, Matsumura N, Ladermann A, Denard PJ, Walch G. Relationship between massive chronic rotator cuff tear pattern and loss of active shoulder range of motion. J Shoulder Elbow Surg 2014;23:1195-1202. 10.1016/j.jse.2013.11.019

53 Collin P, Thomazeau H, Walch G, Gerber C, Mansat P, Favard L et al. Clinical and structural outcome twenty years after repair of isolated supraspinatus tendon tears. J Shoulder Elbow Surg 2019;28:196-202. 10.1016/j.jse.2018.07.023

54 Collin P, Treseder T, Denard PJ, Neyton L, Walch G, Ladermann A. What is the Best Clinical Test for Assessment of the Teres Minor in Massive Rotator Cuff Tears? Clin Orthop Relat Res 2015;473:2959-2966. 10.1007/s11999-015-4392-9

55 Colvin AC, Egorova N, Harrison AK, Moskowitz A, Flatow EL. National trends in rotator cuff repair. J Bone Joint Surg Am 2012;94:227-233. 10.2106/JBJS.J.00739

56 Constant CR, Murley AH. A clinical method of functional assessment of the shoulder. Clin Orthop Relat Res 1987:160-164.

57 Cook KF, Roddey TS, Olson SL, Gartsman GM, Valenzuela FF, Hanten WP. Reliability by surgical status of self-reported outcomes in patients who 
have shoulder pathologies. J Orthop Sports Phys Ther 2002;32:336-346. 10.2519/jospt.2002.32.7.336

58 Cunningham G, Nicodeme-Paulin E, Smith MM, Holzer N, Cass B, Young AA. The greater tuberosity angle: a new predictor for rotator cuff tear. $\mathrm{J}$ Shoulder Elbow Surg 2018;27:1415-1421. 10.1016/j.jse.2018.02.051

59 Dabija DI, Gao C, Edwards TL, Kuhn JE, Jain NB. Genetic and familial predisposition to rotator cuff disease: a systematic review. J Shoulder Elbow Surg 2017;26:1103-1112. 10.1016/j.jse.2016.11.038

60 Davidson J, Burkhart SS. The geometric classification of rotator cuff tears: a system linking tear pattern to treatment and prognosis. Arthroscopy 2010;26:417-424. 10.1016/j.arthro.2009.07.009

61 de Jesus JO, Parker L, Frangos AJ, Nazarian LN. Accuracy of MRI, MR arthrography, and ultrasound in the diagnosis of rotator cuff tears: a meta-analysis. AJR Am J Roentgenol 2009;192:1701-1707. 10.2214/ajr.08.1241

62 de Witte PB, Henseler JF, Nagels J, Vliet Vlieland TP, Nelissen RG. The Western Ontario rotator cuff index in rotator cuff disease patients: a comprehensive reliability and responsiveness validation study. Am J Sports Med 2012;40:1611-1619. 10.1177/0363546512446591

63 Denard PJ, Brady PC, Adams CR, Tokish JM, Burkhart SS. Preliminary Results of Arthroscopic Superior Capsule Reconstruction with Dermal Allograft. Arthroscopy 2018;34:93-99. 10.1016/j.arthro.2017.08.265

64 Denard PJ, Duey RE, Dai X, Hanypsiak B, Burkhart SS. Relationship of the subscapular nerves to the base of the coracoid. Arthroscopy 2013;29:986989. 10.1016/j.arthro.2013.02.005

65 DeOrio JK, Cofield RH. Results of a second attempt at surgical repair of a failed initial rotator-cuff repair. J Bone Joint Surg Am 1984;66:563-567.

66 Dickinson RN, Ayers GD, Archer KR, Fan R, Page C, Higgins LD et al. Physical therapy versus natural history in outcomes of rotator cuff tears: the Rotator Cuff Outcomes Workgroup (ROW) cohort study. J Shoulder Elbow Surg 2018;28:833-838. 10.1016/j.jse.2018.10.001

67 Djerbi I, Chammas M, Mirous MP, Lazerges C, Coulet B. Impact of cardiovascular risk factor on the prevalence and severity of symptomatic full-thickness rotator cuff tears. Orthop Traumatol Surg Res 2015;101:S269-273. 10.1016/j.otsr.2015.06.011

68 Dornan GJ, Katthagen JC, Tahal DS, Petri M, Greenspoon JA, Denard PJ et al. Cost-Effectiveness of Arthroscopic Rotator Cuff Repair Versus Reverse Total Shoulder Arthroplasty for the Treatment of Massive Rotator Cuff Tears in Patients With Pseudoparalysis and Nonarthritic Shoulders. Arthroscopy 2017;33:716-725.

69 Doyle AJ, Burks RT. Comparison of humeral head retroversion with the humeral axis/biceps groove relationship: a study in live subjects and cadavers. J Shoulder Elbow Surg 1998;7:453-457.

70 Dunn WR, Schackman BR, Walsh C, Lyman S, Jones EC, Warren RF et al. Variation in orthopaedic surgeons' perceptions about the indications for rotator cuff surgery. J Bone Joint Surg Am 2005;87:1978-1984. 10.2106/jbjs.d.02944

71 Ekhtiari S, Adili AF, Memon M, Leroux T, Henry P, Bedi A et al. Sources, Quality, and Reported Outcomes of Superior Capsular Reconstruction: a Systematic Review. Curr Rev Musculoskelet Med 2019;12:173-180. 10.1007/s12178-019-09551-9 
72 Elhassan B. Lower trapezius transfer for shoulder external rotation in patients with paralytic shoulder. J Hand Surg Am 2014;39:556-562. 10.1016/j.jhsa.2013.12.016

73 Elhassan BT, Wagner ER, Werthel JD. Outcome of lower trapezius transfer to reconstruct massive irreparable posterior-superior rotator cuff tear. J Shoulder Elbow Surg 2016;25:1346-1353. 10.1016/j.jse.2015.12.006

74 Ellman H. Arthroscopic subacromial decompression: analysis of one- to three-year results. Arthroscopy 1987;3:173-181.

75 Ellman H. Diagnosis and treatment of incomplete rotator cuff tears. Clin Orthop Relat Res 1990:64-74.

76 Ellman H, Gartsman GM. Open repair of full thickness rotator cuff tears. In: Ellman H GG, editor. Arthroscopic shoulder surgery and related disorders. Philadelphia PA: Lea and Febiger; 1993, p. 181-202.

77 Ernstbrunner L, Suter A, Catanzaro S, Rahm S, Gerber C. Reverse Total Shoulder Arthroplasty for Massive, Irreparable Rotator Cuff Tears Before the Age of 6o Years: Long-Term Results. J Bone Joint Surg Am 2017;99:1721-1729. 10.2106/JBJS.17.00095

78 Evans J, Dattani R, Ramasamy V, Patel V. Responsiveness of the EQ-5D-3L in elective shoulder surgery: Does it adequately represent patient experience? J Orthop Surg 2017;26:1-7.

79 Fagelman M, Sartori M, Freedman KB, Patwardhan AG, Carandang G, Marra G. Biomechanics of coracoacromial arch modification. J Shoulder Elbow Surg 2007;16:101-106. 10.1016/j.jse.2006.01.010

80 Farfaras S, Sernert N, Rostgard Christensen L, Hallstrom EK, Kartus JT. Subacromial Decompression Yields a Better Clinical Outcome Than Therapy Alone: A Prospective Randomized Study of Patients With a Minimum 10-Year Follow-up. Am J Sports Med 2018;46:1397-1407. 10.1177/0363546518755759

81 Farrall LA. Arthroscopic rotator cuff repairs using suture anchors. Aorn J 1995;62:739-746, 748, 750; quiz 754, 756-738. 10.1016/sooo12092(06)63525-4

82 Favard L, Levigne C, Nerot C, Gerber C, De Wilde L, Mole D. Reverse prostheses in arthropathies with cuff tear: are survivorship and function maintained over time? Clin Orthop Relat Res 2011;469:2469-2475. 10.1007/s11999-011-1833-y

83 Fenlin JM, Jr., Chase JM, Rushton SA, Frieman BG. Tuberoplasty: creation of an acromiohumeral articulation-a treatment option for massive, irreparable rotator cuff tears. J Shoulder Elbow Surg 2002;11:136-142.

84 Ferreira-Valente MA, Pais-Ribeiro JL, Jensen MP. Validity of four pain intensity rating scales. Pain 2011;152:2399-2404. 10.1016/j.pain.2011.07.005

85 Fleega BA. Arthroscopic transhumeral rotator cuff repair: Giant needle technique. Arthroscopy 2002;18:218-223.

86 Fritsch KO, Hamoud H, Allam AH, Grossmann A, Nur El-Din AH, AbdelMaksoud $\mathrm{G}$ et al. The orthopedic diseases of ancient Egypt. Anat Rec (Hoboken) 2015;298:1036-1046. 10.1002/ar.23136

87 Fucentese SF, von Roll AL, Pfirrmann CW, Gerber C, Jost B. Evolution of nonoperatively treated symptomatic isolated full-thickness supraspinatus tears. J Bone Joint Surg Am 2012;94:801-808. 10.2106/jbjs.i.01286

88 Fuchs B, Weishaupt D, Zanetti M, Hodler J, Gerber C. Fatty degeneration of the muscles of the rotator cuff: assessment by computed tomography 
versus magnetic resonance imaging. J Shoulder Elbow Surg 1999;8:599605 .

89 Gagey N, Gagey O, Bastian G, Lassau JP. The fibrous frame of the supraspinatus muscle. Correlations between anatomy and MRI findings. Surg Radiol Anat 1990;12:291-292.

90 Galatz LM, Ball CM, Teefey SA, Middleton WD, Yamaguchi K. The outcome and repair integrity of completely arthroscopically repaired large and massive rotator cuff tears. J Bone Joint Surg Am 2004;86-A:219-224.

91 Gartsman GM. Arthroscopic acromioplasty for lesions of the rotator cuff. J Bone Joint Surg Am 1990;72:169-180.

92 Gaunt BW, McCluskey GM, Uhl TL. An electromyographic evaluation of subdividing active-assistive shoulder elevation exercises. Sports Health 2010;2:424-432. 10.1177/1941738110366840

93 Gerber C, Fuchs B, Hodler J. The results of repair of massive tears of the rotator cuff. J Bone Joint Surg Am 2000;82:505-515.

94 Gerber C, Maquieira G, Espinosa N. Latissimus dorsi transfer for the treatment of irreparable rotator cuff tears. J Bone Joint Surg Am 2006;88-A:113-120.

95 Gerber C, Meyer DC, Frey E, von Rechenberg B, Hoppeler H, Frigg R et al. Neer Award 2007: Reversion of structural muscle changes caused by chronic rotator cuff tears using continuous musculotendinous traction. An experimental study in sheep. J Shoulder Elbow Surg 2009;18:163-171. 10.1016/j.jse.2008.09.003

96 Gerber C, Schneeberger AG, Beck M, Schlegel U. Mechanical strength of repairs of the rotator cuff. J Bone Joint Surg Br 1994;76:371-380.

97 Gerber C, Vinh TS, Hertel R, Hess CW. Latissimus dorsi transfer for the treatment of massive tears of the rotator cuff. A preliminary report. Clin Orthop Relat Res 1988:51-61.

98 Gervasi E, Cautero E, Dekel A. Fluoroscopy-guided implantation of subacromial "biodegradable spacer" using local anesthesia in patients with irreparable rotator cuff tear. Arthrosc Tech 2014;3:e455-458. 10.1016/j.eats.2014.05.010

99 Giphart JE, Elser F, Dewing CB, Torry MR, Millett PJ. The long head of the biceps tendon has minimal effect on in vivo glenohumeral kinematics: a biplane fluoroscopy study. Am J Sports Med 2012;40:202-212. 10.1177/0363546511423629

100 Gohlke F, Essigkrug B, Schmitz F. The pattern of the collagen fiber bundles of the capsule of the glenohumeral joint. J Shoulder Elbow Surg 1994;3:111-128. 10.1016/s1058-2746(09)80090-6

101 Goutallier D, Postel JM, Bernageau J, Lavau L, Voisin MC. Fatty muscle degeneration in cuff ruptures. Pre- and postoperative evaluation by CT scan. Clin Orthop Relat Res 1994:78-83.

102 Goutallier D, Postel JM, Gleyze P, Leguilloux P, Van Driessche S. Influence of cuff muscle fatty degeneration on anatomic and functional outcomes after simple suture of full-thickness tears. J Shoulder Elbow Surg 2003;12:550-554. 10.1016/s1058274603002118

103 Gruber G, Bernhardt GA, Clar H, Zacherl M, Glehr M, Wurnig C. Measurement of the acromiohumeral interval on standardized anteroposterior radiographs: a prospective study of observer variability. J Shoulder Elbow Surg 2010;19:10-13. 10.1016/j.jse.2009.04.010 
104 Gueniche J, Bierry G. Rotator cuff muscles fatty infiltration increases with age: retrospective review of 210 patients with intact cuff on computed tomography arthrography. J Shoulder Elbow Surg 2019;28:617-624. 10.1016/j.jse.2018.09.020

105 Gumina S, Albino P, Giaracuni M, Vestri A, Ripani M, Postacchini F. The safe zone for avoiding suprascapular nerve injury during shoulder arthroscopy: an anatomical study on 500 dry scapulae. J Shoulder Elbow Surg 2011;20:1317-1322. 10.1016/j.jse.2011.01.033

106 Gumina S, Arceri V, Carbone S, Albino P, Passaretti D, Campagna V et al. The association between arterial hypertension and rotator cuff tear: the influence on rotator cuff tear sizes. J Shoulder Elbow Surg 2013;22:229232. 10.1016/j.jse.2012.05.023

107 Gumina S, Candela V, Passaretti D, Latino G, Venditto T, Mariani L et al. The association between body fat and rotator cuff tear: the influence on rotator cuff tear sizes. J Shoulder Elbow Surg 2014;23:1669-1674. 10.1016/j.jse.2014.03.016

108 Gwilym SE, Watkins B, Cooper CD, Harvie P, Auplish S, Pollard TC et al. Genetic influences in the progression of tears of the rotator cuff. J Bone Joint Surg Br 2009;91:915-917. 10.1302/0301-620x.91b7.22353

109 Halder AM, O’ Driscoll SW, Heers G, Mura N, Zobitz ME, An KN et al. Biomechanical Comparison of Effects of Supraspinatus Tendon Detachments, Tendon Defects, and Muscle Retractions. J Bone Joint Surg (Am) 2002;84-A:780-785.

110 Hallgren HC, Eliasson P, Aspenberg P, Adolfsson LE. Elevated plasma levels of TIMP-1 in patients with rotator cuff tear. Acta Orthop 2012;83:523-528. 10.3109/17453674.2012.736174

111 Hamada J, Nimura A, Yoshizaki K, Akita K. Anatomic study and electromyographic analysis of the teres minor muscle. J Shoulder Elbow Surg 2017;26:870-877. 10.1016/j.jse.2016.09.046

112 Hamada K, Fukuda H, Mikasa M, Kobayashi Y. Roentgenographic findings in massive rotator cuff tears. A long-term observation. Clin Orthop Relat Res 1990:92-96.

113 Hamada K, Yamanaka K, Uchiyama Y, Mikasa T, Mikasa M. A radiographic classification of massive rotator cuff tear arthritis. Clin Orthop Relat Res 2011;469:2452-2460. 10.1007/s11999-011-1896-9

114 Harryman DT, 2nd, Mack LA, Wang KY, Jackins SE, Richardson ML, Matsen FA, 3rd. Repairs of the rotator cuff. Correlation of functional results with integrity of the cuff. J Bone Joint Surg Am 1991;73:982-989.

115 Harter M, Reuter K, Gross-Hardt K, Bengel J. Screening for anxiety, depressive and somatoform disorders in rehabilitation--validity of HADS and GHQ-12 in patients with musculoskeletal disease. Disabil Rehabil 2001;23:737-744.

116 Harvie P, Ostlere SJ, Teh J, McNally EG, Clipsham K, Burston BJ et al. Genetic influences in the aetiology of tears of the rotator cuff. Sibling risk of a full-thickness tear. J Bone Joint Surg Br 2004;86:696-700.

117 Hashimoto T, Nobuhara K, Hamada T. Pathologic evidence of degeneration as a primary cause of rotator cuff tear. Clin Orthop Relat Res 2003:111120. 10.1097/01.blo.0000092974.12414.22

118 Hawker GA, Mian S, Kendzerska T, French M. Measures of adult pain: Visual Analog Scale for Pain (VAS Pain), Numeric Rating Scale for Pain (NRS Pain), McGill Pain Questionnaire (MPQ), Short-Form McGill Pain 
Questionnaire (SF-MPQ), Chronic Pain Grade Scale (CPGS), Short Form36 Bodily Pain Scale (SF-36 BPS), and Measure of Intermittent and Constant Osteoarthritis Pain (ICOAP). Arthritis Care Res (Hoboken) 2011;63 Suppl 11:S240-252. 10.1002/acr.20543

119 Hein J, Reilly JM, Chae J, Maerz T, Anderson K. Retear Rates After Arthroscopic Single-Row, Double-Row, and Suture Bridge Rotator Cuff Repair at a Minimum of 1 Year of Imaging Follow-up: A Systematic Review. Arthroscopy 2015;31:2274-2281. 10.1016/j.arthro.2015.06.004

120 Herve A, Thomazeau H, Favard L, Colmar M, Mansat P, Walch G et al. Clinical and radiological outcomes of osteoarthritis twenty years after rotator cuff repair. Orthop Traumatol Surg Res 2019;105:813-818. 10.1016/j.otsr.2019.02.013

121 Heuberer PR, Smolen D, Pauzenberger L, Plachel F, Salem S, Laky B et al. Longitudinal Long-term Magnetic Resonance Imaging and Clinical Follow-up After Single-Row Arthroscopic Rotator Cuff Repair: Clinical Superiority of Structural Tendon Integrity. Am J Sports Med 2017;45:1283-1288. 10.1177/0363546517689873

122 Hinsley H, Nicholls A, Daines M, Wallace G, Arden N, Carr A. Classification of rotator cuff tendinopathy using high definition ultrasound. Muscles Ligaments Tendons J 2014;4:391-397.

123 Hoe-Hansen CE, Palm L, Norlin R. The influence of cuff pathology on shoulder function after arthroscopic subacromial decompression: a $3^{-}$ and 6-year follow-up study. J Shoulder Elbow Surg 1999;8:585-589.

124 Holmgren T, Bjornsson Hallgren H, Oberg B, Adolfsson L, Johansson K. Effect of specific exercise strategy on need for surgery in patients with subacromial impingement syndrome: randomised controlled study. BMJ 2012;344:e787. 10.1136/bmj.e787

125 Holmgren T, Oberg B, Adolfsson L, Bjornsson Hallgren H, Johansson K. Minimal important changes in the Constant-Murley score in patients with subacromial pain. J Shoulder Elbow Surg 2014. 10.1016/j.jse.2014.01.014

126 Hsu JE, Gee AO, Lippitt SB, Matsen FA. The Rotator Cuff. In: Rockwood CA, Matsen FA, Wirth MA, Lippitt SB, Fehringer EV, Sperling JW, editors. Rockwood \& Matsen's The Shoulder: Elsevier; 2017.

127 Huang H, Grant JA, Miller BS, Mirza FM, Gagnier JJ. A Systematic Review of the Psychometric Properties of Patient-Reported Outcome Instruments for Use in Patients With Rotator Cuff Disease. Am J Sports Med 2015;43:2572-2582. 10.1177/0363546514565096

128 Huang R, Wang S, Wang Y, Qin X, Sun Y. Systematic Review of AllArthroscopic Versus Mini-Open Repair of Rotator Cuff Tears: A MetaAnalysis. Sci Rep 2016;6:22857. 10.1038/srep22857

129 Huang SW, Wang WT, Chou LC, Liou TH, Chen YW, Lin HW. Diabetes mellitus increases the risk of rotator cuff tear repair surgery: A population-based cohort study. Journal of Diabetes \& Its Complications 2016;30:1473-1477. 10.1016/j.jdiacomp.2016.07.015

130 Iannotti JP, McCarron J, Raymond CJ, Ricchetti ET, Abboud JA, Brems JJ et al. Agreement study of radiographic classification of rotator cuff tear arthropathy. J Shoulder Elbow Surg 2010;19:1243-1249. 10.1016/j.jse.2010.02.010 
131 Iannotti JP, Zlatkin MB, Esterhai JL, Kressel HY, Dalinka MK, Spindler KP. Magnetic resonance imaging of the shoulder. Sensitivity, specificity, and predictive value. J Bone Joint Surg Am 1991;73:17-29.

132 Inman VT, Saunders JB, Abbott LC. Observations of the function of the shoulder joint. 1944. Clin Orthop Relat Res 1996:3-12. 10.1097/00003086-199609000-00002

133 Jaeger M, Berndt T, Ruhmann O, Lerch S. Patients With Impingement Syndrome With and Without Rotator Cuff Tears Do Well 20 Years After Arthroscopic Subacromial Decompression. Arthroscopy 2015;32:409415. 10.1016/j.arthro.2015.08.026

134 Jain NB, Ayers GD, Fan R, Kuhn JE, Warner JJP, Baumgarten KM et al. Comparative Effectiveness of Operative Versus Nonoperative Treatment for Rotator Cuff Tears: A Propensity Score Analysis From the ROW Cohort. Am J Sports Med 2019;47:3065-3072. 10.1177/0363546519873840

135 Jain NB, Ayers GD, Koudelkova H, Archer KR, Dickinson R, Richardson B et al. Operative vs Nonoperative Treatment for Atraumatic Rotator Cuff Tears: A Trial Protocol for the Arthroscopic Rotator Cuff Pragmatic Randomized Clinical Trial. JAMA Netw Open 2019;2:e199050. 10.1001/jamanetworkopen.2019.9050

136 Jensen MP, Chen C, Brugger AM. Interpretation of visual analog scale ratings and change scores: a reanalysis of two clinical trials of postoperative pain. J Pain 2003;4:407-414.

137 Jenssen KK, Lundgreen K, Madsen JE, Dimmen S. Targeted intervention of acute postoperative infection after rotator cuff repair results in good functional outcomes. Knee Surg Sports Traumatol Arthrosc 2018;26:285291. 10.1007/s00167-017-4743-Z

138 Kappe T, Cakir B, Reichel H, Elsharkawi M. Reliability of radiologic classification for cuff tear arthropathy. J Shoulder Elbow Surg 2011;20:543-547. 10.1016/j.jse.2011.01.012

139 Karthikeyan S, Griffin DR, Parsons N, Lawrence TM, Modi CS, Drew SJ et al. Microvascular blood flow in normal and pathologic rotator cuffs. J Shoulder Elbow Surg 2015;24:1954-1960. 10.1016/j.jse.2015.07.014

140 Kato A, Nimura A, Yamaguchi K, Mochizuki T, Sugaya H, Akita K. An anatomical study of the transverse part of the infraspinatus muscle that is closely related with the supraspinatus muscle. Surg Radiol Anat 2012;34:257-265. 10.1007/s00276-011-0872-O

141 Keener JD, Galatz LM, Teefey SA, Middleton WD, Steger-May K, StobbsCucchi G et al. A prospective evaluation of survivorship of asymptomatic degenerative rotator cuff tears. J Bone Joint Surg Am 2015;97:89-98. 10.2106/jbjs.n.00099

142 Keener JD, Hsu JE, Steger-May K, Teefey SA, Chamberlain AM, Yamaguchi K. Patterns of tear progression for asymptomatic degenerative rotator cuff tears. J Shoulder Elbow Surg 2015;24:1845-1851. 10.1016/j.jse.2015.08.038

143 Keener JD, Steger-May K, Stobbs G, Yamaguchi K. Asymptomatic rotator cuff tears: patient demographics and baseline shoulder function. J Shoulder Elbow Surg 2010;19:1191-1198. 10.1016/j.jse.2010.07.017

144 Keener JD, Wei AS, Kim HM, Steger-May K, Yamaguchi K. Proximal humeral migration in shoulders with symptomatic and asymptomatic 
rotator cuff tears. J Bone Joint Surg Am 2009;91:1405-1413. 10.2106/jbjs.h.00854

145 Kempf JF, Gleyze P, Bonnomet F, Walch G, Mole D, Frank A et al. A multicenter study of 210 rotator cuff tears treated by arthroscopic acromioplasty. Arthroscopy 1999;15:56-66. 10.1053/ar.1999.v15.015005

146 Kennedy MS, Nicholson HD, Woodley SJ. Clinical anatomy of the subacromial and related shoulder bursae: A review of the literature. Clin Anat 2017;30:213-226. 10.1002/ca.22823

147 Ketola S, Lehtinen J, Arnala I. Arthroscopic decompression not recommended in the treatment of rotator cuff tendinopathy. Bone joint $\mathrm{J}$ 2017;99-B:799-805. 10.1302/0301-620X.99B6

148 Kim HM, Dahiya N, Teefey SA, Keener JD, Galatz LM, Yamaguchi K. Relationship of tear size and location to fatty degeneration of the rotator cuff. J Bone Joint Surg Am 2010;92:829-839. 10.2106/jbjs.h.01746

149 Kim YS, Kim SE, Bae SH, Lee HJ, Jee WH, Park CK. Tear progression of symptomatic full-thickness and partial-thickness rotator cuff tears as measured by repeated MRI. Knee Surg Sports Traumatol Arthrosc 2016. 10.1007/s00167-016-4388-3

150 Kirkley A, Alvarez C, Griffin S. The development and evaluation of a disease-specific quality-of-life questionnaire for disorders of the rotator cuff: The Western Ontario Rotator Cuff Index. Clin J Sport Med 2003;13:84-92.

151 Kissenberth MJ, Rulewicz GJ, Hamilton SC, Bruch HE, Hawkins RJ. A positive tangent sign predicts the repairability of rotator cuff tears. J Shoulder Elbow Surg 2014;23:1023-1027. 10.1016/j.jse.2014.02.014

152 Kuhn JE. Exercise in the treatment of rotator cuff impingement: a systematic review and a synthesized evidence-based rehabilitation protocol. J Shoulder Elbow Surg 2009;18:138-160. 10.1016/j.jse.2008.06.004

153 Kuhn JE, Dunn WR, Sanders R, An Q, Baumgarten KM, Bishop JY et al. Effectiveness of physical therapy in treating atraumatic full-thickness rotator cuff tears: a multicenter prospective cohort study. J Shoulder Elbow Surg 2013;22:1371-1379. 10.1016/j.jse.2013.01.026

154 Kukkonen J, Joukainen A, Lehtinen J, Mattila KT, Tuominen EK, Kauko T et al. Treatment of non-traumatic rotator cuff tears: A randomised controlled trial with one-year clinical results. Bone Joint J 2014;96-B:7581. 10.1302/0301-620x.96b1.32168

155 Kukkonen J, Joukainen A, Lehtinen J, Mattila KT, Tuominen EK, Kauko T et al. Treatment of Nontraumatic Rotator Cuff Tears: A Randomized Controlled Trial with Two Years of Clinical and Imaging Follow-up. J Bone Joint Surg Am 2015;97:1729-1737. 10.2106/jbjs.n.01051

156 Kukkonen J, Kauko T, Vahlberg T, Joukainen A, Aarimaa V. Investigating minimal clinically important difference for Constant score in patients undergoing rotator cuff surgery. J Shoulder Elbow Surg 2013. 10.1016/j.jse.2013.05.002

157 Kwong CA, Ono Y, Carroll MJ, Fruson LW, More KD, Thornton GM et al. Full-Thickness Rotator Cuff Tears: What Is the Rate of Tear Progression? A Systematic Review. Arthroscopy 2019;35:228-234. 10.1016/j.arthro.2018.07.031

158 Lafosse L, Brozska R, Toussaint B, Gobezie R. The outcome and structural integrity of arthroscopic rotator cuff repair with use of the double-row 
suture anchor technique. J Bone Joint Surg Am 2007;89:1533-1541. 10.2106/jbjs.f.oo305

159 Lafosse L, Jost B, Reiland Y, Audebert S, Toussaint B, Gobezie R. Structural integrity and clinical outcomes after arthroscopic repair of isolated subscapularis tears. J Bone Joint Surg Am 2007;89:1184-1193. 10.2106/JBJS.F.oooo7

16o Lambers Heerspink FO, van Raay JJ, Koorevaar RC, van Eerden PJ, Westerbeek RE, van 't Riet E et al. Comparing surgical repair with conservative treatment for degenerative rotator cuff tears: a randomized controlled trial. J Shoulder Elbow Surg 2015;24:1274-1281. 10.1016/j.jse.2015.05.040

161 Laumonerie P, Blasco L, Tibbo ME, Bonnevialle N, Labrousse M, Chaynes P et al. Sensory innervation of the subacromial bursa by the distal suprascapular nerve: a new description of its anatomic distribution. J Shoulder Elbow Surg 2019;28:1788-1794. 10.1016/j.jse.2019.02.016

162 Leroux T, Chahal J, Wasserstein D, Verma NN, Romeo AA. A Systematic Review and Meta-analysis Comparing Clinical Outcomes After Concurrent Rotator Cuff Repair and Long Head Biceps Tenodesis or Tenotomy. Sports Health 2015;7:303-307. 10.1177/1941738114539627

163 Lewington MR, Ferguson DP, Smith TD, Burks R, Coady C, Wong IH. Graft Utilization in the Bridging Reconstruction of Irreparable Rotator Cuff Tears: A Systematic Review. Am J Sports Med 2017:363546517694355. 10.1177/0363546517694355

164 Levy HJ, Uribe JW, Delaney LG. Arthroscopic assisted rotator cuff repair: preliminary results. Arthroscopy 1990;6:55-60. 10.1016/07498063(90)90099-y

165 Levy O, Mullett H, Roberts S, Copeland S. The role of anterior deltoid reeducation in patients with massive irreparable degenerative rotator cuff tears. J Shoulder Elbow Surg 2008;17:863-870.

166 Li X, Olszewski N, Abdul-Rassoul H, Curry EJ, Galvin JW, Eichinger JK. Relationship Between the Critical Shoulder Angle and Shoulder Disease. JBJS Rev 2018;6:e1. 10.2106/JBJS.RVW.17.00161

167 Liem D, Buschmann VE, Schmidt C, Gosheger G, Vogler T, Schulte TL et al. The prevalence of rotator cuff tears: is the contralateral shoulder at risk? Am J Sports Med 2014;42:826-830. 10.1177/0363546513519324

168 Lo IK, Burkhart SS. Double-row arthroscopic rotator cuff repair: reestablishing the footprint of the rotator cuff. Arthroscopy 2003;19:10351042.

169 Lo IK, Marchuk LL, Hollinshead R, Hart DA, Frank CB. Matrix metalloproteinase and tissue inhibitor of matrix metalloproteinase mRNA levels are specifically altered in torn rotator cuff tendons. Am J Sports Med 2004;32:1223-1229. 10.1177/0363546503262200

170 Loew M, Magosch P, Lichtenberg S, Habermeyer P, Porschke F. How to discriminate between acute traumatic and chronic degenerative rotator cuff lesions: an analysis of specific criteria on radiography and magnetic resonance imaging. J Shoulder Elbow Surg 2015;24:1685-1693. 10.1016/j.jse.2015.06.005

171 Lohr JF, Uhthoff HK. The microvascular pattern of the supraspinatus tendon. Clin Orthop Relat Res 1990:35-38. 
172 Longo UG, Berton A, Khan WS, Maffulli N, Denaro V. Histopathology of rotator cuff tears. Sports Med Arthrosc Rev 2011;19:227-236. 10.1097/JSA.obo13e318213bccb

173 Makhni EC, Swart E, Steinhaus ME, Mather RC, 3rd, Levine WN, Bach BR, Jr. et al. Cost-Effectiveness of Reverse Total Shoulder Arthroplasty Versus Arthroscopic Rotator Cuff Repair for Symptomatic Large and Massive Rotator Cuff Tears. Arthroscopy 2016;32:1771-1780. 10.1016/j.arthro.2016.01.063

174 Malahias MA, Kostretzis L, Chronopoulos E, Brilakis E, Avramidis G, Antonogiannakis E. Arthroscopic partial repair for massive rotator cuff tears: does it work? A systematic review. Sports Med Open 2019;5:13. 10.1186/s40798-019-0186-Z

175 Mall NA, Kim HM, Keener JD, Steger-May K, Teefey SA, Middleton WD et al. Symptomatic progression of asymptomatic rotator cuff tears: a prospective study of clinical and sonographic variables. J Bone Joint Surg Am 2010;92:2623-2633. 10.2106/JBJS.I.00506

176 Mall NA, Lee AS, Chahal J, Sherman SL, Romeo AA, Verma NN et al. An evidenced-based examination of the epidemiology and outcomes of traumatic rotator cuff tears. Arthroscopy 2013;29:366-376. 10.1016/j.arthro.2012.06.024

177 Maman E, Harris C, White L, Tomlinson G, Shashank M, Boynton E. Outcome of nonoperative treatment of symptomatic rotator cuff tears monitored by magnetic resonance imaging. J Bone Joint Surg Am 2009;91:1898-1906. 10.2106/jbjs.g.01335

178 Martinoli C. Musculoskeletal ultrasound: technical guidelines. Insights Imaging 2010;1:99-141. 10.1007/s13244-010-0032-9

179 Mason Ml, Allen HS. The rate of healing of tendons: an experimental study of tensile strength. Ann Surg 1941;113:424-459.

180 Massimini DF, Singh A, Wells JH, Li G, Warner JJ. Suprascapular nerve anatomy during shoulder motion: a cadaveric proof of concept study with implications for neurogenic shoulder pain. J Shoulder Elbow Surg 2013;22:463-470. 10.1016/j.jse.2012.04.018

181 Massoud SN, Levy O, Copeland SA. Subacromial decompression. Treatment for small- and medium-sized tears of the rotator cuff. J Bone Joint Surg Br 2002;84:955-960.

182 Mather RC, 3rd, Koenig L, Acevedo D, Dall TM, Gallo P, Romeo A et al. The societal and economic value of rotator cuff repair. J Bone Joint Surg Am 2013;95:1993-2000. 10.2106/JBJS.L.01495

183 Matsen FA, 3rd, Whitson A, Jackins SE, Hsu JE. Significant improvement in patient self-assessed comfort and function at six weeks after the smooth and move procedure for shoulders with irreparable rotator cuff tears and retained active elevation. Int Orthop 2019. 10.1007/soo264019-04310-4

184 Matson AP, Kim C, Bajpai S, Green CL, Hash TW, Garrigues GE. The effect of obesity on fatty infiltration of the rotator cuff musculature in patients without rotator cuff tears. Shoulder Elbow 2019;11:30-38. $10.1177 / 1758573217736008$

185 McLaughlin HL. Lesions of the musculotendinous cuff of the shoulder. The exposure and treatment of tears with retraction. J Bone Joint Surg (Am) 1944;24:31. 
186 Mesiha MM, Derwin KA, Sibole SC, Erdemir A, McCarron JA. The biomechanical relevance of anterior rotator cuff cable tears in a cadaveric shoulder model. J Bone Joint Surg Am 2013;95:1817-1824. 10.2106/JBJS.L.00784

187 Michener LA, McClure PW, Karduna AR. Anatomical and biomechanical mechanisms of subacromial impingement syndrome. Clin Biomech (Bristol, Avon) 2003;18:369-379.

188 Mihata T, Lee TQ, Watanabe C, Fukunishi K, Ohue M, Tsujimura T et al. Clinical results of arthroscopic superior capsule reconstruction for irreparable rotator cuff tears. Arthroscopy 2013;29:459-470. 10.1016/j.arthro.2012.10.022

189 Mihata T, McGarry MH, Pirolo JM, Kinoshita M, Lee TQ. Superior capsule reconstruction to restore superior stability in irreparable rotator cuff tears: a biomechanical cadaveric study. Am J Sports Med 2012;40:22482255. 10.1177/0363546512456195

190 Millar NL, Aq W, Molloy TJ, Bonar F, Murrell GAC. Cytokines and apoptosis in supraspinatus tendinopathy. J Bone Joint Surg (Br) 2009;91-B:417-424.

191 Minagawa H, Yamamoto N, Abe H, Fukuda M, Seki N, Kikuchi K et al. Prevalence of symptomatic and asymptomatic rotator cuff tears in the general population: From mass-screening in one village. J Orthop 2013;10:8-12. 10.1016/j.jor.2013.01.008

192 Mochizuki T, Sugaya H, Uomizu M, Maeda K, Matsuki K, Sekiya I et al. Humeral insertion of the supraspinatus and infraspinatus. New anatomical findings regarding the footprint of the rotator cuff. J Bone Joint Surg Am 2008;90:962-969. 10.2106/jbjs.g.00427

193 Moon AS, Patel HA, Ithurburn MP, Brabston EW, Ponce BA, Momaya AM. Subacromial Spacer Implantation for the Treatment of Massive Irreparable Rotator Cuff Tears: A Systematic Review. Arthroscopy 2019;35:607-614.

194 Moor BK, Wieser K, Slankamenac K, Gerber C, Bouaicha S. Relationship of individual scapular anatomy and degenerative rotator cuff tears. J Shoulder Elbow Surg 2014;23:536-541. 10.1016/j.jse.2013.11.008

195 Moorman CT, Warren RF, Deng XH, Wickiewicz TL, Torzilli PA. Role of coracoacromial ligament and related structures in glenohumeral stability: a cadaveric study. J Surg Orthop Adv 2012;21:210-217.

196 Moosmayer S, Gartner AV, Tariq R. The natural course of nonoperatively treated rotator cuff tears: an 8.8-year follow-up of tear anatomy and clinical outcome in 49 patients. J Shoulder Elbow Surg 2017. 10.1016/j.jse.2016.10.002

197 Moosmayer S, Lund G, Seljom U, Svege I, Hennig T, Tariq R et al. Comparison between surgery and physiotherapy in the treatment of small and medium-sized tears of the rotator cuff: A randomised controlled study of 103 patients with one-year follow-up. J Bone Joint Surg Br 2010;92:83-91. 10.1302/0301-620x.92b1.22609

198 Moosmayer S, Lund G, Seljom US, Haldorsen B, Svege IC, Hennig T et al. At a 10-Year Follow-up, Tendon Repair Is Superior to Physiotherapy in the Treatment of Small and Medium-Sized Rotator Cuff Tears. J Bone Joint Surg Am 2019;101:1050-1060. 10.2106/JBJS.18.01373 
199 Moosmayer S, Tariq R, Stiris M, Smith HJ. The natural history of asymptomatic rotator cuff tears: a three-year follow-up of fifty cases. $\mathrm{J}$ Bone Joint Surg Am 2013;95:1249-1255. 10.2106/jbjs.l.00185

200 Mori D, Funakoshi N, Yamashita F. Arthroscopic surgery of irreparable large or massive rotator cuff tears with low-grade fatty degeneration of the infraspinatus: patch autograft procedure versus partial repair procedure. Arthroscopy 2013;29:1911-1921. 10.1016/j.arthro.2013.08.032

201 Morikawa D, Johnson JD, Kia C, McCarthy MBR, Macken C, Bellas N et al. Examining the Potency of Subacromial Bursal Cells as a Potential Augmentation for Rotator Cuff Healing: An In Vitro Study. Arthroscopy 2019. 10.1016/j.arthro.2019.05.024

202 Murphy MM, Tashjian RZ, Burks RT. Rotator Cuff Repair Technique With Transosseous Knotless Anchor System. Arthrosc Tech 2018;7:e927-e937. 10.1016/j.eats.2018.05.003

203 Murphy RJ, Daines MT, Carr AJ, Rees JL. An independent learning method for orthopaedic surgeons performing shoulder ultrasound to identify fullthickness tears of the rotator cuff. J Bone Joint Surg Am 2013;95:266272. 10.2106/JBJS.K.00706

204 Nakamura Y, Yokoya S, Mochizuki Y, Harada Y, Kikugawa K, Ochi M. Monitoring of progression of nonsurgically treated rotator cuff tears by magnetic resonance imaging. J Orthop Sci 2015;20:314-320. 10.1007/s00776-014-0680-6

205 Nam JH, Park S, Lee HR, Kim SH. Outcomes After Limited or Extensive Bursectomy During Rotator Cuff Repair: Randomized Controlled Trial. Arthroscopy 2018;34:3167-3174. 10.1016/j.arthro.2018.06.056

206 Namdari S, Donegan RP, Dahiya N, Galatz LM, Yamaguchi K, Keener JD. Characteristics of small to medium-sized rotator cuff tears with and without disruption of the anterior supraspinatus tendon. J Shoulder Elbow Surg 2014;23:20-27. 10.1016/j.jse.2013.05.015

207 Narasimhan R, Shamse K, Nash C, Dhingra D, Kennedy S. Prevalence of subscapularis tears and accuracy of shoulder ultrasound in pre-operative diagnosis. Int Orthop 2016;40:975-979.

208 Neer CS, 2nd. Anterior acromioplasty for the chronic impingement syndrome in the shoulder: a preliminary report. J Bone Joint Surg Am 1972 jan; 54:41-50.

209 Neer CS, 2nd. Impingement lesions. Clin Orthop Relat Res 1983:70-77.

210 Neer CS, 2nd, Craig EV, Fukuda H. Cuff-tear arthropathy. J Bone Joint Surg Am 1983;65:1232-1244.

211 Neviaser JS, Neviaser RJ, Neviaser TJ. The repair of chronic massive ruptures of the rotator cuff of the shoulder by use of a freeze-dried rotator cuff. J Bone Joint Surg Am 1978;60:681-684.

212 Nicholson GP, Goodman DA, Flatow EL, Bigliani LU. The acromion: morphologic condition and age-related changes. A study of 420 scapulas. J Shoulder Elbow Surg 1996;5:1-11.

213 Norlin R, Adolfsson L. Small full-thickness tears do well ten to thirteen years after arthroscopic subacromial decompression. J Shoulder Elbow Surg 2008;17:12S-16S. 10.1016/j.jse.2007.06.020

214 Nove-Josserand L, Costa P, Liotard JP, Safar JF, Walch G, Zilber S. Results of latissimus dorsi tendon transfer for irreparable cuff tears. Orthop Traumatol Surg Res 2009;95:108-113. 10.1016/j.otsr.2008.10.002 
215 Nove-Josserand L, Edwards TB, O'Connor DP, Walch G. The acromiohumeral and coracohumeral intervals are abnormal in rotator cuff tears with muscular fatty degeneration. Clin Orthop Relat Res 2005:90-96.

216 Nyffeler RW, Werner CML, Sukhtankar A, Schmid MR, Gerber C. Association of a Large Lateral Extension of the Acromion with Rotator Cuff Tears. J Bone Joint Surg (Am) 2006;88-A:800-805.

217 Odak S, Powell E, Temperley D, Haines JF, Trail I. Randomized controlled trial to assess the efficacy of arthroscopic subacromial decompression with and without rotator cuff repair using a mini-open technique. Shoulder Elbow 2012;4:112-116. 10.1111/j.1758-5740.2011.00175.x

218 Ozaki J, Fujimoto S, Masuhara K, Tamai S, Yoshimoto S. Reconstruction of chronic massive rotator cuff tears with synthetic materials. Clin Orthop Relat Res 1986:173-183.

219 Paavola M, Malmivaara A, Taimela S, Kanto K, Inkinen J, Kalske J et al. Subacromial decompression versus diagnostic arthroscopy for shoulder impingement: randomised, placebo surgery controlled clinical trial. BMJ 2018;362:k286o. 10.1136/bmj.k286o

220 Papadonikolakis A, McKenna M, Warme W, Martin BI, Matsen FA, 3rd. Published evidence relevant to the diagnosis of impingement syndrome of the shoulder. J Bone Joint Surg Am 2011;93:1827-1832. 10.2106/JBJS.J.01748

221 Park HB, Gwark JY, Im JH, Jung J, Na JB, Yoon CH. Factors Associated with Atraumatic Posterosuperior Rotator Cuff Tears. J Bone Joint Surg Am 2018;100:1397-1405. 10.2106/JBJS.16.01592

222 Park JH, Yang SH, Rhee SM, Oh JH. The effect of concomitant coracohumeral ligament release in arthroscopic rotator cuff repair to prevent postoperative stiffness: a retrospective comparative study. Knee Surg Sports Traumatol Arthrosc 2019. 10.1007/s00167-019-05433-2

223 Park MC, ElAttrache NS, Tibone JE, Ahmad CS, Jun BJ, Lee TQ. Part I: Footprint contact characteristics for a transosseous-equivalent rotator cuff repair technique compared with a double-row repair technique. $\mathbf{J}$ Shoulder Elbow Surg 2007;16:461-468. 10.1016/j.jse.2006.09.010

224 Park MC, Tibone JE, ElAttrache NS, Ahmad CS, Jun BJ, Lee TQ. Part II: Biomechanical assessment for a footprint-restoring transosseousequivalent rotator cuff repair technique compared with a double-row repair technique. J Shoulder Elbow Surg 2007;16:469-476. 10.1016/j.jse.2006.09.011

225 Patte D. Classification of rotator cuff lesions. Clin Orthop Relat Res 1990;254:81-86.

226 Picavet HSJ, Schouten JSAG. Musculoskeletal pain in the Netherlands: prevalences, consequences and risk groups, the DMC3-study. Pain 2003;102:167-178. 10.1016/s0304-3959(02)00372-x

227 Piper CC, Hughes AJ, Ma Y, Wang H, Neviaser AS. Operative versus nonoperative treatment for the management of full-thickness rotator cuff tears: a systematic review and meta-analysis. J Shoulder Elbow Surg 2017. 10.1016/j.jse.2017.09.032

228 Pope DP, Croft PR, Pritchard CM, Silman AJ. Prevalence of shoulder pain in the community: the influence of case definition. Ann Rheum Dis 1997;56:308-312. 10.1136/ard.56.5.308 
229 Ramme AJ, Robbins CB, Patel KA, Carpenter JE, Bedi A, Gagnier JJ et al. Surgical Versus Nonsurgical Management of Rotator Cuff Tears: A Matched-Pair Analysis. J Bone Joint Surg Am 2019;101:1775-1782. 10.2106/JBJS.18.01473

230 Randelli P, Cucchi D, Ragone V, de Girolamo L, Cabitza P, Randelli M. History of rotator cuff surgery. Knee Surg Sports Traumatol Arthrosc 2015;23:344-362. 10.1007/s00167-014-3445-Z

231 Randelli PS, Menon A, Nocerino E, Aliprandi A, Feroldi FM, Mazzoleni MG et al. Long-term Results of Arthroscopic Rotator Cuff Repair: Initial Tear Size Matters: A Prospective Study on Clinical and Radiological Results at a Minimum Follow-up of 10 Years. Am J Sports Med 2019:363546519865529. 10.1177/0363546519865529

232 Rathbun JB, Macnab I. The microvascular pattern of the rotator cuff. J Bone Joint Surg Br 1970;52:540-553.

233 Rhee SM, Kim JY, Kim JY, Cho SJ, Kim JH, Rhee YG. The critical shoulder angle: can it be sufficient to reflect the shoulder joint without the humeral head? J Shoulder Elbow Surg 2019;28:731-741. 10.1016/j.jse.2018.08.039

234 Ro KH, Park JH, Lee SH, Song DI, Jeong HJ, Jeong WK. Status of the contralateral rotator cuff in patients undergoing rotator cuff repair. Am J Sports Med 2015;43:1091-1098. 10.1177/0363546515571554

235 Roh MS, Wang VM, April EW, Pollock RG, Bigliani LU, Flatow EL. Anterior and posterior musculotendinous anatomy of the supraspinatus. J Shoulder Elbow Surg 2000;9:436-440. 10.1067/mse.2000.108387

236 Roquelaure Y, Ha C, Leclerc A, Touranchet A, Sauteron M, Melchior M et al. Epidemiologic surveillance of upper-extremity musculoskeletal disorders in the working population. Arthritis Rheum 2006;55:765-778. 10.1002/art.22222

237 Roye RP, W.A. G, Yates CK. Arthroscopic subacromial decompression: twoto seven-year follow-up. Arthroscopy 1995;11:301-306.

238 Rugg CM, Gallo RA, Craig EV, Feeley BT. The pathogenesis and management of cuff tear arthropathy. J Shoulder Elbow Surg 2018;27:2271-2283. 10.1016/j.jse.2018.07.020

239 Ryosa A, Kukkonen J, Bjornsson Hallgren HC, Moosmayer S, Holmgren T, Ranebo $\mathrm{M}$ et al. Acute Cuff Tear Repair Trial (ACCURATE): protocol for a multicentre, randomised, placebo-controlled trial on the efficacy of arthroscopic rotator cuff repair. BMJ Open 2019;9:e025022. 10.1136/bmjopen-2018-025022

240 Ryosa A, Laimi K, Aarimaa V, Lehtimaki K, Kukkonen J, Saltychev M. Surgery or conservative treatment for rotator cuff tear: a meta-analysis. Disabil Rehabil 2017;39:1357-1363. 10.1080/09638288.2016.1198431

241 Safran O, Schroeder J, Bloom R, Weil Y, Milgrom C. Natural history of nonoperatively treated symptomatic rotator cuff tears in patients 60 years old or younger. Am J Sports Med 2011;39:710-714. 10.1177/0363546510393944

242 Samilson RL, Prieto V. Dislocation arthropathy of the shoulder. J Bone Joint Surg Am 1983;65:456-460.

243 Saupe N, Pfirrmann CW, Schmid MR, Jost B, Werner CM, Zanetti M. Association between rotator cuff abnormalities and reduced acromiohumeral distance. AJR Am J Roentgenol 2006;187:376-382. 10.2214/ajr.05.0435 
244 Savarese E, Romeo R. New solution for massive, irreparable rotator cuff tears: the subacromial "biodegradable spacer". Arthrosc Tech 2012;1:e6974. 10.1016/j.eats.2012.02.002

245 Schmitt H, Hansmann H, Brocai D, Loew M. Long term changes of the throwing arm of former elite javelin throwers. Int J Sports Med 2001;22:275-279.

246 Sethi N, Wright R, Yamaguchi K. Disorders of the long head of the biceps tendon. J Shoulder Elbow Surg 1999;8:644-654.

247 Spiegl UJ, Euler SA, Millett PJ, Hepp P. Summary of Meta-Analyses Dealing with Single-Row versus Double-Row Repair Techniques for Rotator Cuff Tears. Open Orthop J 2016;10:330-338. 10.2174/1874325001610010330

$248 \mathrm{Su}$ WR, Budoff JE, Luo ZP. The effect of coracoacromial ligament excision and acromioplasty on superior and anterosuperior glenohumeral stability. Arthroscopy 2009;25:13-18. 10.1016/j.arthro.2008.10.004

249 Svendsen SW, Gelineck J, Mathiassen SE, Bonde JP, Frich LH, StengaardPedersen $\mathrm{K}$ et al. Work above shoulder level and degenerative alterations of the rotator cuff tendons: a magnetic resonance imaging study. Arthritis Rheum 2004;50:3314-3322. 10.1002/art.20495

250 Tashjian RZ, Farnham JM, Albright FS, Teerlink CC, Cannon-Albright LA. Evidence for an inherited predisposition contributing to the risk for rotator cuff disease. J Bone Joint Surg Am 2009;91:1136-1142. 10.2106/jbjs.h.oo831

251 Teunis T, Lubberts B, Reilly BT, Ring D. A systematic review and pooled analysis of the prevalence of rotator cuff disease with increasing age. $\mathrm{J}$ Shoulder Elbow Surg 2014;23:1913-1921. 10.1016/j.jse.2014.08.001

252 Thal R. A technique for arthroscopic mattress suture placement. Arthroscopy 1993;9:605-607.

253 Tosounidis T, Hadjileontis C, Triantafyllou C, Sidiropoulou V, Kafanas A, Kontakis G. Evidence of sympathetic innervation and alpha1-adrenergic receptors of the long head of the biceps brachii tendon. J Orthop Sci 2013;18:238-244. 10.1007/s00776-012-0346-1

254 van der Zwaal P, Thomassen BJ, Nieuwenhuijse MJ, Lindenburg R, Swen JW, van Arkel ER. Clinical outcome in all-arthroscopic versus mini-open rotator cuff repair in small to medium-sized tears: a randomized controlled trial in 100 patients with 1-year follow-up. Arthroscopy 2013;29:266-273. 10.1016/j.arthro.2012.08.022

255 Wartolowska K, Judge A, Hopewell S, Collins GS, Dean BJ, Rombach I et al. Use of placebo controls in the evaluation of surgery: systematic review. BMJ 2014;348:g3253. 10.1136/bmj.g3253

256 Veen EJD, Donders CM, Westerbeek RE, Derks RPH, Landman EBM, Koorevaar CT. Predictive findings on magnetic resonance imaging in patients with symptomatic acromioclavicular osteoarthritis. J Shoulder Elbow Surg 2018;27:e252-e258. 10.1016/j.jse.2018.01.001

257 Verhelst L, Vandekerckhove P, Sergeant G, K. L, Van Hoonacker P, Berghs B. Reversed arthroscopic subacromial decompression for symptomatic irreparable rotator cuff tears: mid-term follow-up results in 34 shoulders. J Shoulder Elbow Surg 2010;19:601-608.

258 Werner CM, Conrad SJ, Meyer DC, Keller A, Hodler J, Gerber C. Intermethod agreement and interobserver correlation of radiologic 
acromiohumeral distance measurements. J Shoulder Elbow Surg 2008;17:237-240. 10.1016/j.jse.2007.06.002

259 Virk MS, Cole BJ. Proximal Biceps Tendon and Rotator Cuff Tears. Clin Sports Med 2016;35:153-161. 10.1016/j.csm.2015.08.010

26o Visotsky JL, Basamania C, Seebauer L, Rockwood C, Jensen KL. Cuff tear arthropathy: pathogenesis, classification, and algorithm for treatment. J Bone Joint Surg (Am) 2004;86-A:35-40.

261 Yamaguchi K, Ditsios K, Middleton WD, Hildebolt CF, Galatz LM, Teefey SA. The demographic and morphological features of rotator cuff disease. A comparison of asymptomatic and symptomatic shoulders. J Bone Joint Surg Am 2006;88:1699-1704. 10.2106/jbjs.e.00835

262 Yamaguchi K, Sher JS, Andersen WK, Garretson R, Uribe JW, Hechtman K et al. Glenohumeral motion in patients with rotator cuff tears: a comparison of asymptomatic and symptomatic shoulders. J Shoulder Elbow Surg 2000;9:6-11.

263 Yamaguchi K, Tetro AM, Blam O, Evanoff BA, Teefey SA, Middleton WD. Natural history of asymptomatic rotator cuff tears: a longitudinal analysis of asymptomatic tears detected sonographically. J Shoulder Elbow Surg 2001;10:199-203. 10.1067/mse.2001.113086

264 Yamamoto A, Takagishi K, Osawa T, Yanagawa T, Nakajima D, Shitara H et al. Prevalence and risk factors of a rotator cuff tear in the general population. J Shoulder Elbow Surg 2010;19:116-120. 10.1016/j.jse.2009.04.006

265 Yamamoto N, Mineta M, Kawakami J, Sano H, Itoi E. Risk Factors for Tear Progression in Symptomatic Rotator Cuff Tears: A Prospective Study of 174 Shoulders. Am J Sports Med 2017;45:2524-2531. 10.1177/0363546517709780

266 Yang Y, Qu J. The effects of hyperlipidemia on rotator cuff diseases: a systematic review. J Orthop Surg Res 2018;13:204. 10.1186/s13018-0180912-O

267 Yian EH, Sodl JF, Dionysian E, Schneeberger AG. Anterior deltoid reeducation for irreparable rotator cuff tears revisited. J Shoulder Elbow Surg 2017;26:1562-1565.

268 Zanetti M, Gerber C, Hodler J. Quantitative assessment of the muscles of the rotator cuff with magnetic resonance imaging. Invest Radiol 1998;33:163-170.

269 Zigmond AS, Snaith RP. The hospital anxiety and depression scale. Acta Psychiatr Scand 1983;67:361-370.

270 Zingg PO, Jost B, Sukthankar A, Buhler M, Pfirrmann CW, Gerber C. Clinical and structural outcomes of nonoperative management of massive rotator cuff tears. J Bone Joint Surg Am 2007;89:1928-1934. 10.2106/jbjs.f.01073

271 Zumstein MA, Ladermann A, Raniga S, Schar MO. The biology of rotator cuff healing. Orthop Traumatol Surg Res 2017;103:S1-S10. 10.1016/j.otsr.2016.11.003

272 Zuo J, Sano H, Itoi E. Changes in pennation angle in rotator cuff muscles with torn tendons. J Orthop Sci 2012;17:58-63. 10.1007/s00776-0110176-6 
Rotator cuff tears-short and long-term aspects on treatment outcome 
PAPERS 



\section{Papers}

The papers associated with this thesis have been removed for copyright reasons. For more details about these see:

http://urn.kb.se/resolve?urn=urn:nbn:se:liu:diva-162408 


\section{FACULTY OF MEDICINE AND HEALTH SCIENCES}

Linköping University Medical Dissertation No. 1727, 2020

Department of Clinical and Experimental Medicine

Linköping University

SE-58183 Linköping, Sweden

\section{www.liu.se}

\begin{tabular}{|c|c|c|c|c|}
\hline Paper & Aim & Method & Material & Conclusions \\
\hline $\mathbf{I}$ & $\begin{array}{l}\text { Investigate if the condition of the } \\
\text { glenohumeral joint and the rotator } \\
\text { cuff had deteriorated at a minimum } \\
\text { of } 21 \text { years after an acromioplasty } \\
\text { without cuff repair, in patients with } \\
\text { partial and full-thickness tears. }\end{array}$ & $\begin{array}{l}\text { Retrospective } 21-25 \\
\text { years follow-up with } \\
\text { ultrasound, } \\
\text { radiographs and } \\
\text { clinical scores. }\end{array}$ & 69 patients & $\begin{array}{l}\text { Full-thickness tears: Yes } \\
\text { 74\% arthropathy } \\
\text { 87\% tear progression } \\
\text { Partial tears: No, with } \\
\text { reservations } \\
\text { 7\% arthropathy } \\
\text { 42\% tear progression }\end{array}$ \\
\hline II & $\begin{array}{l}\text { Investigate the frequency of } \\
\text { contralateral full-thickness rotator } \\
\text { cuff tears and cuff tear arthropathy } \\
\text { in patients with an arthroscopically } \\
\text { documented cuff tear in one } \\
\text { shoulder. }\end{array}$ & $\begin{array}{l}\text { Descriptive } \\
\text { epidemiology study. }\end{array}$ & 61 patients & $\begin{array}{l}\mathbf{5 0 . 8 \%} \text { overall } \\
\text { From } \mathbf{1 3 . 6} \text { to } \mathbf{9 0 \%}, \\
\text { depending on status of index } \\
\text { shoulder. } \\
\text { Strong correlation between } \\
\text { shoulders. }\end{array}$ \\
\hline III & $\begin{array}{l}\text { Investigate if a bridging rotator cuff } \\
\text { repair with a synthetic interposition } \\
\text { graft had prevented cuff tear } \\
\text { arthropathy and preserved shoulder } \\
\text { function in a long-term perspective. }\end{array}$ & $\begin{array}{l}\text { Retrospective 17-20 } \\
\text { years follow-up with } \\
\text { ultrasound, } \\
\text { radiographs and } \\
\text { clinical scores. }\end{array}$ & 12 patients & $\begin{array}{l}\text { No } \\
\quad 75 \% \text { Cuff tear arthropathy } \\
\text { No difference compared to } \\
\text { nonoperated contralateral } \\
\text { shoulder } \\
\quad \text { Functional scores low }\end{array}$ \\
\hline IV & $\begin{array}{l}\text { Investigate if operative repair of an } \\
\text { acute traumatic full-thickness cuff } \\
\text { tear involving mainly supraspinatus } \\
\text { was superior to physiotherapy } \\
\text { without repair in a one year } \\
\text { perspective. }\end{array}$ & $\begin{array}{l}\text { Prospective } \\
\text { randomised trial. }\end{array}$ & 58 patients & $\begin{array}{l}\text { No } \\
\text { But tear progression noted in } \\
29 \% \text { of unrepaired patients }\end{array}$ \\
\hline
\end{tabular}

